\title{
Untersuchungen zum Mechanismus der katalytischen Aktivierung von Spleißosomen aus Saccharomyces cerevisiae
}

\author{
Dissertation \\ zur Erlangung des Doktorgrades \\ der Mathematisch-Naturwissenschaftlichen Fakultäten \\ der Georg-August-Universität zu Göttingen
}

vorgelegt von

Nicolas Rasche

aus Bad Driburg

Göttingen 2012 


\section{Table of contents}

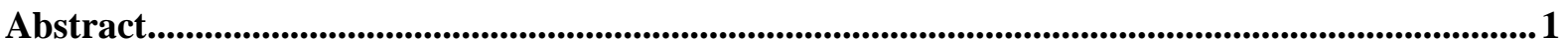

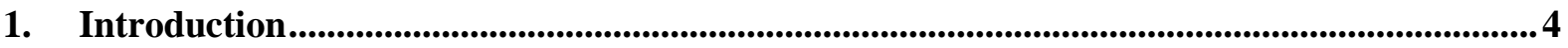

$1.1 \quad$ Mosaic structure of eukaryotic genes and RNA splicing ..................................................... 4

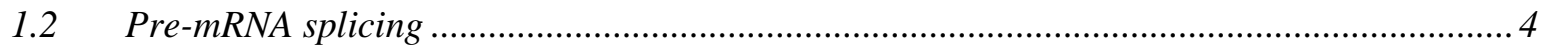

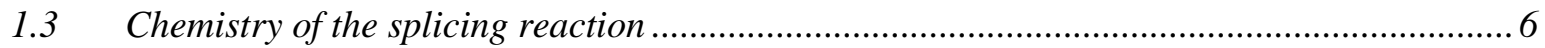

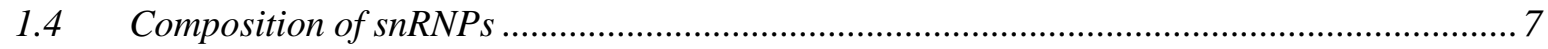

1.5 Spliceosome assembly in Saccharomyces cerevisiae ..........................................................11

1.6 Dynamics of the spliceosomal RNA-network ....................................................................... 13

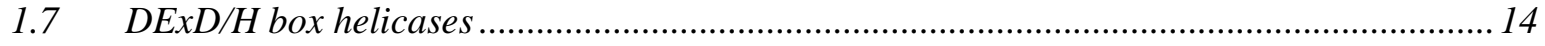

$1.8 \quad$ Dynamics of the spliceosomal protein composition .............................................................. 17

1.9 Similarities between the spliceosome and group II introns .................................................21

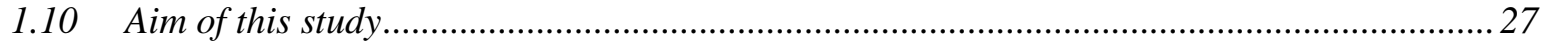

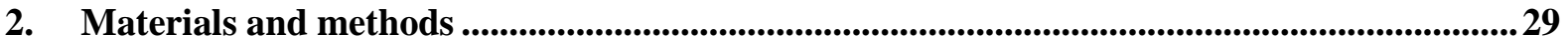

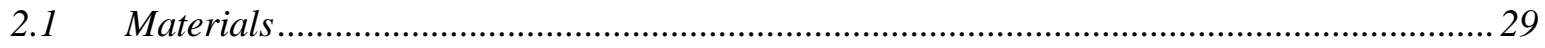

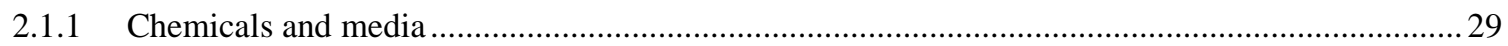

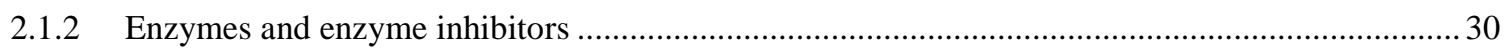

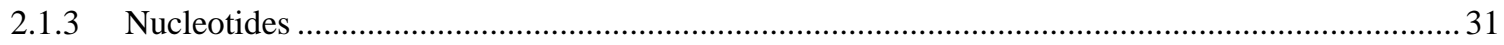

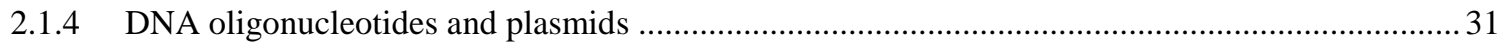

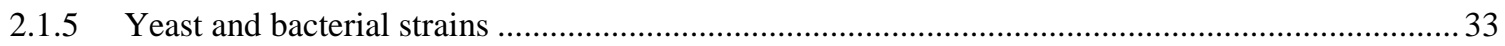

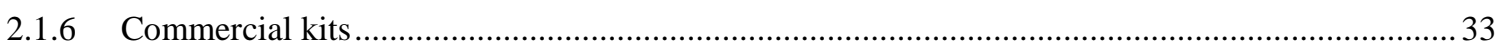

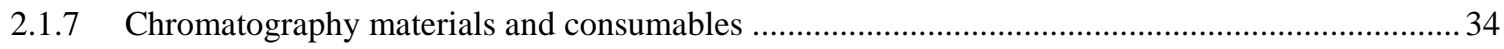

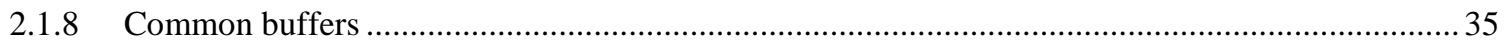

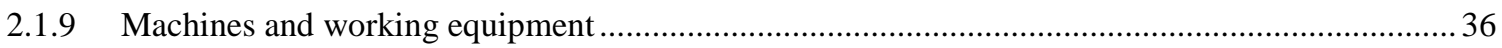

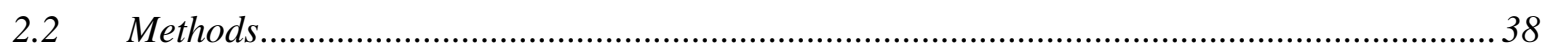

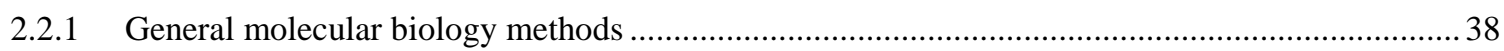

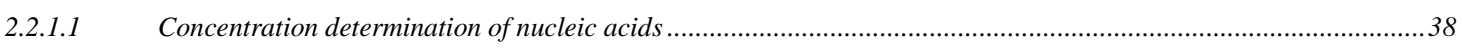

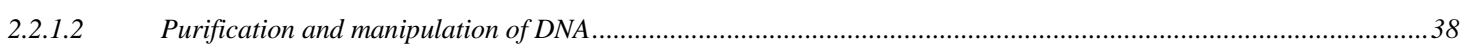

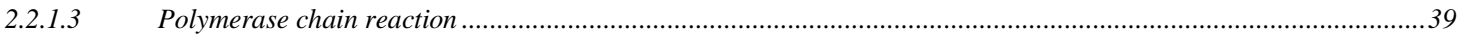

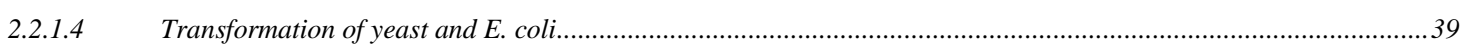

2.2.1.5 Phenol-chloroform-isoamylalcohol (PCI) extraction and ethanol precipitation .....................................................40

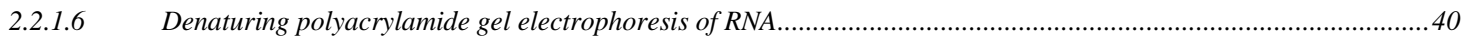

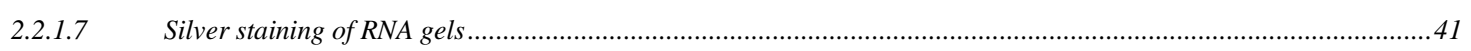

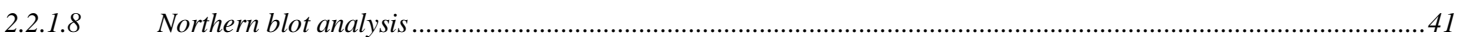

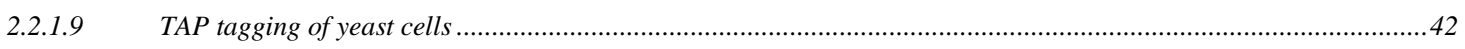

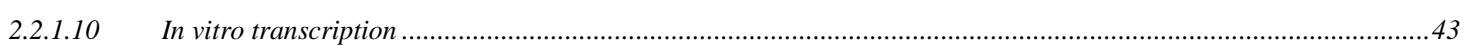


2.2.2 Protein-biochemistry standard methods.

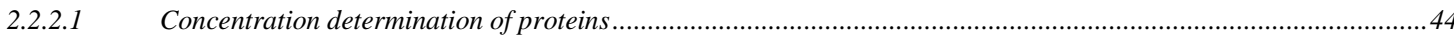

2.2.2.2 Denaturing Polyacrylamide Gel Electrophoresis (PAGE) .................................................................................45

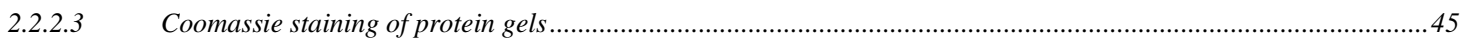

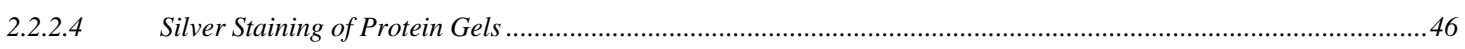

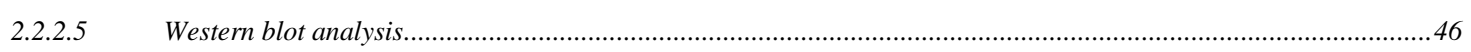

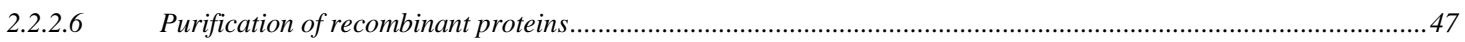

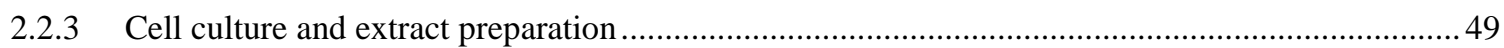

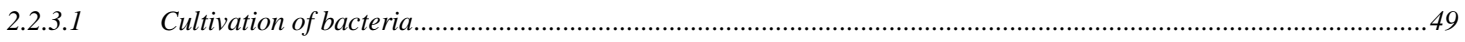

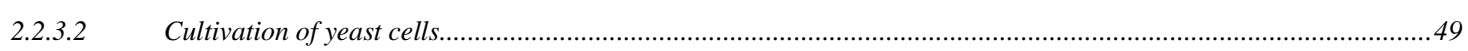

2.2.3.3 Preparation of yeast whole cell extracts and immunodepletion...............................................................................50

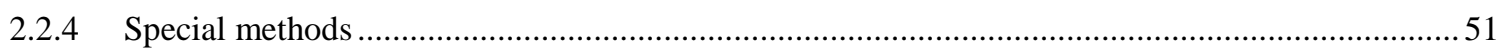

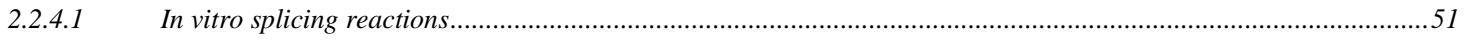

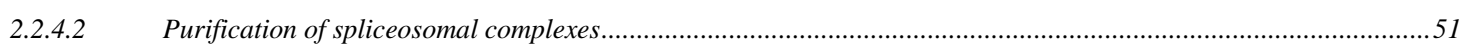

2.2.4.3 UV-crosslinking of spliceosomal complexes...................................................................................................52

2.2.4.4 Immunoprecipitation of protein-RNA crosslinks..............................................................................................5

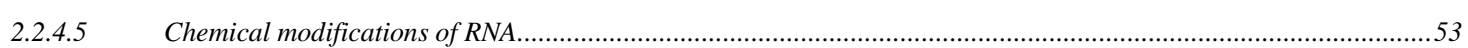

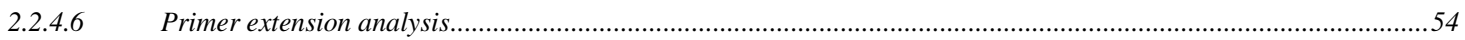

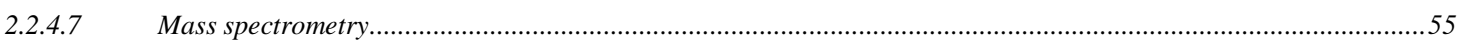

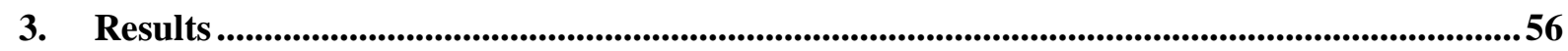

3.1 Cwc2 can be crosslinked to U6 RNA and the pre-mRNA in activated spliceosomes............56

3.2 Cwc2 interacts with the U6-ISL and a region upstream of the U6 ACAGAGA box .............61

3.1 Structure probing of native and Cwc2-depleted $B^{\text {act }}$ complexes .........................................68

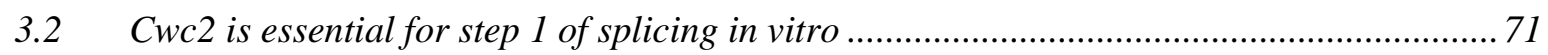

3.3 Cwc2 is not required for the activation of the spliceosome or for its remodelling by Prp2.75

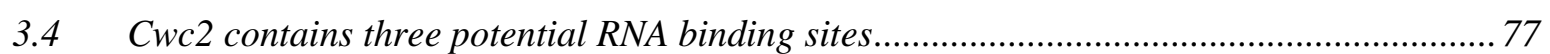

3.5 RBM22, the human homologue of Cwc2, interacts with U6 snRNA at sites equivalent to those contacted by Cwc2 in yeast spliceosomes ........................................................... 81

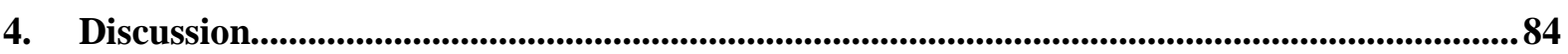

4.1 Cwc2 interacts with catalytic RNA-structural elements in the spliceosome ........................84

4.2 Cwc2 is required for pre-mRNA splicing in vitro and it is not required for the Prp2mediated remodeling of the activated spliceosome ......................................................87

4.3 Structural requirements of Cwc2 for multiple RNA interactions.......................................88

4.4 Evolutionary conservation of Cwc2 function in splicing ................................................90

4.5 Cwc2: a link between the RNA-catalytic center and the protein network of the spliceosome..

4.6 A potential role for Cwc2/RBM22 in promoting an active conformation of the spliceosome's catalytic RNA elements ........................................................................................ 93

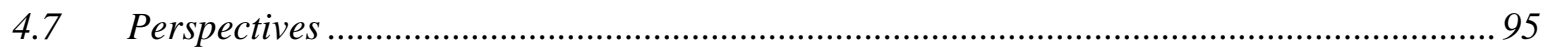




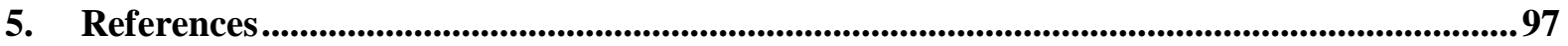

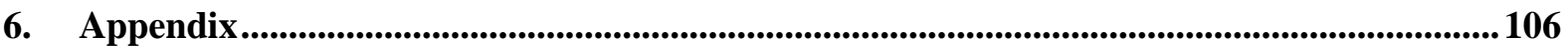

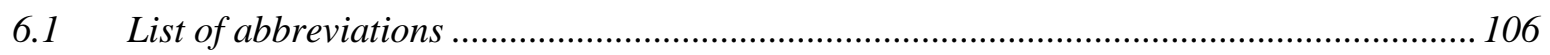

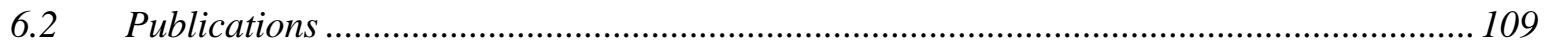

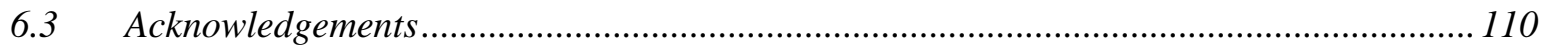

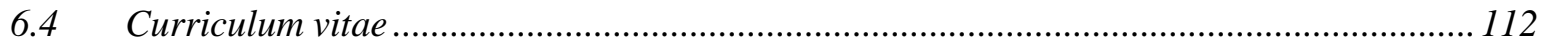

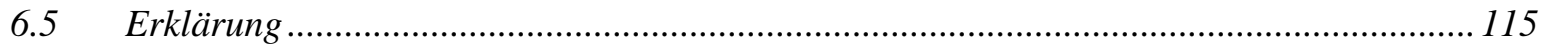




\section{Abstract}

Pre-mRNA splicing is catalyzed by the spliceosome, a multimegadalton ribonucleoprotein (RNP) complex. It assembles anew on each pre-mRNA intron by the stepwise binding of five snRNPs (U1, U2, U4, U5 and U6) and numerous proteins leading to the formation of the spliceosomal complex $\mathrm{B}$ which does not have yet an active catalytic site. For the establishment of the active site major structural changes are required, resulting in the formation of the activated $\mathrm{B}$ complex $\left(\mathrm{B}^{\text {act }}\right)$, which is then converted into the catalytically activated B* complex by the action of the Prp2 RNA helicase. Following the recruitment of the splicing factor Cwc25, the first step of splicing occurs, whereby the 5' splice site of the pre-mRNA is cleaved and the 5' end of the intron is ligated to the branch site adenosine to form a lariat-like structure; concomitantly the $\mathrm{C}$ complex is formed. At this time the second step of splicing occurs which leads to exon ligation. The newly formed mRNP is released from the spliceosome and the intron lariat spliceosome is disassembled. The released snRNPs are thought to re-assemble for a new round of splicing.

A complex RNA-RNA network involving the snRNAs and the pre-mRNA is formed during spliceosome assembly, and the resulting RNA structure plays a central role in catalysing the two steps of splicing. During spliceosome activation, U6 snRNA rearranges and forms an internal stem-loop (ISL) which plays a central role in the catalysis of splicing. The U6-ISL contains an internal bulge region that is critical for metal-ion binding and contains functionally important residues. U6 snRNA also forms base pairs with U2 snRNA generating the U2/U6 helix I. Finally, U6 snRNA via its conserved ACAGAGA sequence, also forms base pairs with the 5 ' end of the intron. In this arrangement, the branch site is juxtaposed with the 5 ' splice site.

While the importance of individual RNA-structural elements such as U6-ISL, U2/U6 helix I and the U6-ACAGAGA/5' splice site helix for splicing catalysis is well established, little was known at the time I started this work about how these various RNA elements are brought into a catalytically active tertiary conformation. Interestingly, if one examines how the catalytic center of the group II self-splicing introns is organized, a number of similarities between pre-mRNA and group II intron splicing can be recognized and indicate that the RNA elements of the respective catalytic core adopt similar folds in both 
systems. These include (i) the identical chemistry of the catalytic steps of both kinds of splicing and (ii) the great similarity between catalytically important structural elements in group II introns and the spliceosomal RNA network, especially between domain V (DV) of group II introns (which forms a stem-loop) and the U6-ISL, both of which bind catalytically active metal ions. One of the most impressive features revealed by the recently published crystal structure of an intact self-spliced group IIC intron is how numerous long-distance interactions between conserved structural elements of DI to VI and DV are essential to induce an unusual, catalytically important fold in DV.

In view of the paucity of conserved RNA tertiary structures in spliceosomal introns that might direct the folding and juxtaposition of essential catalytic RNA-structural elements (i.e U6-ISL and U2/U6 helix I) into an active conformation, it seems likely that spliceosomal proteins may have taken over this function, at least in part. Good candidates would be one or more of those proteins that become stably integrated into the spliceosome during its activation (i.e., the formation of the $\mathrm{B}^{\text {act }}$ complex). In yeast, these include a protein complex termed the "nineteen complex" (NTC) that consists of eight core proteins, and an additional set of NTC-related proteins. Among these, the yeast Cwc2 protein was of particular interest since it has an RRM and a zinc-finger domain, is essential for pre-mRNA splicing in vivo and has been shown to contact U6 snRNA during splicing in yeast extracts.

Here we show that Cwc2 is essential for the first step of splicing in vitro, and that it is not required for the Prp2-mediated remodelling step that generates the catalytically competent B* complex. We demonstrate that in purified catalytically active spliceosomes, Cwc2 contacts the U6-ISL, as well as regions of the U6 snRNA and the intron adjacent to the 5' splice site. Chemical structure-probing further suggests that Cwc2 may also directly or indirectly contact U6/U2 helix I. Thus, our data place Cwc2 at the heart of the spliceosome's catalytic center. During this time the crystal structure of the Cwc2 functional core was solved by our group, and could be used to determine structurefunction relationships by rational mutagenesis of Cwc2 combined with splicing. In addition, mass spectrometric analysis of RNA-protein crosslinks and electrophoretic mobility shift assays (EMSA) showed that Cwc2 acts as a multipartite RNA binding platform to bring RNA elements of the spliceosome's catalytic center into an active conformation. 
Interestingly, we also show that RNA interactions involving Cwc2 are evolutionarily conserved, as demonstrated by studies of its human counterpart RBM22, indicating that the observed Cwc2/RBM22 RNA contacts in the spliceosome are functionally important. We propose that Cwc2, in co-operation with the essential splicing factor Prp8, induces an active conformation of the catalytic RNA elements in the spliceosome. In conclusion, our data suggest that the function of RNA-RNA tertiary interactions within group II introns, that is, to induce a catalytically active RNA conformation of DV, has probably been taken over by proteins that contact the functionally analogous U6-ISL, within the spliceosome. 


\section{Introduction}

\subsection{Mosaic structure of eukaryotic genes and RNA splicing}

The central dogma of molecular biology stated by Francis Crick in 1970 (Crick, 1970) describes the transfer of information encoded within DNA into a specific amino acid sequence, called protein. During this process, DNA is transcribed first into RNA by an enzyme called RNA polymerase. In a process named translation, a macromolecular structure, the ribosome, subsequently converts the RNA sequence into an amino acid polymer. While the flow of information between DNA and RNA can proceed in both directions, a protein sequence cannot be retranslated.

In eukaryotic cells at first the DNA is usually transcribed into a precursor messenger RNA (pre-mRNA) containing large non-coding sequences (introns). During a process called RNA splicing, introns are removed from the transcripts and the coding sequences (exons) are ligated together. RNA splicing is accomplished by one of the largest and most complex cellular machineries, the spliceosome. Only after that pre-mRNA transcripts undergo RNA splicing and acquire two additional major modifications-, (i.e. 5'capping and 3'polyadenylation), the mature mRNA is exported to the cytoplasm to be translated.

\subsection{Pre-mRNA splicing}

From the chemical point of view the splicing reaction as such is very simple. Nevertheless, in vivo the spliceosome has to select the correct splice sites very precisely because even a mistake of one single nucleotide would result in a frameshift which could change the complete open reading frame (ORF) of the transcript. Especially in higher eukaryotes, as in humans, exons often are very short ( $\sim 50$ bases on average) compared to much longer introns ( 3500 bases in average), which can reach up to more than $100 \mathrm{~kb}$ in length and can count up to 116 introns per gene (Deutsch \& Long, 1999). Under this perspective it is very demanding for the spliceosome to recognize the exact boundaries of an exon and therefore pre-mRNAs contain several conserved motifs helping to define the splice sites. 


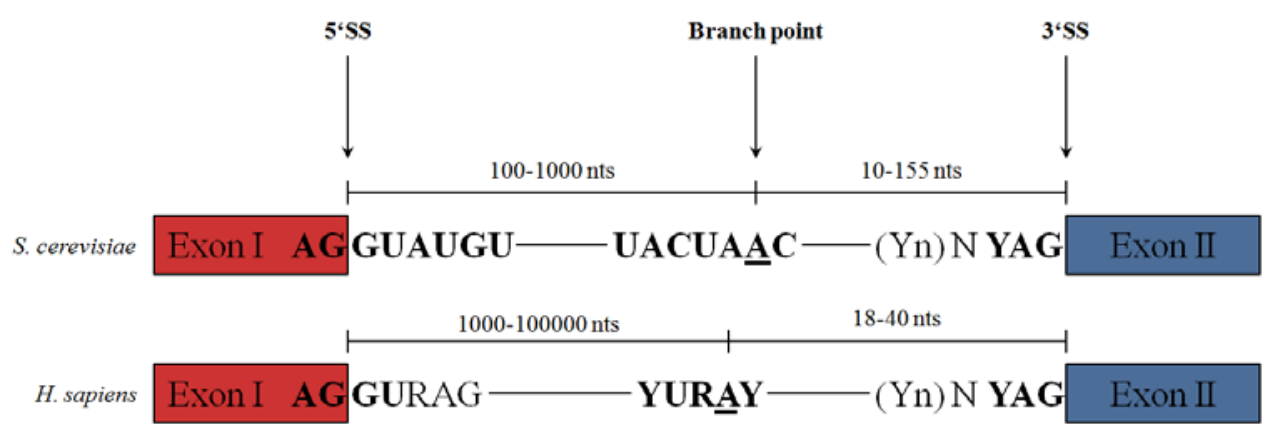

Figure 1.1: Comparison of conserved sequence elements between introns from $S$. cerevisiae and H. sapiens

Nucleotides with $90 \%$ or higher conservation are shown in bold. The BP adenosine is underlined. The polypyrimidine tract is represented by (Yn); purines are shown with ' $\mathrm{R}$ '; ns = nucleotides. The scheme is not drawn to scale.

In the yeast Saccharomyces cerevisiae (S. cerevisiae) these cis-acting elements are highly conserved (Figure 1.1). The 5' splice site (5’SS) sequence defines the boundary between an exon and a downstream intron and is composed of R/GUAUGUU ('R' is a purine, '/' indicates the exon/intron boundary)(Lopez \& Seraphin, 1999). While in S. cerevisiae the 5'SS is $90 \%$ conserved, the human consensus sequence AG/GURAG is rather degenerate. The 3'splice site (3'SS) sequence defines the boundary between an intron and a downstream exon and is composed of YAG/ (' $\mathrm{Y}$ ' is a pyrimidine, '/' indicates the exon/intron boundary) in S. cerevisiae as well as in H. sapiens. In many introns the 3'SS is preceded by a stretch of 8-12 pyrimidines called the polypyrimidine tract, which usually ends one nucleotide upstream of the 3'SS. The polypyrimidine tract seems to be more important for splicing of human than for splicing of yeast introns.

Another conserved sequence element surrounds the adenosine (branch adenosine, branch point, BP) which forms a branched intermediate in the course of the first step of splicing. This sequence is therefore called branch point sequence (BPS). The consensus sequence is composed of UACUA스 and in yeast it is usually located 10-60 nucleotides upstream of the 3’SS (Spingola et al, 1999).

In contrast to $H$. sapiens the majority of genes from S.cerevisiae do not contain introns. Only about 250 of the 6000 genes were found to be interrupted by non-coding sequences. Nevertheless, most of those genes encode ribosomal proteins, thus intron containing transcripts are highly abundant within the yeast cell. Therefore, almost $30 \%$ of all 
transcripts undergo splicing although only approximately $4 \%$ of yeast genes contain introns.

In contrast to $H$. sapiens yeast introns are usually much shorter (100-400 nts) and there are only very few examples where pre-mRNAs are differentially spliced, a process referred to as alternative splicing. Alternative splicing is very common in H. sapiens and leads to a much higher diversity of gene products from only a limited number of genes.

\subsection{Chemistry of the splicing reaction}

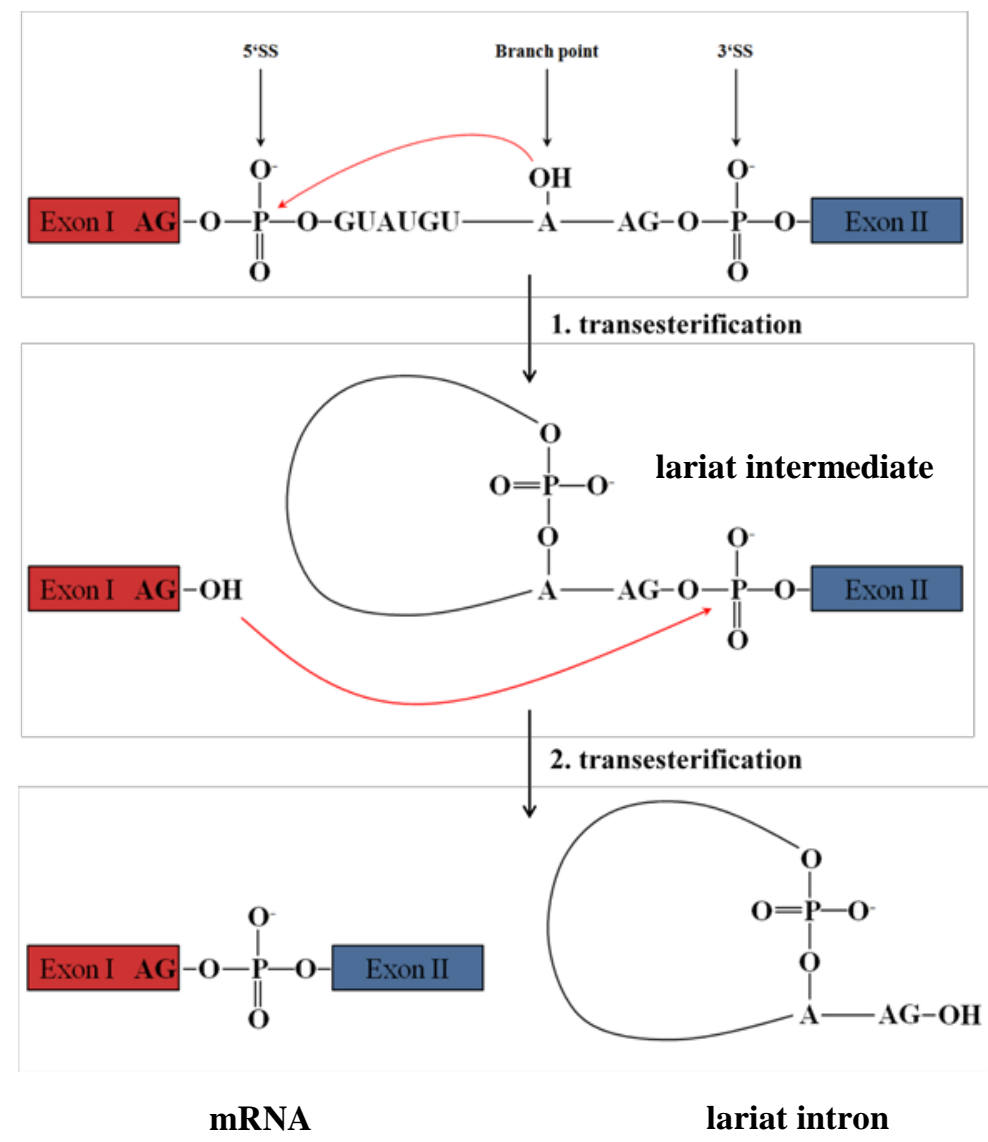

Figure 1.2: Chemistry of the splicing reaction

RNA splicing proceeds via two consecutive transesterification reactions, leading to the excision of the lariat intron and the joining of the exons.

The excision of introns from pre-mRNA requires two distinct transesterification reactions (Moore \& Sharp, 1993). First, the 2'-hydroxyl group of the branch point adenosine carries out a nucleophilic attack on the phosphorus atom at the 5'SS, resulting in cleavage of the 
pre-mRNA into the 5' exon and a lariat structured intermediate (Figure 1.2). In the second step, the phosphorus atom at the 3'SS is attacked by the nascent 3'-hydroxyl group of the 5' exon, displacing the bond to the lariat intron and thereby joining the 5' and 3' exons to form the mature mRNA product. The transesterification reactions as such are essentially isoenergetic. Nevertheless, several factors of the spliceosome require ATP for their function.

\subsection{Composition of snRNPs}

In eukaryotes pre-mRNA splicing is catalyzed by the spliceosome, a large ribonuclear complex. In contrast to the ribosome which, once bound to its substrate, shows a high degree of processivity, the spliceosome assembles anew on each pre-mRNA. The assembly and disassembly of the spliceosome is therefore organized in a very dynamic manner.

\begin{tabular}{|c|c|c|c|}
\hline \multicolumn{2}{|c|}{ S. cerevisiae } & \multicolumn{2}{|c|}{ H. sapiens } \\
\hline snRNA & length(nts) & snRNA & length(nts) \\
\hline U1 & 568 & U1 & 164 \\
\hline $\mathrm{U} 2$ & 1175 & $\mathrm{U} 2$ & 187 \\
\hline $\mathrm{U} 4$ & 160 & $\mathrm{U} 4$ & 145 \\
\hline U5L & 214 & - & - \\
\hline U5S & 179 & - & - \\
\hline U6 & 112 & U6 & 106 \\
\hline
\end{tabular}

Table 1.1: Spliceosomal RNAs in S. cerevisiae and H. sapiens

In $H$. sapiens more than 10 isoforms of U5 snRNA exist which are not shown in this table.

The spliceosome is formed from several subunits, referred to as small nuclear ribonucleoproteins (snRNPs), and various non-snRNP splicing factors. Each snRNP consists of an RNA, namely U1, U2, U4, U5 or U6 snRNA, and several protein factors. Except for U6, these snRNAs are transcribed by the RNA polymerase II as snRNA precursors containing additional 3' nucleotides and a monomethylated m7G cap structure. These pre-snRNAs are then exported into the cytoplasm where the snRNP assembly is 


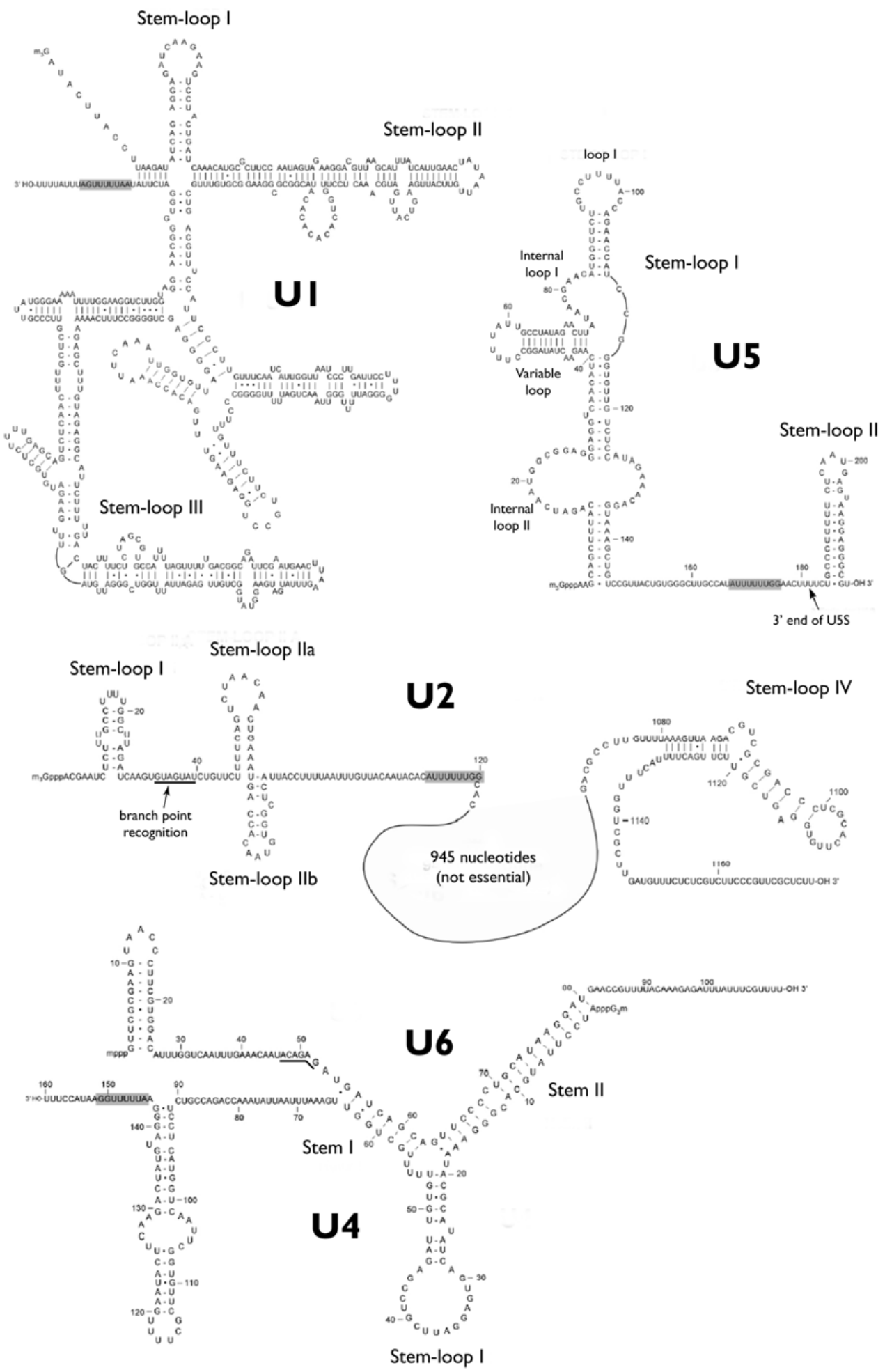

Figure 1.3: Secondary structures for the yeast U snRNAs

Schematic representation of proposed secondary structures of yeast snRNAs. The Sm binding site is indicated with a grey shadow. The conserved ACAGA box motif in U6 snRNA is underlined. Adapted from Kretzner et al (1990)(U1); Shuster and Guthrie (1988)(U2); Frank et al (1994); (Will \& Lührmann, 2006)(U5); Brow and Guthrie (1988)(U6, U4/U6). 


\begin{tabular}{|c|c|c|c|c|c|c|c|c|c|c|c|c|c|c|c|}
\hline \multicolumn{8}{|c|}{ Saccharomyces cerevisiae } & \multicolumn{8}{|c|}{ Homo sapiens } \\
\hline Protein & U1 & U2 & U5 & U4/U6 & \multicolumn{3}{|c|}{ U4/U6.U5 } & Protein & U1 & U2 & U5 & U4/U6 & \multicolumn{3}{|c|}{ U4/U6.U5 } \\
\hline SmB & $\cdot$ & • & • & $\bullet$ & • & & - & $\mathrm{SmB} / \mathrm{B}^{*}$ & $\cdot$ & $\cdot$ & • & • & • & & • \\
\hline SmD1 & - & - & - & - & • & & $\bullet$ & SmD1 & $\bullet$ & - & - & • & $\bullet$ & & $\bullet$ \\
\hline SmD2 & - & • & - & - & • & & - & SmD2 & $\bullet$ & $\bullet$ & • & $\bullet$ & • & & • \\
\hline SmD3 & - & - & • & - & • & & - & SmD3 & - & - & - & - & • & & • \\
\hline SmE & • & - & • & - & • & & - & $\operatorname{SmE}$ & - & • & - & - & • & & - \\
\hline SimF & - & - & • & - & • & & - & $\operatorname{SmF}$ & - & - & - & - & • & & • \\
\hline SmG & - & - & - & - & • & & - & SmG & - & $\bullet$ & $\bullet$ & - & • & & $\bullet$ \\
\hline Lsm2 & & & & $\circ$ & & $\circ$ & & Lsm2 & & & & $\circ$ & & $\circ$ & \\
\hline Lsm3 & & & & $\circ$ & & $\circ$ & & Lsm3 & & & & $\circ$ & & $\circ$ & \\
\hline Lsm4 & & & & 。 & & 。 & & $\operatorname{Lsm} 4$ & & & & $\circ$ & & $\circ$ & \\
\hline Lsm5 & & & & 。 & & $\circ$ & & Lsm5 & & & & $\circ$ & & $\circ$ & \\
\hline Lsm6 & & & & $\circ$ & & $\circ$ & & Lsm6 & & & & $\circ$ & & 。 & \\
\hline Lsm7 & & & & 。 & & 。 & & Lsm7 & & & & 。 & & 。 & \\
\hline Lsm8 & & & & $\circ$ & & $\circ$ & & Lsm8 & & & & $\circ$ & & $\circ$ & \\
\hline Snp1 & - & & & & & & & $70 \mathrm{~K}$ & - & & & & & & \\
\hline Mud1 & - & & & & & & & U1-A & • & & & & & & \\
\hline U1-C & • & & & & & & & U1-C & $\bullet$ & & & & & & \\
\hline Nam8 & - & & & & & & & n.o. & & & & & & & \\
\hline Prp39 & - & & & & & & & n.o. & & & & & & & \\
\hline Prp40 & - & & & & & & & FBP11 & & & & & & & \\
\hline Prp42 & - & & & & & & & n.o. & & & & & & & \\
\hline Snu56 & $\bullet$ & & & & & & & n.o. & & & & & & & \\
\hline Snu71 & - & & & & & & & n.o. & & & & & & & \\
\hline Luc7 & - & & & & & & & CGI-74 & & & & & & & \\
\hline Lea1 & & - & & & & & & U2-A & & $\bullet$ & & & & & \\
\hline Yb9 & & - & & & & & & U2-B" & & • & & & & & \\
\hline Prp21 & & - & & & & & & SFa120 & & - & & & & & \\
\hline Prp11 & & - & & & & & & Sf3a66 & & - & & & & & \\
\hline Prp9 & & - & & & & & & SP3a60 & & - & & & & & \\
\hline Hsh155 & & - & & & & & & Sf3b155 & & - & & & & & \\
\hline Cus1 & & - & & & & & & Sf3b145 & & - & & & & & \\
\hline Rse1 & & - & & & & & & Sf3b130 & & - & & & & & \\
\hline Hsh49 & & - & & & & & & SE3b49 & & • & & & & & \\
\hline Rds 3 & & - & & & & & & p14 & & - & & & & & \\
\hline Ysf3 & & - & & & & & & $\begin{array}{l}\text { Sf3b14b } \\
\text { Sf3b10 }\end{array}$ & & : & & & & & \\
\hline Prp5 & & & & & & & & hPrp5 & & $\bullet$ & & & & & \\
\hline n.o. & & & & & & & & $S R 140$ & & - & & & & & \\
\hline n.o. & & & & & & & & CHERP & & - & & & & & \\
\hline Prp43 & & & & & & & & hPrp43 & & - & & & & & \\
\hline n.o. & & & & & & & & $S P F 45$ & & - & & & & & \\
\hline n.o. & & & & & & & & $S P F 31$ & & - & & & & & \\
\hline n.o. & & & & & & & & SPF3O & & - & & & & & \\
\hline Prp8 & & & $\bullet$ & & & & & $220 \mathrm{~K}$ & & & - & & & & \\
\hline Brr2 & & & • & & & & & $200 \mathrm{~K}$ & & & - & & & & \\
\hline Snu114 & & & - & & & & & $116 \mathrm{~K}$ & & & - & & & & \\
\hline Prp28 & & & - & & & & & $100 \mathrm{~K}$ & & & - & & & & \\
\hline Lin1 & & & - & & & & & $52 \mathrm{~K}$ & & & • & & & & \\
\hline Dib1 & & & • & & & & & $15 \mathrm{~K}$ & & & • & & & & \\
\hline n.o. & & & & & & & & $40 \mathrm{~K}$ & & & • & & & & \\
\hline Prp3 & & & & - & & • & & $90 \mathrm{~K}$ & & & & - & & • & \\
\hline Prp4 & & & & - & & - & & $60 \mathrm{~K}$ & & & & - & & • & \\
\hline Snu13 & & & & - & & • & & $15.5 \mathrm{~K}$ & & & & $\bullet$ & & • & \\
\hline n.o. & & & & & & & & СурН & & & & - & & • & \\
\hline Prp6 & & & & & & $\bullet$ & & $102 \mathrm{~K}$ & & & $\bullet$ & & & $\bullet$ & \\
\hline Prp31 & & & & & & • & & $61 \mathrm{~K}$ & & & & $\bullet$ & & • & \\
\hline Prp38 & & & & & & • & & FLJ-14936 & & & & & & & \\
\hline Snu23 & & & & & & • & & FLJ-31121 & & & & & & & \\
\hline Snu66 & & & & & & - & & $110 \mathrm{~K}$ & & & & & & - & \\
\hline Spp381 & & & & & & • & & n.o. & & & & & & & \\
\hline Sad1 & & & & & & & & $65 \mathrm{~K}$ & & & & & & $\bullet$ & \\
\hline n.o. & & & & & & & & $27 \mathrm{~K}$ & & & & & & - & \\
\hline
\end{tabular}

Table 1.2: Protein composition of snRNPs from S.cerevisiae and $H$. sapiens

Shown are the Sm proteins, common to the U1, U2, U4, and the U5 snRNP as well as the Lsm proteins for the U6 snRNP. In addition several particle specific proteins are shown (Brow (2002), Will and Lührmann (2006)). 

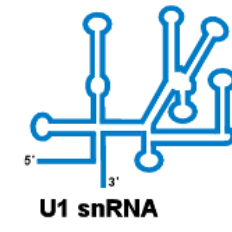

Sm

S np 1

Mud1

Yhe1

Prp39

Snu 71

Prp40

Prp42

Nam8

Snu56

Lue 7
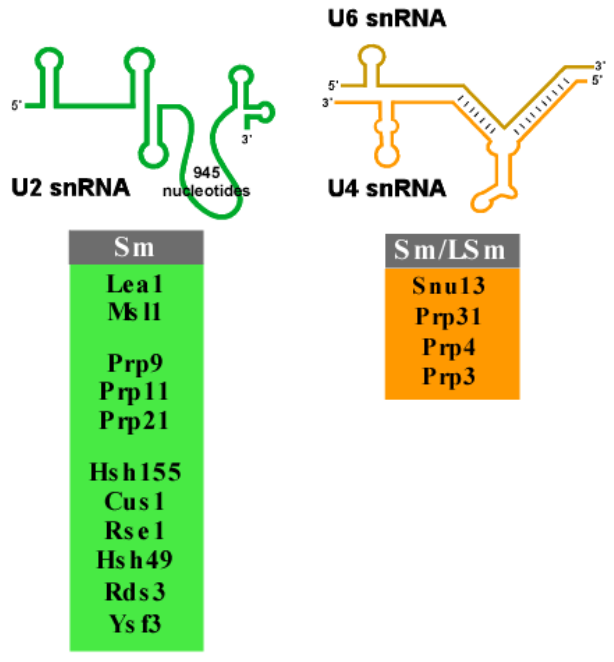

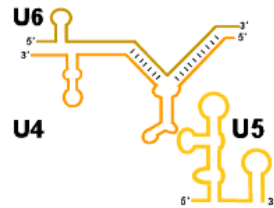

$\mathrm{S}$ m/LSm

Prp8

Brr2

Brr2

Prp6

Dib 1

Snu13

Prp31

Prp4

Prp3

Snu66

Sad1

Spp381

Prp38

Snu2

Figure 1.4: Protein and snRNA composition of U snRNPs from $S$. cerevisiae

S. cerevisiae snRNA structures are shown as colored lines and intermolecular basepairing interactions are indicated by dashes. The common Sm/Lsm proteins are highlighted in grey, and particle-specific proteins are assigned to the corresponding snRNA through the same color code. Typical snRNP subcomplexes are represented as colored circles at the top of this illustration (This figure was kindly provided by Dr. Patrizia Fabrizio, department of cellular biochemistry, MPI-BPC).

initiated. The snRNA precursors assemble in a stepwise manner with a group of seven proteins referred to as the Sm proteins, namely B/B', D3, D2, D1, E, F and G. In this process the Sm proteins build a ring like formation around a conserved sequence element within the pre-snRNAs and thereby form the snRNP core structure. Subsequently to the Sm core assembly, the m7G cap is hypermethylated into a 2,2,7-trimethylated cap (m3G) structure and the pre-snRNAs undergo 3' end processing. The m3G cap in conjunction with the Sm core acts as a nuclear localization signal which is required for the subsequent import into the nucleus. The assembly of U6 snRNP is thought to take place entirely within the nucleus. U6 snRNA is transcribed by RNA polymerase III and is monomethylated at its 5' $\gamma$-phosphate. The U6 snRNA lacks a Sm site and therefore the core structure of U6 is comprised of a set of protein factors referred to as LSm proteins, namely LSm2, LSm3, LSm4, LSm5, LSm6, LSm7 and LSm8. LSm proteins share conserved structural motifs with the Sm proteins and interact with a uridine rich tract at 
the 3' end of U6 snRNA. In Table 1.1 the spliceosomal snRNAs of S.cerevisiae and $H$. sapiens are listed. Note that there are two isoforms of U5 snRNA in S. cerevisiae referred to as U5 long (U5L) and U5 short (U5S). Both originate from the same primary transcript but are differentially processed at their 3' end.

Phylogenetic comparative methods have shown a high degree of sequence conservation between snRNAs from different species. Especially stretches known to be involved in interactions with pre-mRNA, proteins or other snRNAs are highly conserved. This conservation is also reflected in very similar models of secondary structure (Figure 1.3).

In addition to the core components mentioned above which are common among different snRNPs, each snRNP is also composed of particle specific factors listed and schematically presented in Figure 1.4. The topic of this work mainly focuses on pre-mRNA splicing in the yeast S. cerevisiae where many of the proteins related to splicing are named "Prp" proteins to indicate their function in pre-mRNA processing.

\subsection{Spliceosome assembly in Saccharomyces cerevisiae}

The current understanding of spliceosome assembly is mainly based on biochemical studies of in vitro splicing systems. Using a combination of native gel electrophoresis, glycerol gradient centrifugation and affinity selection, it was possible to isolate and characterize defined spliceosomal assembly intermediates. On the basis of these investigations a stepwise model of spliceosome assembly is widely accepted today.

A scheme of the stepwise assembly of spliceosomes from S. cerevisiae is shown in Figure 1.5. First, the U1 snRNP is recruited to the 5'SS in a process which in part is mediated through base-pairing of the 5' end of U1 snRNA with the conserved nucleotides of the 5'SS. In an ATP dependent step the U2 snRNP binds to the branch point region thus forming complex A. The U2 snRNP is anchored to the BPS via base-pairing of the U2 snRNA with intron sequences (Madhani \& Guthrie, 1994a) and binding of several protein factors primarily upstream of the BPS (Gozani et al, 1996; Gozani et al, 1998). In the next step the preformed U4/U6.U5 tri-snRNP is recruited to complex A, forming complex B. Although complex B contains a full set of snRNPs it is not catalytically active yet. The transformation of the pre-catalytic spliceosome into the catalytically active complex requires major structural rearrangements mainly driven by $\mathrm{DExD} / \mathrm{H}$ box type 
ATPases/helicases. As indicated in Figure 1.5 DExD/H box type ATPases/helicases are essential for several steps of splicing and therefore their function will be described more extensively in chapter 1.7. During activation of the spliceosome and transition from

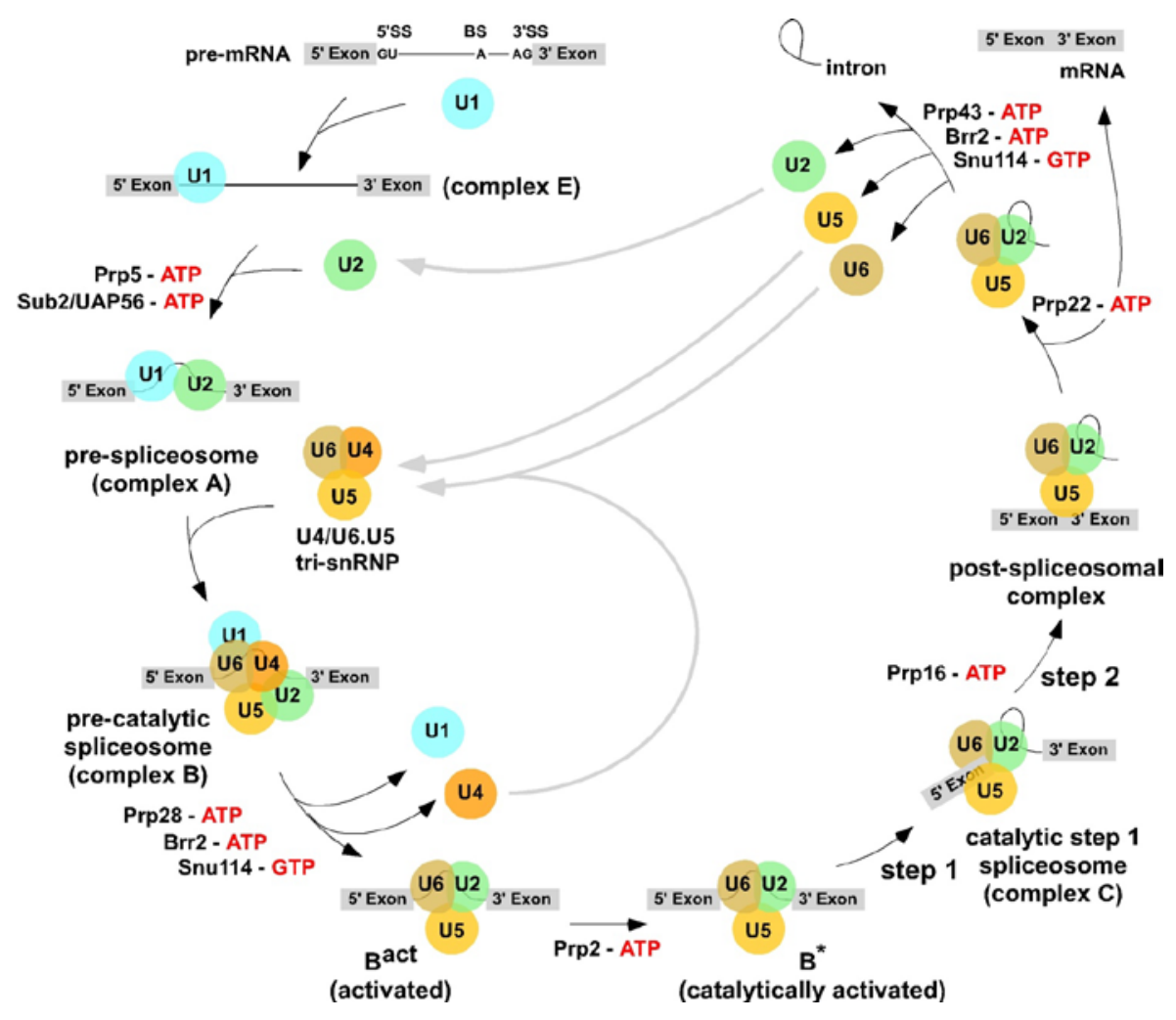

Figure 1.5: Spliceosome assembly in S. cerevisiae

Schematic presentation of the stepwise assembly of the spliceosome on a pre-mRNA. U snRNPs are represented as circles labeled with the respective U snRNA. Helicases, required for important remodeling events are indicated. Recycling of snRNPs is indicated by grey arrows. Spliceosomal complexes are named according to the human standard nomenclature (the figure was kindly provided by Dr. Patrizia Fabrizio).

complex B to complex $\mathrm{B}^{\text {act }}$, the $\mathrm{U} 1$ and $\mathrm{U} 4$ snRNPs are released. The complex $\mathrm{B}^{\text {act }}$ is then catalytically activated by Prp2 to form complex $\mathrm{B}^{*}$, which catalyzes the first step of splicing thereby generating complex C. Prior to the second step of splicing the spliceosome once more undergoes a major remodeling event which leads to rearrangements at the catalytic center which are required for exon ligation and also to assist with splicing fidelity (Konarska et al, 2006). After the release of the mature mRNA, the intron lariat is degraded and the snRNPs are recycled for another round of splicing. 


\subsection{Dynamics of the spliceosomal RNA-network}

During spliceosome assembly, a complex RNA-network is formed involving intra- and intermolecular interactions between snRNAs, as well as interactions between snRNAs and the pre-mRNA (Staley \& Guthrie, 1998; Wahl et al, 2009). During the splicing cycle the RNA network undergoes several major structural rearrangements. Initially, U1 recognizes the 5'SS while U2 forms a short duplex with the BPS. In this duplex the branch point adenosine is bulged out, enabling it to carry out the nucleophilic attack during the first step of splicing. Within the tri-snRNP, U4 and U6 are extensively base paired. This interaction has to be disrupted upon integration into complex A, allowing U6 to replace U1 at the 5'SS. In this process U6 forms base pairs with the 5' end of the intron via its conserved ACAGAGA motif. In addition, U6 is now able to form short duplexes with U2, namely helix Ia, Ib and II. Helix Ib contains the invariant AGC triad of U6 that has been suggested to be involved in binding a catalytic metal ion and was shown to be essential for splicing.
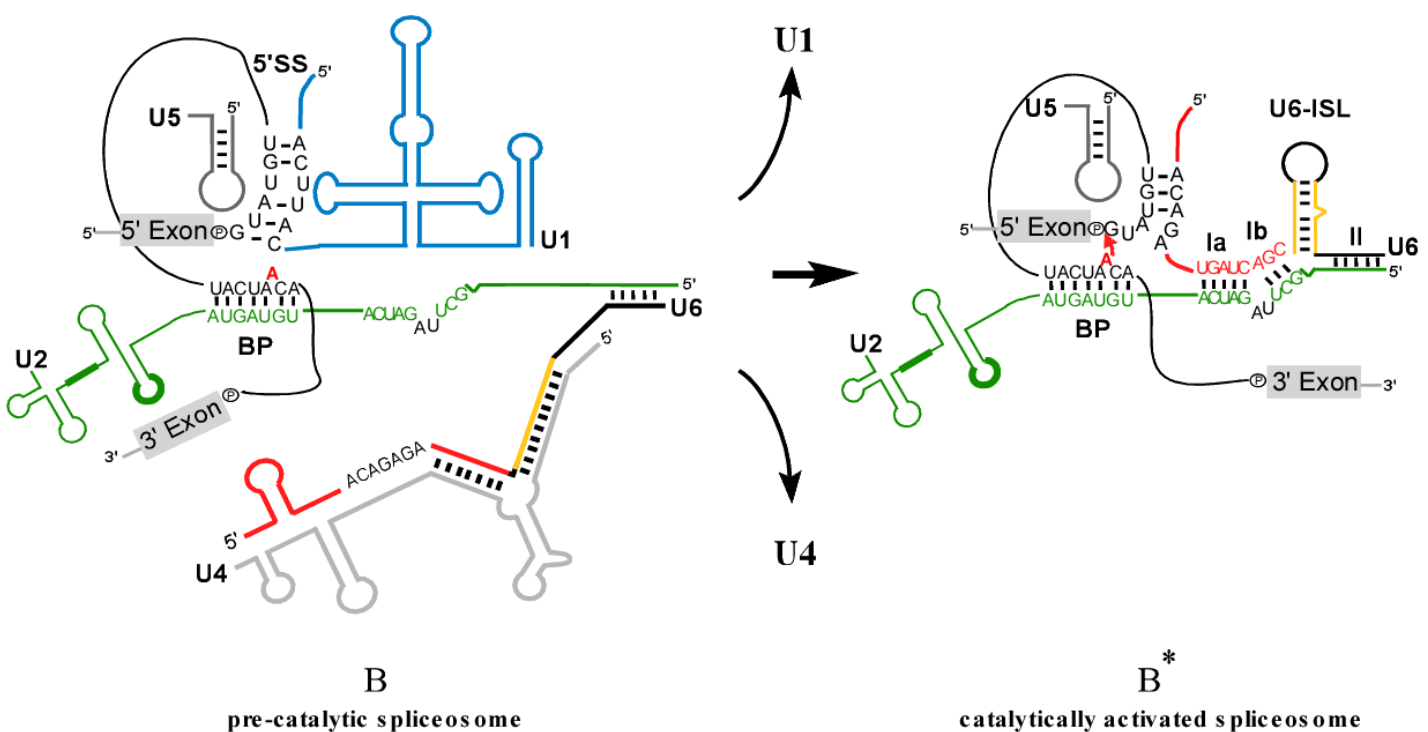

Figure 1.6: Dynamics of the spliceosomal RNA network during catalytic activation

Schematic representation of the RNA rearrangements occuring within the spliceosomal RNA network during spliceosome activation. Left: pre-catalytic spliceosome, B complex; right: catalytically activated spliceosome before the first catalytic step, $\mathrm{B}^{*}$ complex. Important RNA regions are assigned by their sequence content in Latin letters or in case of U6 snRNA with colored lines (yellow line: sequence forming the U6-ISL after catalytic activation, red line: region involved in basepairing interactions with U2 (helices Ia and Ib, indicated with the primary sequence on the right). The branchpoint $\mathrm{A}$ is highlighted in red and is bulged out from the U2-BP helix (left and right). (This figure was kindly provided by Dr. Patrizia Fabrizio, department of cellular biochemistry, MPI-BPC). 
Through the interaction of U6 with U2 the BP is brought in proximity to the 5'SS.The release from U4 also allows U6 to adopt an intramolecular stem loop structure (U6-ISL), comprising a bulge loop coordinating a $\mathrm{Mg}^{2+}$ ion which is crucial for the catalysis of the splicing reaction (Yean et al, 2000).

Upon integration of the tri-snRNP, loop I of U5 contacts exon nucleotides upstream of the 5'SS. After the first step of splicing, the U5 loop I extends its interaction to exon nucleotides downstream of the 3'SS. Most probably these interactions are required to align both exons for catalysis of the second step of splicing.

The RNA network shaped through all these described remodeling events (Figure 1.6, B*catalytically activated spliceosome) forms the core of the catalytic center of the spliceosome and, in addition, the necessity of $\mathrm{Mg}^{2+}$ ions for the catalysis of the splicing reaction suggests an RNA based catalysis which could be similar to the mechanism depicted for group II selfsplicing introns (see also chapter 1.9 for more details).

\subsection{DExD/H box helicases}

Due to the dynamic character of the splicing reaction at several stages of spliceosome assembly, active driving forces are required for rearrangements of the RNA network or to separate interaction partners allowing them to form new contacts. Some members of the family of DExD/H-type RNA-depended ATPases have been found to be crucial for a number of steps throughout the whole splicing cycle. In general, this type of enzyme was shown to be involved in almost every aspect of RNA metabolism (Cordin et al, 2012) by catalyzing reactions like the separation of double stranded RNA or the displacement of proteins from RNA (Fairman et al, 2004). In the spliceosomal context at least eight ATPases of the DExD/H-type, conserved between human and yeast, have been described so far (Table 1.3).

At the early stages of spliceosome assembly Sub2 and Prp5 are required to facilitate the interaction of the U2 snRNP with the BPS. In this context it is assumed that Sub2 might be responsible for the displacement of SF1 from the BP to open this region for interactions with the U2 snRNP (Staley \& Guthrie, 1998; Wahl et al, 2009). For Prp5 it was suggested that it interacts with SF3a components to facilitate an ATP-dependent remodeling of the U2 structure, required for the interaction of the branch-pairing region of U2 snRNA with 
the BPS (Abu Dayyeh et al, 2002; Wiest et al, 1996). Prp5 might also be required to monitor the fidelity of base pairing in the branch region (Xu \& Query, 2007). During catalytic activation several interactions formed in the early assembly stages of the spliceosome have to be broken again. The ATPase Prp28 is involved in the release of U1 snRNP to free the 5'SS for interactions with the U6 snRNA. At approximately the same time U6 and U4 snRNA have to be dissociated since they are still tightly base paired within the tri-snRNP. The helicase Brr2 is responsible for the unwinding of U6 and U4 snRNA to promote base-pairing of U6 with U2 snRNA. Since Brr2 stays associated with the spliceosome and is required again during disassembly its activity needs to be strictly controlled (Small et al, 2006). In summary, the combined action of these enzymes yields the $\mathrm{B}^{\text {act }}$ complex. The final catalytic activation of $\mathrm{B}^{\text {act }}$ to yield $\mathrm{B}^{*}$, requires the RNA helicase Prp2. The B* complex catalyses step 1 of splicing, yielding the $\mathrm{C}$ complex. After a further remodelling step, which requires the RNA helicase Prp16, complex C catalyses the second step.

\begin{tabular}{|c|c|c|}
\hline DExD/H-box ATPase & Human homologue & Stage in splicing cycle \\
\hline Sub2 & UAP56 & Pre-spliceosome \\
\hline Prp5 & hPrp5 & Pre-spliceosome \\
\hline Prp28 & U5-100 kD & Early activation \\
\hline Brr2 & U5-200 kD & Early activation \\
\hline Prp2 & hPrp2 & Late step-1 activation \\
\hline Prp16 & hPrp16 & Step-2 activation \\
\hline Prp22 & hPrp22 & mRNA release \\
\hline Prp43 & hPrp43 & Disassembly \\
\hline
\end{tabular}

Table 1.3: Spliceosomal ATPases from S.cerevisiae and H. sapiens

Spliceosomal helicases conserved between $S$. cerevisiae and $H$. sapiens. The function of each ATPase is indicated in the right column. The table was adapted from Brow (2002).

Before the second step of catalysis can occur, the action of the helicase Prp16 is required. Prp16 was isolated as a suppressor of a branch A to branch $\mathrm{C}$ mutation of the pre-mRNA substrate, thus it affects the fidelity of branch site usage (Cordin et al, 2012). Only recently, it was shown to mediate the release of the spliceosomal first step proteins Cwc25 and Yju2 to allow the binding of the second step proteins Prp22, Prp18 and Slu7 (Tseng et al, 2011). Recent experiments performed in our department however showed that under physiological salt concentrations (75 $\mathrm{mM} \mathrm{KCl}$ ), the addition of Prp16 and ATP to the C 
complex does not lead to the release of Cwc25 directly. Only the further addition of Slu7 and Prp18 leads to a quantitative dissociation of Cwc25 from the spliceosome concomitant with step 2 catalysis (Odenwälder et al., in preparation).

Subsequent to the ligation of the exons the mRNA is released from the spliceosome in a process driven by the helicase Prp22 (Company et al, 1991; Schwer \& Gross, 1998). Genetic analysis implicate that Prp22 is involved in breaking contacts between Prp8 and the conserved loop 1 of U5 snRNA (Aronova et al, 2007; Schneider et al, 2004) and thereby separating the U5 snRNP and the mRNA. After the release of the mRNA, the intron-lariat complex is disassembled by the action of Prp43 enabling the associated spliceosomal snRNPs to participate in another round of splicing (Arenas \& Abelson, 1997).

It has been shown that several DExD/H-box helicases such as Prp5, Prp2, Prp16 and Prp22 couple rearrangements of RNPs with proofreading functions that ensure the accurate succession of the splicing process and allow for the rejection of substrates or intermediates that are aberrant. In this context a two-state model for the spliceosome is discussed. Since the substrates for the two chemical reactions are different, at least a partial rearrangement of the substrate(s) and/or enzyme at the catalytic center is required to reposition the splicing intermediates generated during the first catalytic step, so that the reactive groups involved in the second step are brought into the right conformation for the second step. Therefore, the spliceosome most probably can alternate between two discrete conformational states during the catalytic phase, binding the substrates differently for the two steps (Konarska \& Query, 2005b). This hypothesis is mainly based on several mutations in spliceosomal factors (Prp8, Prp16, U6 snRNA, Isy1) which were shown to alter the relative efficiencies of the first and second steps. Therefore it has been suggested that the catalytic center of the spliceosome may alternate between two different states during the catalytic phase. It has also been suggested that the first and second catalytic steps require different conformational states of the spliceosome during the catalytic phase (Konarska \& Query, 2005b). Since the ATPases Prp2 and Prp16 are essential for the activation of the spliceosome prior to the first and second catalytic steps, respectively, it seems likely that the equilibrium between these conformational states is modulated by these factors. In particular, the ATPase Prp16 promotes the transition between the first and second steps, and thereby it provides an opportunity for discarding aberrant substrates that do not proceed efficiently to the second step. This modulation of transition and opportunity for discarding probably occurs at several points in both assembly and 
post-catalytic phases. However, very little is currently known about the nature of these remodelling steps.

\subsection{Dynamics of the spliceosomal protein composition}

Although there is evidence that the splicing reaction per se might be RNA catalyzed, proteins account for a major component of the spliceosome and can make up more than two thirds of its total mass. First analysis of mixed populations of complete spliceosomal complexes revealed that next to known snRNP protein factors also numerous non-snRNP factors are associated with the spliceosome. However, the recent possibility of purifying spliceosomal complexes at defined stages provided not only an insight into the complete protein composition but also into protein dynamics during spliceosome assembly (Fabrizio et al, 2009). Mass spectrometric analysis revealed substantial changes in the protein composition of spliceosomal complexes between different stages of assembly (Figure 1.7). It was shown that at the stage of complex B not only the preformed tri-snRNP is recruited to the spliceosome but also several non-snRNP proteins. A complex termed "nineteen complex” (NTC) joins, which consists of Prp19, Cef1, Snt309, Syf1, Clf1, Isy1, Ntc20 and Syf2 which is required for promoting stable interactions of U5 and U6 snRNAs with the pre-mRNA during the activation of the spliceosome (Chan \& Cheng, 2005; Chan et al, 2003). Together with the NTC also the factors Prp45 and Prp46 and the RES complex (retention and splicing) are found to be components of complex B. However, at the stage of complex B these factors are present in substoichiometric amounts and only during the transition from complex B to $\mathrm{B}^{\text {act }}$ the NTC, Prp45, Prp46 and the RES complex become stably associated with the spliceosome. During this transition also 35 protein factors are released from the spliceosome, including tri-snRNP specific factors and all proteins associated with $\mathrm{U} 1$ and $\mathrm{U} 4 / \mathrm{U} 6$. At the same time a set of additional proteins (Ecm2, Cwc2, Cwc15, Bud31, Yju2, Prp17, Cwc21, Cwc22, Cwc24, Cwc27) is recruited (Fabrizio et al, 2009). For simplicity, the latter group will henceforth be termed "NTCrelated proteins”, because several of them have been shown to interact loosely with one or more of the NTC core proteins. Like the NTC related proteins also the DEAH helicase Prp2 and its cofactor Spp2 associate with the spliceosome at the stage of $\mathrm{B}^{\text {act }}$ complex. However, Prp2 and Spp2 are not required for a stable assembly of $\mathrm{B}^{\text {act }}$ complexes but are 


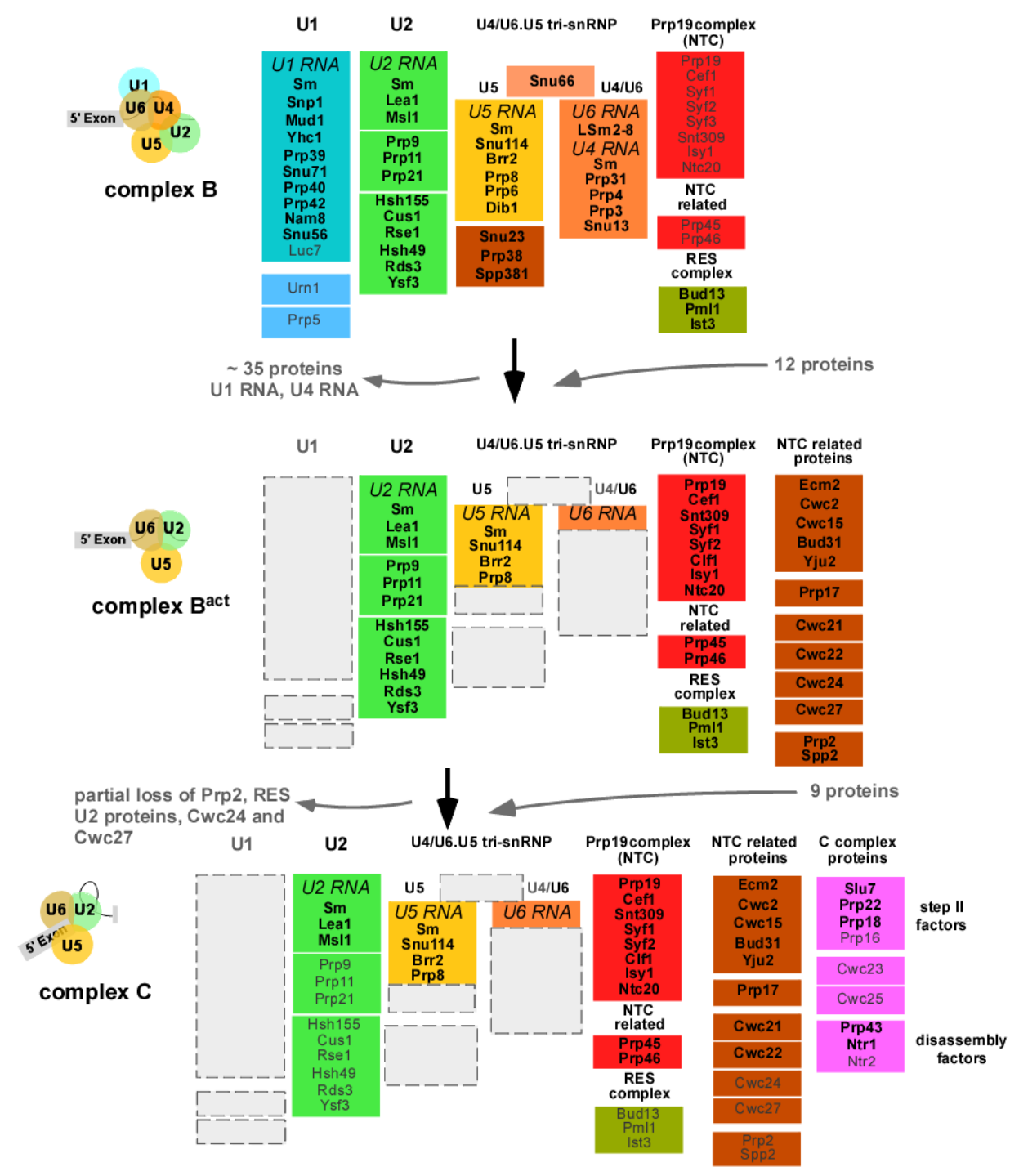

Figure 1.7: Compositional dynamics of yeast spliceosomes (adapted from Fabrizio et al (2009))

Protein composition of distinct spliceosomal complexes determined by mass spectrometry. Affiliation to respective U snRNPs is indicated above the boxes. The Prp19 complex is shown in red. Other proteins are classified according to their specific recruitment to the spliceosome at a certain stage of spliceosomal assembly cycle, i.e. $\mathrm{B}^{\text {act }}$ complex and $\mathrm{C}$ complex proteins, indicated in brown and purple, respectively. Recruitment and release of proteins is depicted by grey arrows. Schematic representations of $B, B^{\text {act }}$ and $C$ complexes are shown on the left.

rather needed purely mechanistically. Using an in vitro complementation system it was shown that upon ATP hydrolysis, Prp2 promotes a structural rearrangement that 
transforms $\mathrm{B}^{\text {act }}$ into a catalytically active complex named $\mathrm{B}^{*}$. If this complex is supplemented with Cwc25, efficient catalysis of step I can occur (Warkocki et al, 2009). However, Cwc25 is not associated with $\mathrm{B}^{\text {act }}$ complexes but most probably is recruited to the spliceosome during its catalytic activation just prior to step 1. Prp2 and Spp2 are found to be less abundant in complex $\mathrm{C}$ suggesting that both proteins are released from the spliceosome during the transition from $\mathrm{B}^{\text {act }}$ to $\mathrm{C}$ complex. Interestingly, also a destabilization of the U2 associated SF3a/SF3b proteins is observed during this transition, indicating that upon Prp2 remodeling, the region around the BPS might be rearranged to position the BP adenosine for the nucleophilic attack at the 5'SS. Besides Prp2, Spp2 and the U2 factors also Cwc24, Cwc27 and the members of the RES complex (Bud13, Pml1, Ist3) are less abundant in $\mathrm{C}$ complex.

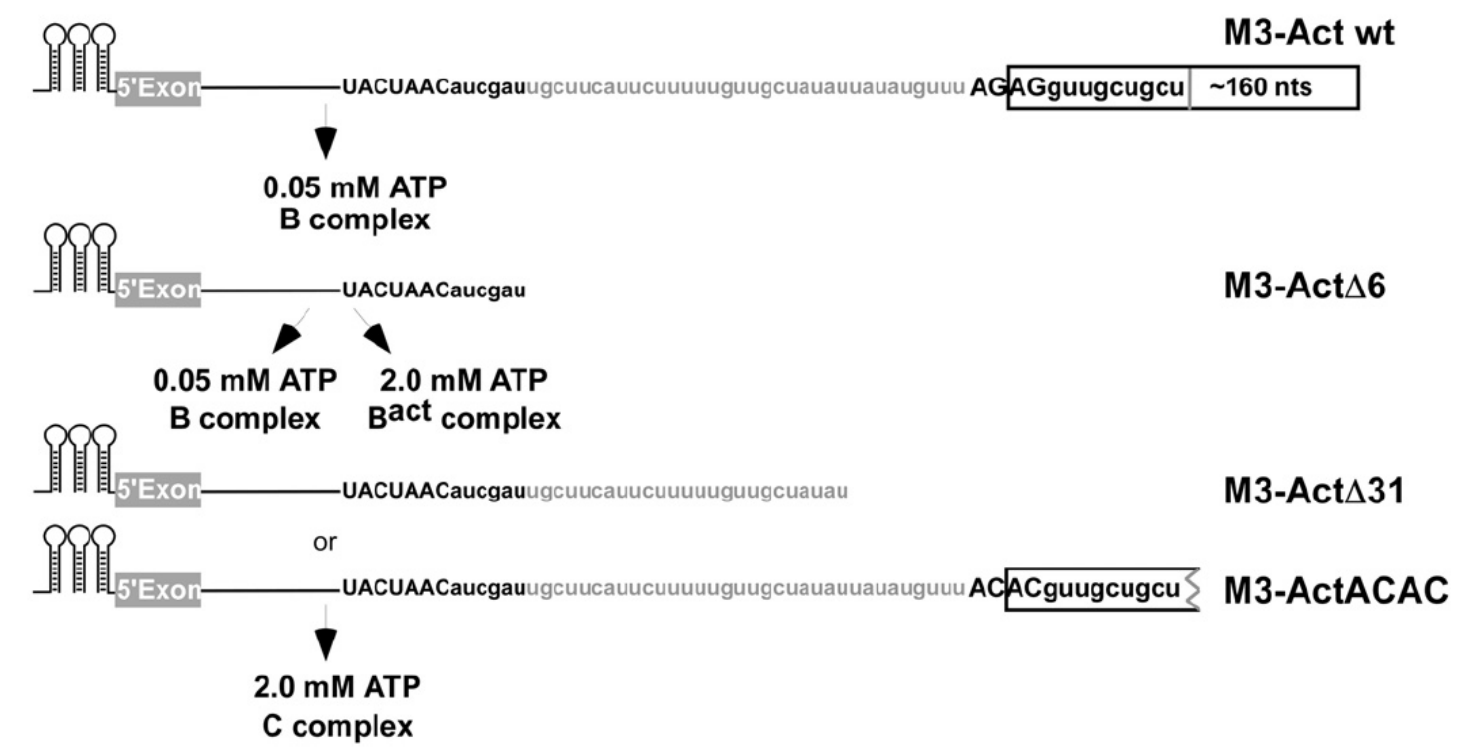

Figure 1.8: Pre-mRNA constructs used for the purification of spliceosomes (adapted from Fabrizio et al, 2009)

M3-Act wt is used to assemble either complex B under low ATP concentrations or $\mathrm{B}^{\text {act }} / \mathrm{B}^{*}$ complex after the heat inactivation of Prp2. M3-ActD6 is truncated six nucleotides downstream of the BPS and is used to stall $\mathrm{B}^{\text {act }}$ complexes while M3-ActD31 is truncated 31 nucleotides after the BPS and stalls spliceosome assembly at the stage of complex C.

Nevertheless, a set of proteins not found in $\mathrm{B}$ and $\mathrm{B}^{\mathrm{act}}$ complexes is recruited to the spliceosome at the stage of C complex. These include Cwc23 and Cwc25, the second step factors Slu7, Prp22, Prp18 and Prp16 and the disassembly factors Prp43, Ntr1 and Ntr2. Prp16 is represented in substoichiometric amounts within the $\mathrm{C}$ complex indicating that it might be only transiently associated with the spliceosome. Note that Prp17, another step 2 
factor, was already present in $\mathrm{B}^{\text {act }}$ complexes. To isolate spliceosomal complexes at these defined stages, different pre-mRNA constructs are used (Figure 1.8). The M3Act $\Delta 6$ premRNA is truncated 6 nucleotides after the BPS and is used to stall spliceosome assembly at the stage of $\mathrm{B}^{\text {act }}$ complex while the M3Act $\Delta 31$ construct contains 31 nucleotides after the BPS, resulting in a block of splicing at the stage of complex C. B* complexes are purified employing an in vitro reconstitution system which is based on the temperature sensitivity of the DEAH box helicase Prp2. In yeast extract derived from a strain carrying the temperature sensitive mutant of Prp2, Prp2 can be inactivated by heat treatment.

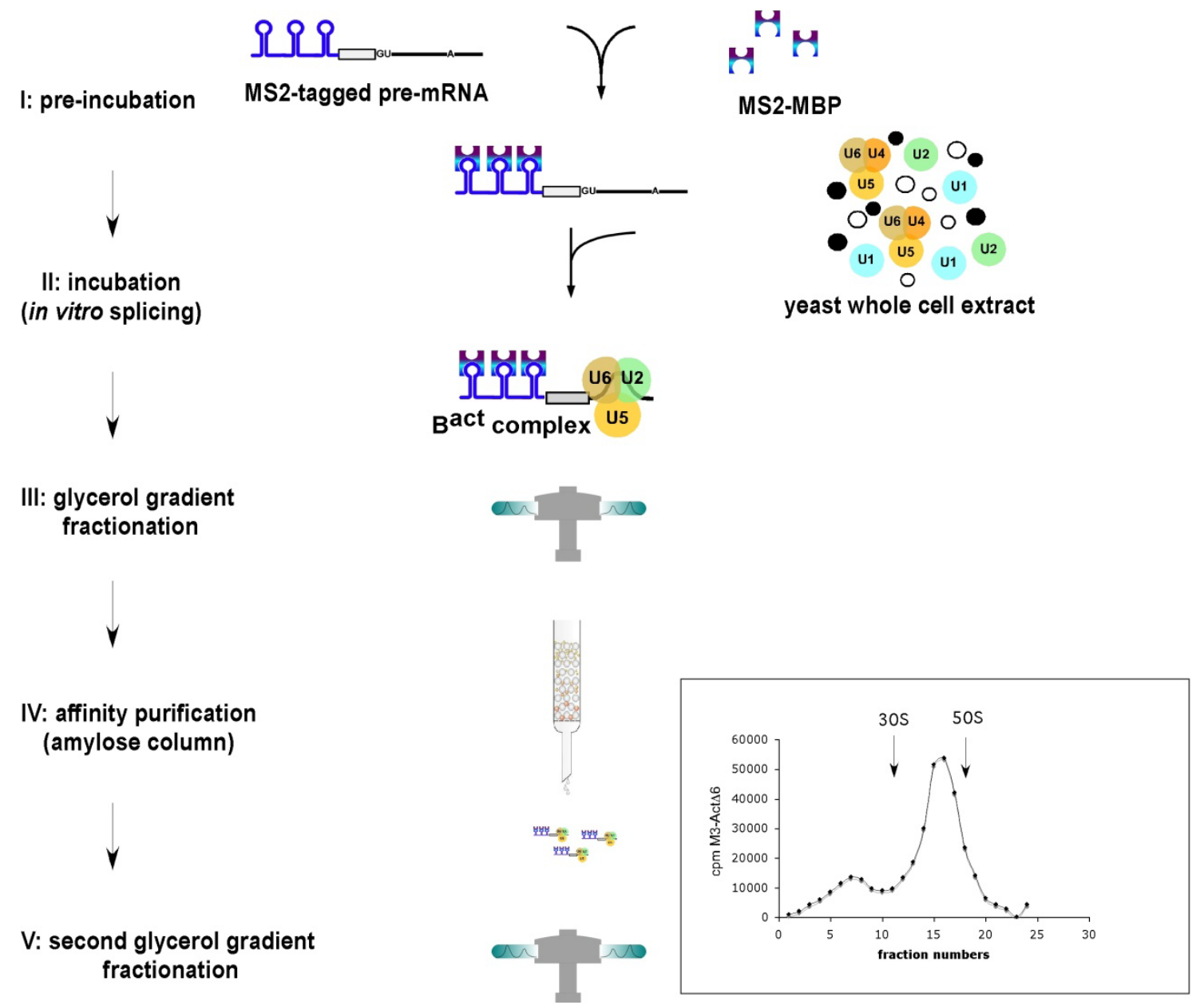

Figure 1.9: Three step purification of spliceosomal complexes

In vitro splicing was carried out using yeast whole cell extract and one of the pre-mRNA constructs shown in Figure 1.8. The reactions were first separated via glycerol gradient centrifugation and subsequently purified on an amylose matrix. A second glycerol gradient centrifugation was carried out if very high purity was required. (This figure was kindly provided by Dr. Patrizia Fabrizio, department of cellular biochemistry, MPI-BPC). 
Splicing in extract lacking the function of Prp2 results in a complete arrest of spliceosome assembly at the level of $B^{\text {act }}$ complex (named $B^{\text {act } \Delta \text { Prp2 }}$ ) even if M3ActWT pre-mRNA is used, which in a wild type extract is capable of undergoing both steps of splicing. Purified $\mathrm{B}^{\text {act } \Delta \text { Prp2 }}$ spliceosomes can be supplemented with recombinant Prp2 and Spp2 in the presence of ATP to yield B* complexes which upon addition of Cwc25 undergo step 1.

In vitro assembled spliceosomal complexes are purified by glycerol gradient centrifugation followed by affinity chromatography (Figure 1.9). If required also a second glycerol gradient can be performed subsequent to the affinity chromatography step.

\subsection{Similarities between the spliceosome and group II introns}

Group II introns are self-splicing ribozymes that catalyze their own excision from premRNAs (Pyle \& Lambowitz, 2006). They usually contain an intron-encoded reverse transcriptase enabling them to act as retroelements and thereby integrating into the genome through reverse splicing reactions (Robart et al, 2007; Zimmerly et al, 1995). Group II introns were found in bacteria (Ferat \& Michel, 1993), in the organellar genomes of plants, fungi, protists, and some animals (Pyle \& Lambowitz, 2006; Valles et al, 2008). Founded on structural and sequence similarities it is assumed that eukaryotic spliceosomes and group II introns share a common ancestor.

In general, group II introns consist of two major elements, a selfsplicing ribozyme and the gene encoding the reverse transcriptase. The ribozyme is composed of six domains. Domain I (DI), being the largest, acts as a scaffold and is thereby determining the overall intron shape and arranging important interactions. DI for example contains recognition sequences for binding the 5' and 3' exons and the BS nucleophile (Costa et al, 2000; Jacquier \& Michel, 1987). Domain II (DII) directs the folding of the junction (J2/3) between DII and domain III (DIII) which is one of the most conserved elements within group II introns and a major component of the active site. DII also helps to integrate DIII into the ribozyme core where DIII is stimulating the splicing efficiency (Fedorova et al, 2003). Domain IV (DIV) contains the open reading frame for the reverse transcriptase (RT) and also the primary binding sites for the RT (Wank et al, 1999).

Domain VI (DVI) contains the adenosine acting as the nucleophile during the first step of splicing, forming the lariat product (Pyle \& Lambowitz, 2006). 


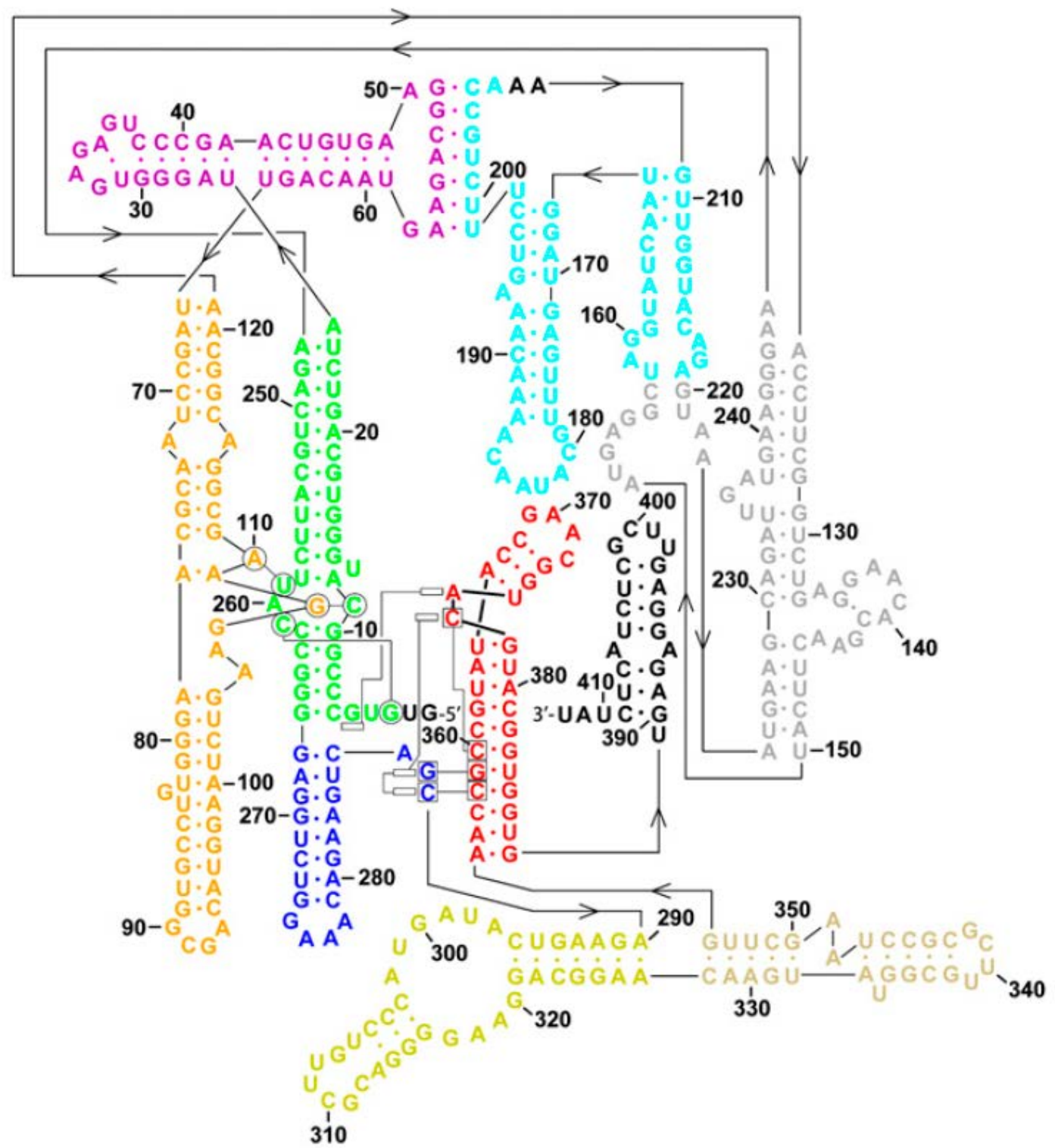

Figure 1.10: Overall secondary structure of the group II intron from Oceanobacillus iheyensis (adapted from (Toor et al, 2008a))

Secondary structure reflecting the coaxial stacking and domain organization evident from the introns crystal structure (Toor et al, 2008a). Watson-Crick tertiary interactions, base triples, and basestacking contacts are shown only for the core of the intron and are represented as open circles, squares, and rectangles, respectively.

The most conserved region within group II introns is domain V (DV), a 30-34 nts stemloop structure. A recent high resolution crystal structure of a group IIC intron from Oceanobacillus iheyensis confirmed that DV is located in the center of the intron where a network of interactions between DV and DI builds the active site. In this context DI acts as scaffold which arranges DV in a catalytically active conformation (Figure 1.10, Figure 
1.11). Some of the most important interactions of DI with DV are shown in a close-up view of DV (Figure 1.12).

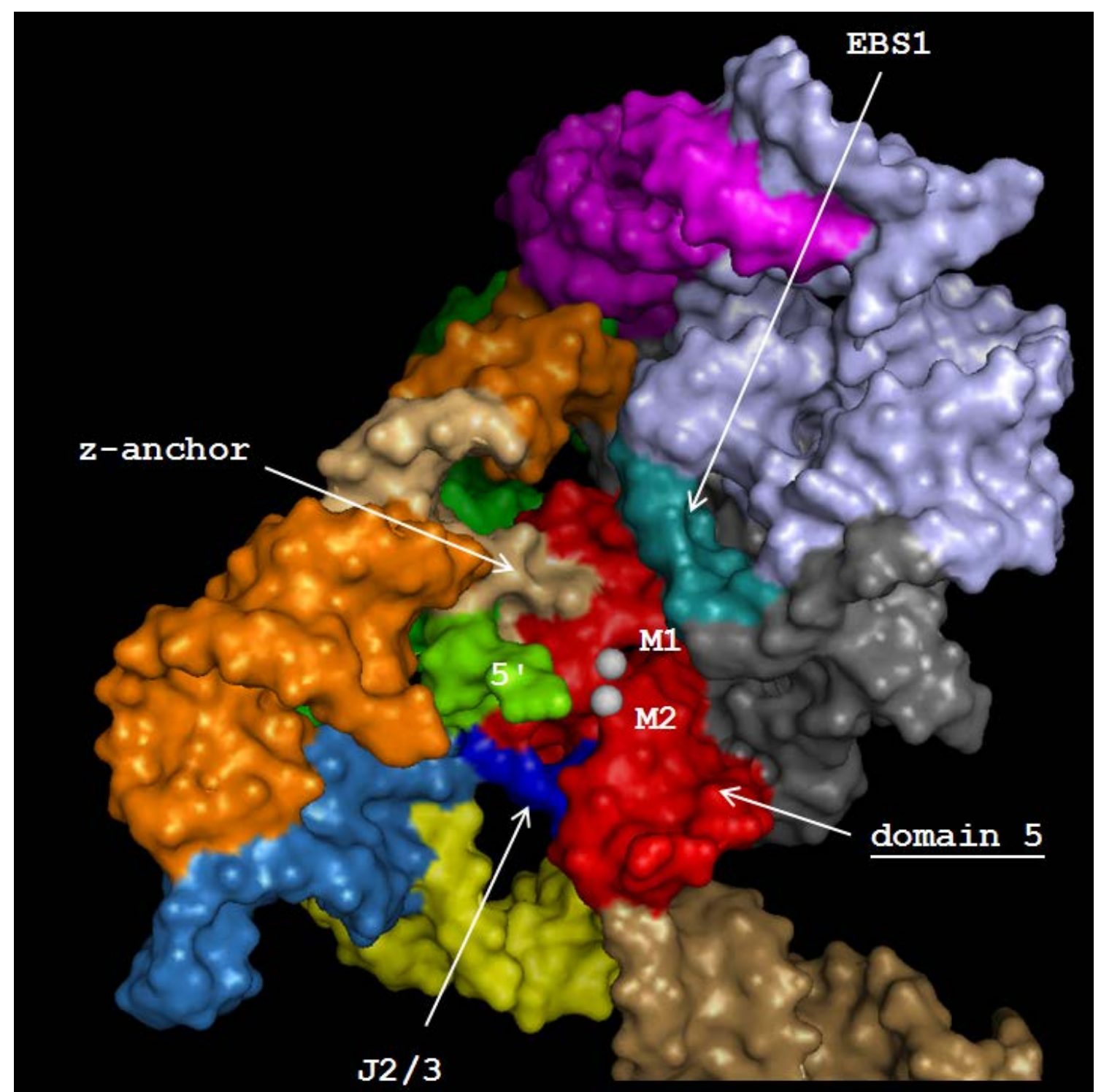

Figure 1.11: Overall structure of the group IIC intron from $O$. iheyensis in a surface representation

DV (red) is enclosed by the large cavity of the intron and crucial tertiary interactions of DV with several distant elements of the intron are indicated. Active site $\mathrm{Mg}^{2+}$ ions are shown as grey spheres. This figure is derived from the crystal structure of the intron (Toor et al, 2008a).

The terminal loop region of DV is arranged by the $\zeta-\zeta$ ' interaction and the EBS1 (exon binding sequence) motif, while the z-anchor motif makes multiple contacts with loop I(i) of DI, the 5' end of the intron and the upper part of the DV stem. In this way these regions are brought in close proximity to each other allowing for example the conserved G5 to contact A376 within helix of DV. This interaction is required to extrude A376 from the DV bulge. Five base pairs away from this two-nucleotide bulge the so called "catalytic 
triad" is located. On the basis of mutagenesis and chemical interference studies it has been suggested that like the bulge also the catalytic triad coordinates catalytic $\mathrm{Mg}^{2+}$ (Gordon \& Piccirilli, 2001; Sigel et al, 2000). Additionally, the catalytic triad forms a triple helix with the $\mathrm{J} 2 / 3$ and together with the bulge, these three elements form a major component of the active site (Boulanger et al, 1995; de Lencastre et al, 2005; Eldho \& Dayie, 2007). Interestingly, the crystal structure shows that the angle between the upper and the lower stem of DV is approximately $45^{\circ}$, resulting in a bend of the RNA structure in a way that the DV bulge and the catalytic triad are closer to each other, namely approximately $3 \AA$ apart. This proximity between the bulge and the catalytic triad allows the formation of a negatively charged pocket that binds the two catalytic $\mathrm{Mg}^{2+}$ ions. As a result of this bended arrangement the distance between the two metal ions is $3.9 \AA$, a distance which was found to be a prerequisite for a two metal ion catalysis (Steitz \& Steitz, 1993).

This whole interplay of RNA-RNA interactions described above between DV and other distinct parts of the intron, aligns the two catalytic $\mathrm{Mg}^{2+}$ ions in the required conformation as well as it brings all elements needed for catalysis in proximity to each other, demonstrating that the entire group II intron structure is required to induce a catalytic conformation in DV (Toor et al, 2008a).

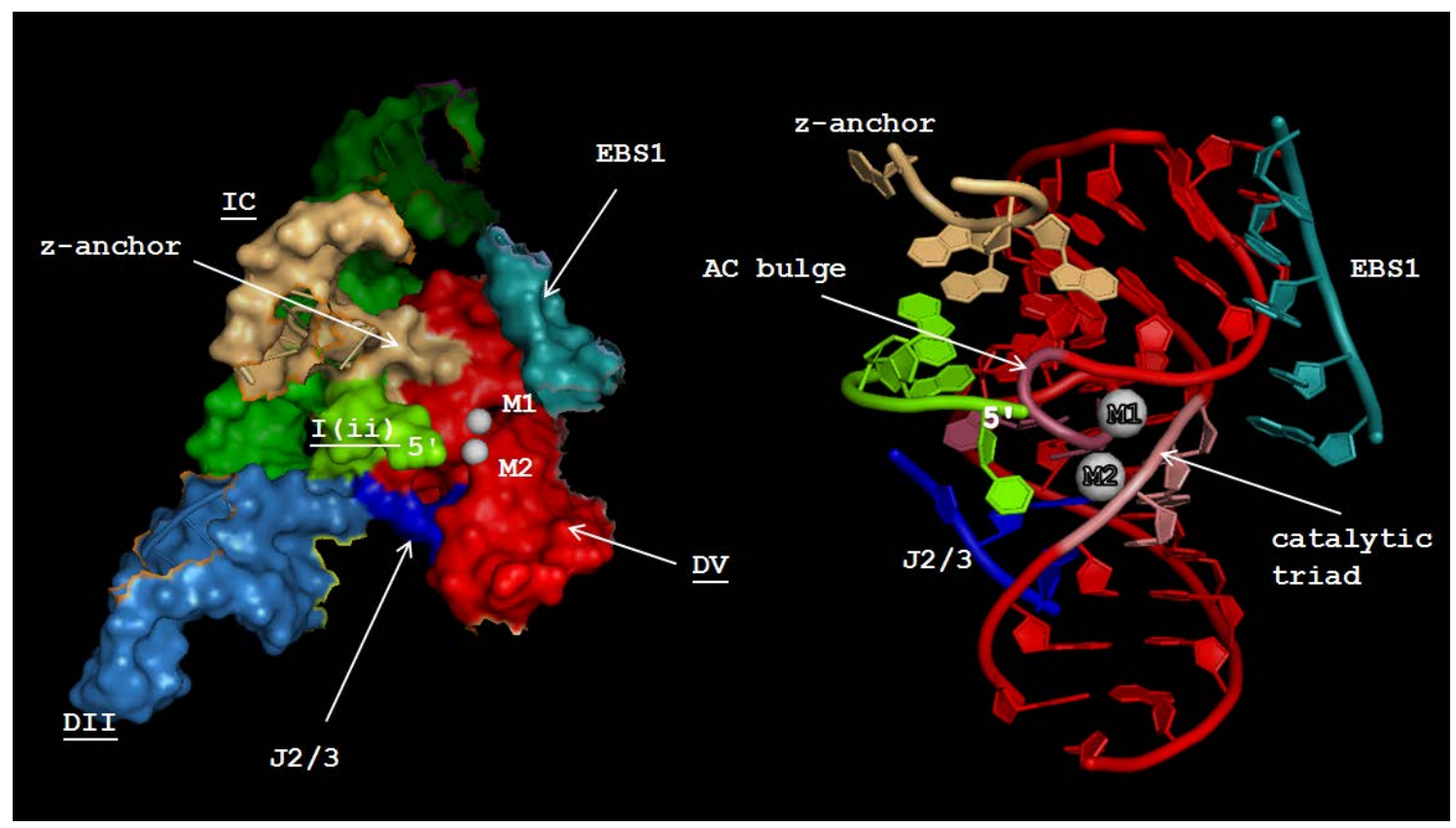

Figure 1.12: Close up view on the catalytic center of the group IIC intron from $O$. iheyensis

The catalytic center is shown in a surface (left) as well as in a ribbon representation (right). Important interactions of DV (red) are indicated in the figure. Active site $\mathrm{Mg}^{2+}$ ions are shown as grey spheres. This figure is derived from the crystal structure of the intron (Toor et al, 2008a). 
group II introns

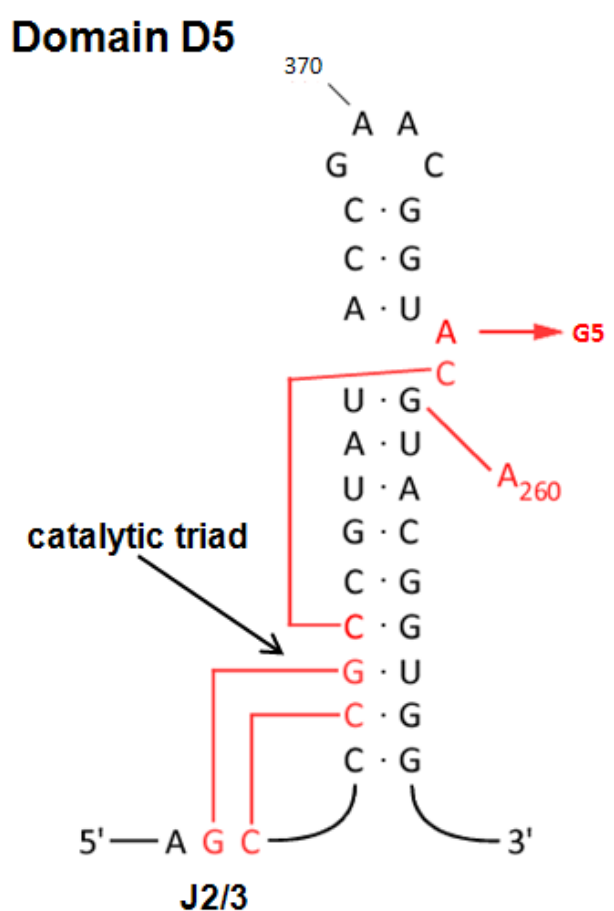

spliceosome

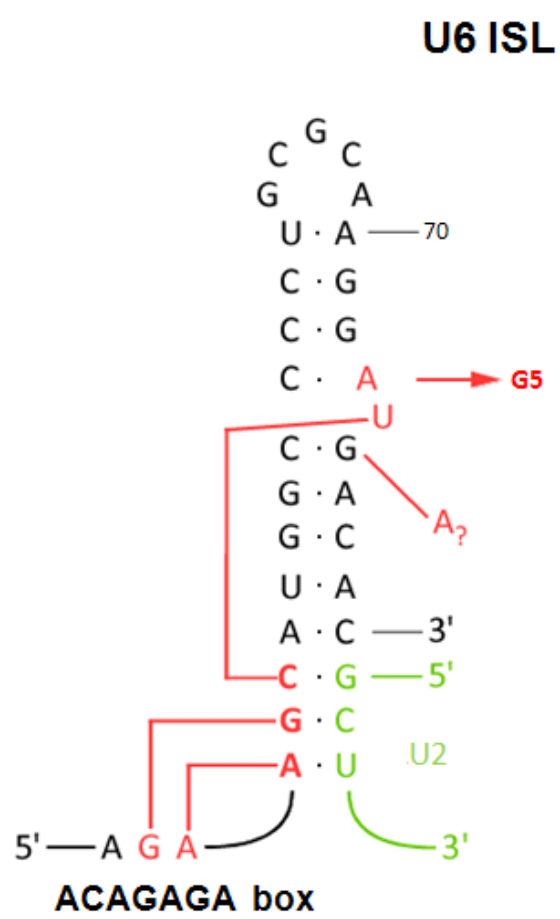

Figure 1.13: Comparison between DV of group II introns and the spliceosomal U6-ISL

Secondary structures of DV (left) and the U6-ISL (right). Tertiary interactions (indicated in red for DV) are observed crystallographically for the O. iheyensis intron. Possible analogous interactions are also shown for the U6-ISL (indicated in red for the U6-ISL).

DV is highly conserved throughout higher organisms and its basic structural features even show a considerable similarity to those of the spliceosomal U6 snRNA ((Keating et al, 2010) see also Figure 1.13). Like DV the U6 snRNA adopts a stem loop structure containing a bulge loop coordinating a $\mathrm{Mg}^{2+}$ ion essential for catalysis (Yean et al, 2000). This bulge is also separated exactly by 5 bases from the catalytic triad and the triad was shown to be involved in binding a second catalytic $\mathrm{Mg}^{2+}$ ion. The function of the conserved J2/3 which contacts the lower stem of DV apparently seems to be analogous to the invariant ACAGAGA box motif of U6 snRNA which was shown to interact with nucleotides close to the bottom of the U6-ISL (Madhani \& Guthrie, 1994b). Other results obtained through phosphorothioate substitution experiments show that sulphur substitutions in DV give the same effects on group II splicing as substitutions at the corresponding positions in U6 snRNA on pre-mRNA splicing and therefore also suggest similarities between the two splicing machineries (Gordon \& Piccirilli, 2001). It was even 
demonstrated that within the minor spliceosome, DV is able to replace the U6atac snRNA, thereby providing functional evidence for a close relation between DV and the U6-ISL (Shukla \& Padgett, 2002). Since it seems to be the major purpose of DI to arrange DV in a catalytically active conformation, the question arises whether within the spliceosome similar mechanisms exist that might perform an analogous function for the structure of the U6-ISL. Some nuclear introns are of remarkable length and probably can fold into complex tertiary structures but due to the fact that they show a high degree of variability, it is not very likely that they play a major role in the formation of the catalytic core of the spliceosome. More obvious would be an interaction of either protein factors and/or other snRNAs with the U6-ISL. Prp8 for example, a major scaffolding protein of the spliceosome, which contacts all of the chemically reactive sites of the pre-mRNA intron, would be an ideal candidate for this task (Grainger \& Beggs, 2005). It might also be that proteins of the NTC are either directly involved in specifying new RNA interactions during splicing, or they achieve this indirectly, by recruiting NTC-related proteins which interact with the spliceosomal RNA network. Consistent with the latter, several NTCrelated proteins possess putative RNA-binding domains or have been shown to display strong genetic interactions with mutations in the catalytic RNA interaction network (Hogg et al, 2010). 


\subsection{Aim of this study}

One of the most fascinating design principles of the spliceosome is that by stepwise recruitment of the snRNPs it assembles initially into a multi-megadalton ribonucleoprotein (RNP) complex, so called B complex, which contains all the snRNPs and additional nonsnRNP splicing factors, but which does not have yet a catalytic site. Mass spectrometry of the yeast spliceosomes has indicated that at least 90 proteins associate with spliceosomes assembled in vitro. Indeed, unlike group II self-splicing introns, nuclear pre-mRNA introns and the spliceosomal snRNAs do not self assemble into a catalytically active structure in the absence of spliceosomal proteins. The formation of the active catalytic center of the spliceosome involves a series of structural rearrangements which are mainly driven by RNA-dependent ATPases/helicases and which are accompanied by several changes in RNA-RNA base pairing interactions (Staley \& Guthrie, 1998).

The question of the nature of the spliceosomal catalytic center and how it is generated during catalytic activation of the B complex is poorly understood and one of the most interesting issues of spliceosomal research. Not only the chemical pathway of nuclear premRNA splicing is identical to that of the self-splicing group II introns but also several critical and highly conserved intermolecular structures formed by the pre-mRNA and the U6 and U2 snRNAs at the heart of the spliceosome are similar to intramolecular structures formed by self-splicing group II introns, supporting the idea that pre-mRNA splicing is essentially catalyzed by RNA with U6 and U2 playing key roles (Wachtel \& Manley, 2009). A recent high resolution crystal structure gave remarkable insight into the organization of the catalytic core of a group IIC self splicing intron (Toor et al, 2008a). Of the six domains of group II introns, domain 5 (DV), shares structural and sequence similarities with the essential and conserved U6-ISL. Surprisingly, the structure observed for DV in the context of the intact group IIC introns, differs greatly from the conformation of this domain when studied in isolation. Within the intact intron the two stems of DV are bended at an angle of approximately $45^{\circ}$, a conformation not observed if DV was examined in isolation. Responsible for this orientation are plenty of tertiary RNA-RNA interactions which help to shape the catalytic center of the intron. Since DV and the U6ISL share several evolutionary conserved similarities, the question arose which factors in the spliceosome might induce a similar conformation of the U6-ISL and thereby help to shape the catalytic center of the spliceosome. No obvious equivalent to some of the 
important RNA elements of group II introns, in particular of DI, is found in the spliceosomal RNA network. It can therefore be hypothesized that the role of DI and other regions of the group II ribozymes is taken over by proteins in the spliceosome.

The aim of this work was to identify protein factors interacting with U6 snRNA within the catalytic center of purified spliceosomes, to map their interaction sites with U6 snRNA and to determine their influence in promoting the catalytically active conformation of the U6-ISL. Knowing the exact way proteins interact with U6 snRNA at the heart of the spliceosome, might give important clues about the structure of the spliceosomal RNA network during splicing. We focused on the yeast protein Cwc2 which was recently shown to be essential for splicing in vivo and to contain a Zn-finger and an RNA recognition motif (RRM). We show that Cwc2 binds in close proximity to highly conserved RNA elements of $\mathrm{U} 6$ in $\mathrm{B}^{\text {act }}$ complexes, including a more direct and defined binding to the U6 ISL in the $\mathrm{B}^{*}$ and $\mathrm{C}$ complexes. This likely confers a proper configuration to the U6-ISL and the pre-mRNA 5' splice site, thus, contributing to splicing catalysis. These interactions are evolutionarily conserved, as shown by studies with Cwc2's human counterpart RBM22, indicating that Cwc2/RBM22-RNA contacts are functionally important. A comparison of the RNP network at the core of the spliceosome revealed by our studies with the recently determined crystal structure of group II introns, suggests that Cwc2 (in yeast) and RBM22 (in human) have evolved to substitute for the network of RNA-RNA interaction that bring the 5' splice site and DV of group II introns (the apparent counterpart of the U6 ISL) into a catalytically active conformation and thereby assist in catalysis. Thus, these data might provide additional evidence for mechanistic similarities between the spliceosome and group II introns and therefore help to shed light on the exact catalytic mechanism of spliceosomes. 


\section{Materials and methods}

\subsection{Materials}

\subsubsection{Chemicals and media}

2-Mercaptoethanol

Acetic acid

Acetone

Agarose, electrophoresis grade

Ammoniumperoxodisulfate (APS)

Ampicillin

Bacto agar

Bacto yeast extract

Bacto peptone

Bradford-assay solution

Brilliant Blue G-Colloidal concentrate

Bromphenol blue

$\mathrm{D}(+)$-glucose monohydrate

Dipotassiumhydrogenphosphate

DNA-molecular weight marker

DTT (Dithiothreitol)

EDTA (Disodium salt dihydrate)

Formaldehyde

Formamide

Glycerol

Glycoblue

HEPES (N-2-Hydroxyethylpiperazin-N-2-ethansulfonic acid) Imidazole

Lithium acetate

Maltose

Methanol

Polyethylene glycol (PEG)
Roth, Germany

Merck, Germany

Merck, Germany

Invitrogen, Netherlands

Merck, Germany

Sigma-Aldrich, Germany

$\mathrm{BD}$, USA

$\mathrm{BD}$, USA

$\mathrm{BD}, \mathrm{USA}$

Bio-Rad, Germany

Sigma-Aldrich, Germany

Merck, Germany

Merck, Germany

Merck, Germany

Gibco, New Zealand

Roth, Germany

Roth, Germany

Merck, Germany

Merck, Germany

Merck, Germany

Ambion, USA

Calbiochem, USA

Merck, Germany

Sigma-Aldrich, Germany

Merck, Germany

Merck, Germany

Sigma-Aldrich, Germany 
Ponceau S

Potassium Chloride

Potassiumdihydrogenphosphate

Pre-stained protein-molecular weight marker

Roti-Phenol-Chloroform-Isoamyl alcohol (PCI)

Rotiphorese Gel 30 solution

Rotiphorese Gel 40 solution

Rotiphorese Gel A and B solution

Silver nitrate

Sodiumdodecylsulfate (SDS)

Sodiumacetate

TEMED (N, N, N', N'-Tetramethylethylendiamine)

Tris-(hydroxymethyl)aminomethane (Tris)

Triton X-100

tRNA E. coli

Nonidet P-40 (Igepal CA-630)

Urea

Xylene cyanol FF
Serva, Germany

Merck, Germany

Merck, Germany

Bio-Rad, Germany

Roth, Germany

Roth, Germany

Roth, Germany

Roth, Germany

Merck, Germany

Serva, Germany

Merck, Germany

Sigma-Aldrich, Germany

Roth, Germany

Merck, Germany

Boehringer, Germany

Sigma-Aldrich, Germany

Merck, Germany

Fluka, Switzerland

\subsubsection{Enzymes and enzyme inhibitors}

AMV Reverse Transcriptase

Aprotinin

Benzamidine

Chymostatin

Complete $^{\mathrm{TM}}$ protease inhibitor tablets EDTA-free

Leupeptin

Pepstatin A

Phenylmethylsulfonylfluoride (PMSF)

Phusion ${ }^{\circledR}$ High-Fidelity DNA Polymerase

Proteinase K
USB, USA

Serva, Germany

Serva, Germany

Serva, Germany

Roche, Germany

Serva, Germany

Serva, Germany

Merck, Germany

New England Biolabs, Germany

Sigma-Aldrich, Germany 
Recombinant RNasin ${ }^{\circledR}$ Ribonuclease Inhibitor

Restriction Enzymes

RNasin (RNase inhibitor; $40 \mathrm{U} / \mu \mathrm{l}$ )

RQ DNase I (1 U/ $\mu \mathrm{l})$

SP6 RNA polymerase

T4 polynucleotide kinase

T7 RNA polymerase

Taq DNA polymerase

TEV Protease, recombinant
Promega, USA

New England Biolabs, Germany

Promega, USA

Promega, USA

New England Biolabs, Germany

New England Biolabs, Germany

dept. Lührmann

Promega, USA

dept. Lührmann

\subsubsection{Nucleotides}

Nucleoside-5'triphosphate (ATP, CTP, GTP, UTP 100 mM each):

Pharmacia, Germany

Deoxynucleoside-5'-triphosphate Mix (dATP, dCTP, dGTP, dTTP 10 mM each):

New England Biolabs, Germany

Dideoxynucleoside-5'-triphosphate (ddATP, ddCTP, ddGTP, ddTTP mM each):

Pharmacia, Germany

Radionucleotides: $\left[\alpha-{ }^{32} \mathrm{P}\right]-\mathrm{UTP},\left[\alpha-{ }^{32} \mathrm{P}\right]-\mathrm{dATP},\left[\gamma-{ }^{32} \mathrm{P}\right]-\mathrm{ATP}$ :

Perkin-Elmer, Germany

\subsubsection{DNA oligonucleotides and plasmids}

DNA oligonucleotides:

$\begin{array}{lll}\text { Name } & \text { sequence (5' to 3') } & \text { description } \\ \text { yU6 94-112 } & \text { AAAACGAAATAAATCTCTT } & \text { complementary to nts 94- } \\ & & 112 \text { of U6 snRNA }\end{array}$




\begin{tabular}{|c|c|c|}
\hline yAct 269-254 & GCAATTGGGACCGTGC & $\begin{array}{l}\text { complementary to nts 254- } \\
269 \text { of M3Act pre-mRNA }\end{array}$ \\
\hline Cwc2-TAP_for & $\begin{array}{l}\text { TTGGTAAGCTTGGTGGTCCCTTG } \\
\text { CTCGATTACCTCTCCTCTGATGA } \\
\text { GGATTCCATGGAAAAGAGAAGA } \\
\text { TG }\end{array}$ & $\begin{array}{l}\text { oligo used for c-terminal } \\
\text { TAP-tagging of Cwc2 }\end{array}$ \\
\hline Cwc2-TAP_rev & $\begin{array}{l}\text { GGGAATGTTAATGGCAGATACTT } \\
\text { AGAATTTGGTGGAAACGATTTTC } \\
\text { TTCTTACGACTCACTATAGGG }\end{array}$ & $\begin{array}{l}\text { oligo used for c-terminal } \\
\text { TAP-tagging of Cwc2 }\end{array}$ \\
\hline Sp6_for & ATTTAGGTGACACTATAG & $\begin{array}{l}\text { used for the generation of } \\
\text { template DNA for in vitro } \\
\text { transcription }\end{array}$ \\
\hline Act_rev & GGAATTCСССТTСАТСАССАА & $\begin{array}{l}\text { used for the generation of } \\
\text { template DNA for in vitro } \\
\text { transcription }\end{array}$ \\
\hline Act $+13+24$ & GATGGTGCAAGC & $\begin{array}{l}\text { used for RNase H directed } \\
\text { cleavage of M3Act pre- } \\
\text { mRNA during C-complex } \\
\text { purification }\end{array}$ \\
\hline
\end{tabular}

\section{Plasmids:}

$\begin{array}{ll}\text { Name } & \begin{array}{l}\text { description } \\ \text { pUC18_T7_M3Act_wt }\end{array} \\ \begin{array}{l}\text { template for in vitro transcription, generated by Dr. Thomas } \\ \text { Ohrt }\end{array} \\ \text { pUC18_T7_M3Act__6 } & \begin{array}{l}\text { template for in vitro transcription, generated by Dr. Thomas } \\ \text { Ohrt }\end{array} \\ \text { pUC18_T7_yU6 } & \begin{array}{l}\text { template for in vitro transcription, provided by Dr. Patrizia } \\ \text { Fabrizio (Fabrizio et al, 1989) }\end{array} \\ \text { pMal_MS2-MBP } & \begin{array}{l}\text { expression of MS2-MBP fusion protein, provided by Robin } \\ \text { Reed and Josep Vilardell }\end{array} \\ \text { pBS1539 } & \text { template for TAP-tagging (Puig et al, 2001) }\end{array}$




\subsubsection{Yeast and bacterial strains}

\section{Yeast strains:}

SC1887 (MAT $\alpha$; ade2; arg4; leu2-3, 112; trp1-289; ura3-52; CWC2::TAP-K.I.URA3 C-terminus); purchased from Euroscarf (Frankfurt am Main).

SC0546 MATa; ade2; arg4; leu2-3; 112; trp1-289; ura3-52; ECM2::TAP-K.I.URA3 C-terminus; purchased from Euroscarf (Frankfurt am Main).

SC1215 MATa; ade2; arg4; leu2-3; 112; trp1-289; ura3-52; YJU2::TAP-K.I.URA3 C-terminus; purchased from Euroscarf (Frankfurt am Main).

YRK1 MATa, trp1 1 1; his3A; ura3-52; lys2-801; ade2-101; SNU114::TAP-K.I.TRP1 C-terminus (Häcker et al., 2008).

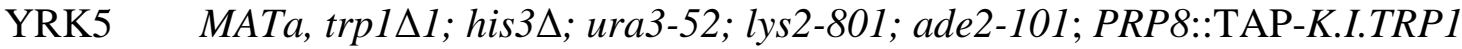
C-terminus (Häcker et al., 2008).

YNR1 MATa; prp2-1; ade2; his3; lys2-801; ura3; CWC2::TAP-K.I.URA3 C-terminus (This study).

3.2.AID/ MATa; prp2-1; ade2; his3; lys2-801; ura3, carrying a G360D

CRL2101 substitution in the helicase domain of Prp2 (Yean and Lin, 1991).

\section{Bacterial strains:}

BL21-CodonPlus(DE3)-RIL cells, F- ompThsdSB ( $r$ B- mB-) gal dcm lacY1, pRARE22 (CMR) pAR5615 (APR) Novagen, USA

DH5 $\alpha$ cells, F', $\varphi 80 \mathrm{~d} l a c Z \Delta \mathrm{M} 15, \Delta($ lacZYA-argF)U169, deoR, recA1, endA1, hsdR17(rk-' $\mathrm{mk}^{+}$), phoA, supE44, $\lambda^{-}$, thi-1, gyrA96, relA1

\subsubsection{Commercial kits}

ECL western blot detection kit

Prime It II random primer labeling kit

Qiagen gel extraction kit
GE Healthcare, UK

Stratagene, USA

Qiagen, Germany 


\subsubsection{Chromatography materials and consumables}

Amylose resin

Calmodulin Sepharose 4B

Cassettes for film exposure

Concentrator

Dialyses membranes MWCO 6000-8000 Da

Heparin Sepharose ${ }^{\mathrm{TM}} 6$ Fast Flow

HisTrap ${ }^{\mathrm{TM}} \mathrm{FF}$ crude columns

IgG Sepharose 6 Fast Flow

Ni-NTA agarose

Nylon membrane Hybond XL

Parafilm

Poly-Prep columns

ProbeQuant ${ }^{\mathrm{TM}} \mathrm{G}-50$ micro columns

ProbeQuant $^{\mathrm{TM}} \mathrm{G}$-25 micro columns

Protein A-Sepharose CL 4B

Protran Nitrocellulose membrane

Slide-A-Lyzer dialysis units (MWCO 6 kDa)

Sterile filters $0.2 \mu \mathrm{m}$ or $0.45 \mu \mathrm{m}$

Superdex 75 16/60 column

Whatman 3MM Paper

X-ray films BioMax MR
New England Biolabs, Germany

GE Healthcare, UK

Kodak, USA

Millipore, USA

SpektraPor, USA

GE Healthcare, UK

GE Healthcare, UK

GE Healthcare, UK

Qiagen, Germany

GE Healthcare, UK

Roth, Germany

Bio-Rad, USA

GE Healthcare, UK

GE Healthcare, UK

GE Healthcare, UK

Schleicher \& Schüll, Germany

Pierce, USA

Sarstedt, Germany

GE Healthcare, UK

Whatman Paper, UK

Kodak, USA 


\subsubsection{Common buffers}

Media, buffers, and solutions were prepared with deionized water (Millipore) and autoclaved if necessary $\left(121^{\circ} \mathrm{C}, 20 \mathrm{~min}, 1\right.$ bar). Solutions with heat-labile components were filter sterilized $(0.22 \mu \mathrm{m})$.

5x DNA loading dye

4x Separating gel buffer

4x Stacking gel buffer

10x TBE

Protein loading dye

RNA loading dye

Slab 4 Buffer

SDS-PAGE Running buffer
$30 \%$ glycerol

5 mM EDTA, pH 8.0

$0.25 \%(\mathrm{w} / \mathrm{v})$ bromophenol blue

$0.25 \%(\mathrm{w} / \mathrm{v})$ xylene cyanol

1.5 M Tris

$0.4 \%(\mathrm{w} / \mathrm{v})$ SDS

adjust to $\mathrm{pH} 8.8$

$0.5 \mathrm{M}$ Tris

$0.4 \%(\mathrm{w} / \mathrm{v}) \mathrm{SDS}$

adjust $\mathrm{pH}$ to 6.8

0.89 M Tris

$0.89 \mathrm{M}$ boric acid

25 mM EDTA pH 8.0

75 mM Tris-HCl, pH 6.8

1.25 mM EDTA, pH 8.0

$20 \%$ (v/v) glycerol

$2.5 \%(\mathrm{w} / \mathrm{v})$ SDS

$0.125 \%$ (w/v) bromophenol blue $50 \mathrm{mM}$ DTT

$80 \%$ formamide

$1 \mathrm{mM}$ EDTA pH 8.0

0.05\% (w/v) bromophenol blue

$0.05 \%(\mathrm{w} / \mathrm{v})$ xylene cyanol

$50 \mathrm{mM}$ Tris

$105 \mathrm{mM}$ glycine

$0.1 \%(\mathrm{w} / \mathrm{v})$ SDS

25 mM Tris-HCl, pH 6.8

$192 \mathrm{mM}$ glycine

$1 \%(\mathrm{w} / \mathrm{v})$ SDS 
10x TBS

Western blotting buffer
$200 \mathrm{mM}$ Tris

$1.37 \mathrm{M} \mathrm{NaCl}$

adjust to $\mathrm{pH} 7.6$

1.5 L Slab4 Buffer

$0.6 \mathrm{~L}$ methanol

$0.9 \mathrm{~L} \mathrm{ddH}_{2} \mathrm{O}$

\subsubsection{Machines and working equipment}

ÄKTA Prime

ÄKTA Explorer

Autoclaves

Biofuge fresco

Biofuge pico

DNA Thermal Cycler

Gel documentation unit

Gelelectrophoresis apparatus

Geldryer Model 583

Gradient Master

'head-over-tail'

Heating blocks

Hybridization oven

Megafuge 1.0R

Milli-Q-water supply apparatus

Nanodrop

$\mathrm{pH}-$ Meter

Phosphorimager Typhoon 8600

Power supply EPS 2A 2000

Power supply EPS 3501/XL

Liquid Scintillation Analyzer Tri-Carb 2100 T

Sorvall SLC-6000 rotor

Sorvall SS-34 Rotor
GE Healthcare, UK

GE Healthcare, UK

H+P Labortechnik, Germany

Kendro, USA

Kendro, USA

Hybaid Omni Gene, UK

Bio-Rad, USA

in-house

Bio-Rad, USA

BioComp Instruments, Canada

Rotor Cole-Parmer, USA

Eppendorf, Germany

Hybaid Biometra, UK

Kendro, USA

Millipore, USA

Thermofisher, Germany

Mettler Toledo, Switzerland

Amersham Pharmacia, Germany

Hoefer Pharmacia Biotech, USA

Amersham Pharmacia, Germany

Packard, USA

Kendro, USA

Kendro, USA 
Sorvall TH660 Rotor

Sorvall T865 Rotor

Sorvall T647.5 Rotor

Speed Vac Concentrator 5301

Spectrophotometer Ultrospec 3000 pro

Surespin 630 rotor

Tabletop centrifuges

Trans-Blot Cell

Ultracentrifuge Evolution

UV lamps (254 nm)

Vortex

X-ray film developer X-Omat 2000

Liquid scintillation analyzer
Kendro, USA

Kendro, USA

Kendro, USA

Eppendorf, Germany

Amersham Pharmacia, Germany

Thermo Fisher Scientific, USA

Heraeus, Germany

Bio-Rad, USA

Kendro, USA

Bachofer, Reutlingen

Janke \& Kunkel, Germany

Kodak, USA

Packard, USA 


\subsection{Methods}

\subsubsection{General molecular biology methods}

\subsubsection{Concentration determination of nucleic acids}

The concentration determination of RNA or DNA is based on the absorption maximum of the aromatic ring system of nucleic acids at a wavelength of $260 \mathrm{~nm}$. The concentration and purity of nucleic acids was estimated using the empirical standard values shown in Table 2.1. The ratio between $\mathrm{OD}_{260}$ and $\mathrm{OD}_{280}$ allows to assess contaminations with proteins or phenol.

$\begin{array}{lllll}1 \mathrm{OD}_{260} \text { equals } & 50 \mu \mathrm{g} / \mathrm{ml} & \text { dsDNA } & \text { pure DNA } & \mathrm{OD}_{260} / \mathrm{OD} 280=1.8 \\ & 40 \mu \mathrm{g} / \mathrm{ml} & \text { ssDNA } & & \\ & & & & \\ & 33 \mu \mathrm{g} / \mathrm{ml} & \text { ssRNA } & \text { pure RNA } & \mathrm{OD}_{260} / \mathrm{OD} 280=2.0\end{array}$

Table 2.1: Empirical standard values used for the concentration determination of nucleic acids

\subsubsection{Purification and manipulation of DNA}

Plasmid DNA was obtained from E. coli cells using QIAGEN Plasmid Purification Kits according to the manufacturer's instructions. QIAGEN plasmid purification protocols are based on a modified alkaline lysis procedure, followed by binding of plasmid DNA to QIAGEN Anion-Exchange Resin under appropriate low-salt and $\mathrm{pH}$ conditions.

Restriction endonucleases were obtained from New England Biolabs (NEB) and the reactions were performed according to the manufacturer's instructions. Generally 1-10 units of enzyme were used to cut $1 \mu \mathrm{g}$ of DNA within $1 \mathrm{~h}$ under the recommended conditions.

DNA fragments were analyzed and purified by agarose gel electrophoresis. Typically, the gels contained 1\% (w/v) agarose, depending on the size of the DNA fragment. The samples were dissolved in DNA loading dye and after separation the nucleic acids were visualized via ethidium bromide $(0.4 \mu \mathrm{g} / \mathrm{ml}$ gel in 1xTBE) staining and subsequent highlighting with UV light. 


\subsubsection{Polymerase chain reaction}

The polymerase chain reaction (PCR) was used to amplify DNA fragments either for analytic (e.g. “colony PCR”) or preparative purposes (e.g. transcription templates). A typical reaction mixture contained $0.4 \mathrm{ng} / \mu \mathrm{l}$ of template, $0.2 \mathrm{mM}$ of each $\mathrm{dNTP}, 0.6 \mu \mathrm{M}$ of each primer, the appropriate reaction buffer and the enzyme. Different kinds of polymerases (Taq-, Pfu- or Phusion-polymerase) were used depending on the purpose of the application.

A typical setup for a PCR included the following steps:

1. $94^{\circ} \mathrm{C} \quad 5 \mathrm{~min} \quad$ initial denaturation

2. $94^{\circ} \mathrm{C} \quad 1 \mathrm{~min} \quad$ cycle denaturation

3. $52^{\circ} \mathrm{C} \quad 1 \mathrm{~min} \quad$ primer annealing

4. $72^{\circ} \mathrm{C} \quad 1 \mathrm{~min} \quad$ elongation steps 2 to 4 were repeated 35 times

5. $72^{\circ} \mathrm{C} \quad 10 \mathrm{~min} \quad$ final elongation

\subsubsection{Transformation of yeast and E. coli}

For transformations, chemically competent cells of S.cerevisiae and E. coli were used.

$50 \mathrm{ml}$ cultures of E.coli were grown to an $\mathrm{OD}_{600}$ of 0.3-0.5 and the cell pellet was washed twice with an ice cold solution of $50 \mathrm{mM} \mathrm{CaCl}_{2}$. After the addition of glycerol to a final concentration of $10 \%$ the cells were frozen in liquid nitrogen and stored at $-80^{\circ} \mathrm{C}$. For transformation competent cells were mixed with 50 ng plasmid DNA and incubated on ice for $30 \mathrm{~min}$, followed by a heat shock at $42^{\circ} \mathrm{C}$ for $1 \mathrm{~min}$. Subsequently, the cells were incubated for $1 \mathrm{~h}$ at $37^{\circ} \mathrm{C}$ in $\mathrm{LB}$ medium before being transferred to Petri dishes containing a selection medium.

$50 \mathrm{ml}$ cultures of $S$. cerevisiae were grown to an $\mathrm{OD}_{600}$ of $0.6-0.8$. The cells were sedimented by brief centrifugation at $2500 \mathrm{x}$ g and washed with buffer containing $10 \mathrm{mM}$ Tris, $\mathrm{pH}$ 7.5. Subsequently, the pellet was resuspended in a buffer containing $10 \mathrm{mM}$ Tris, pH 7.5 and $100 \mathrm{mM}$ lithium acetate (LiT-buffer) and incubated shaking slowly at RT for $40 \mathrm{~min}$. After a brief centrifugation the cells were resuspended in $800 \mu \mathrm{l}$ LiT-buffer and the designated DNA construct (250 ng for plasmids, $40 \mu \mathrm{g}$ for PCR constructs) was mixed with $100 \mu \mathrm{l}$ of cell suspension. As a carrier, salmon sperm DNA (1 mg/ml final concentration) was used and a solution of PEG 3350 (0.5 g PEG/ml LiT final concentration) was added. A heat shock treatment was performed for $5 \mathrm{~min}$ at $42^{\circ} \mathrm{C}$ before the cells were transferred to YPD medium and incubated at $37^{\circ} \mathrm{C}$ (or $25^{\circ} \mathrm{C}$ if the strain was temperature sensitive) for 1 h. Petri dishes 
containing a selection medium were used to select for successful transformants. Positive clones were checked for the correct integration of the construct via colony PCR.

\subsubsection{Phenol-chloroform-isoamylalcohol (PCI) extraction and ethanol precipitation}

The PCI extraction is used to separate nucleic acids from proteins. Phenol and chloroform denature proteins and keep them in the organic phase, while nucleic acids stay in the aqueous phase.

Samples were thoroughly mixed with an equal volume of PCI (phenol/ chloroform/ isoamylalcohol, $\mathrm{pH}$ 7.5-8.0 in the ratio 25:24:1, commercially available from Roth). Phase separation was accelerated by centrifugation at $16000 \mathrm{xg}$ for $5 \mathrm{~min}$. The aqueous phase was transferred into a new tube and nucleic acids were precipitated by adding 3 volumes of absolute ethanol, 0.1 volume of $3 \mathrm{M}$ sodium acetate $\mathrm{pH} 5.3$ and, in case of nucleic acid concentrations below $200 \mathrm{ng} / \mu \mathrm{l}, 10 \mu \mathrm{g} / \mathrm{ml}$ Glycoblue (Ambion) was added as a carrier. Proteins were precipitated from the organic phase by adding 5 volumes of absolute ethanol or acetone. Both, RNA and protein samples were kept at $-20^{\circ} \mathrm{C}$ for at least $30 \mathrm{~min}$. The precipitates were sedimented by centrifugation at $16000 \mathrm{x}$ g for $20 \mathrm{~min}$. The pellet was washed with $70 \%$ ethanol (v/v), subsequently dried and resuspended in the desired solution.

\subsubsection{Denaturing polyacrylamide gel electrophoresis of RNA}

Denaturing polyacrylamide gel electrophoresis was mainly used to separate RNA species up to 1500 bp in size. The gels contained 8M urea as denaturing agent and were used with acrylamide concentrations between $5 \%$ and 10\%. The acrylamide polymerization was initiated by adding ammonium persulfate and TEMED. RNA samples were resuspended in RNA loading dye and denatured at $70^{\circ} \mathrm{C}$ for 3 min prior to gel loading. The electrophoresis was performed in $1 \mathrm{x}$ TBE buffer at a constant voltage. To allow a better separation of the splicing products and intermediates, an optimized ratio of acrylamide to bisacrylamide (29:1) was used. RNAs were visualized either by silver staining or autoradiography. In case of preparative separations e.g. electrophoresis of in vitro transcriptions, UV highlighting was sufficient to visualize the RNA fragments. 


\section{RNA Gel solutions (per $20 \mathrm{ml}$ )}

$8 \mathrm{M}(\mathrm{w} / \mathrm{v})$ Urea

$5 \%$ to $10 \%$ acrylamide (either Rotiphorese Gel 40 solution or a 29:1 mixture of Rotiphorese Gel A and B)

$2 \mathrm{ml} 10 \times \mathrm{TBE}$

$100 \mu \mathrm{l} 10 \%(\mathrm{w} / \mathrm{v})$ APS \& $10 \mu \mathrm{l}$ TEMED

\begin{tabular}{|c|c|c|}
\hline $\begin{array}{c}\text { percentage of } \\
\text { acrylamide } \\
{[\%]}\end{array}$ & $\begin{array}{c}\text { Xylene } \\
\text { Cyanol FF } \\
\text { [bases] }\end{array}$ & $\begin{array}{c}\text { Bromophenol } \\
\text { blue } \\
\text { [bases] }\end{array}$ \\
\hline
\end{tabular}

\begin{tabular}{|c|c|c|}
\hline 5 & 130 & 35 \\
\hline 6 & 106 & 29 \\
\hline 8 & 76 & 26 \\
\hline 10 & 55 & 12 \\
\hline 20 & 28 & 8 \\
\hline
\end{tabular}

Table 2.2: Migration behavior of marker dyes in denaturing polyacrylamide gels

\subsubsection{Silver staining of RNA gels}

Silver staining of RNA gels was essentially performed as described by (Merril et al, 1981). First, the gel was fixed in a solution of $40 \%$ methanol and $10 \%$ acetic acid for at least 30 min or overnight. The gel was then washed twice with a solution of $10 \%$ ethanol and $5 \%$ acetic acid for 15 min. Afterwards, it was briefly rinsed with $\mathrm{ddH}_{2} \mathrm{O}$ and subsequently stained with a solution of $12 \mathrm{mM} \mathrm{AgNO}_{3}$ for $30 \mathrm{~min}$. The stained gel was briefly rinsed with $\mathrm{ddH}_{2} \mathrm{O}$ again and then incubated with the developing solution (0.28 $\mathrm{M} \mathrm{Na}_{2} \mathrm{CO}_{3}, 0.0185 \%$ formaldehyde) until RNA bands became visible. The developing reaction was stopped by the addition of $5 \%$ acetic acid.

\subsubsection{Northern blot analysis}

Northern blotting was used to detect specific RNAs, using radioactively labeled DNA oligomers complementary to the respective RNA.

RNA samples were separated using denaturing polyacrylamide gel electrophoresis (see 2.2.1.6) and subsequently transferred to a nylon membrane via a semidry blotting procedure. The transfer was carried out in $0.5 \mathrm{x}$ TBE at $3 \mathrm{~mA} / \mathrm{cm}^{2}$ of gel surface for $2 \mathrm{~h}$. After blotting, the 
RNAs were crosslinked to the membrane via UV irradiation with $1200 \mu$ Joule x100. Before adding the probes, the membrane was incubated with pre-hybridization buffer (see Table 2.3) at $42^{\circ} \mathrm{C}$ for $2 \mathrm{~h}$. The pre-hybridization buffer was exchanged with fresh hybridization buffer containing the radioactive probes, and the hybridization was carried out for $24-48 \mathrm{~h}$ at $42^{\circ} \mathrm{C}$.

\section{Pre-/ Hybridization Buffer}

$25 \mathrm{mM} \mathrm{Na}_{3} \mathrm{PO}_{4} \mathrm{pH} 6.5$

$6 \times$ SSC

$5 \mathrm{x}$ Deinhardt's solution

$0.5 \%(\mathrm{w} / \mathrm{v}) \mathrm{SDS}$

$50 \%(\mathrm{v} / \mathrm{v})$ Deionized formamide

$0.1 \mathrm{mg} / \mathrm{ml}$ Salmon sperm DNA (5 min denat.)

\section{Wash Buffer 1}

$2 \times$ SSC

$0.5 \%(\mathrm{w} / \mathrm{v})$ SDS

\author{
$20 \times$ SSC \\ $300 \mathrm{mM}$ Na-Citrate \\ $3 \mathrm{M} \mathrm{NaCl}$ \\ $100 \times$ Deinhardt's solution \\ $2 \%$ (w/v) Polyvenylpyrolodase \\ $2 \%(\mathrm{w} / \mathrm{v})$ BSA \\ $2 \%(w / v)$ Ficoll 400
}

\section{Wash Buffer 2}

$2 \mathrm{xSSC}$

$0.1 \%(w / v)$ SDS

Table 2.3: Solutions for Northern blotting

After hybridization, the membrane was washed twice at RT for 5 min with wash buffer 1 and twice with wash buffer 2 . A third wash step with wash buffer 2 was performed for 30 min at $50^{\circ} \mathrm{C}$. The radioactive probes were visualized via autoradiography.

The radioactive probes were generated using the Prime It II random primer labeling kit according to the manufacturer's instructions.

\subsubsection{TAP tagging of yeast cells}

Due to the lack of antibodies against the Cwc2 protein, it was tagged within the Prp2-1 background strain, to be able to immunoprecipitate Cwc2 from purified B*-complexes.

To fuse a TAP-tag to the C-terminus of Cwc2, a construct carrying the TAP-tag sequence and a selection marker was generated via PCR (2.2.1.3). The primers for this reaction were designed to overlap with regions of the yeast chromosome, flanking the end of the CWC2 gene without the stop codon. In this way a homologous recombination allowed the construct to be integrated into the yeast genome in frame, resulting in a stable yeast strain expressing a tagged Cwc2 protein.

The primers used for this PCR were named Cwc2-TAP_for and Cwc2-TAP_rev and as PCR template the plasmid pBS1539 (Puig et al, 2001) was used (see 2.1.4). 
The construct was transformed as described in 2.2.1.4 and the correct integration was checked via PCR. Western blot analysis (2.2.2.5) demonstrated a stable expression of Cwc2TAP in the yeast Prp2-1 background.

\subsubsection{In vitro transcription}

In vitro transcriptions were carried out using linearized plasmid DNA or DNA fragments generated by PCR as templates. Depending on the type of the promoter, either Sp6 or T7 RNA polymerases were used during the reaction. The compositions of typical reaction mixtures are shown below.

\section{“hot” transcription}

$\begin{array}{ll}\text { Template } & 0.1 \mu \mathrm{g} / \mu \mathrm{l} \\ \text { RNA polymerase buffer (NEB) } & 1 \mathrm{x} \\ \text { rNTPs } & \mathrm{A}, \mathrm{C}+\mathrm{G}[0.5 \mathrm{mM}] ; \mathrm{U}[0.1 \mathrm{mM}] \\ \text { RNasin (Promega) } & 2 \mathrm{U} / \mu \mathrm{l} \\ {\left[\alpha{ }^{32} \mathrm{P}\right] \mathrm{UTP}(3000 \mathrm{Ci} / \mathrm{mmol})} & 1 \mu \mathrm{l} / 4 \mu \mathrm{l} \text { reaction } \\ \text { RNA polymerase }(\mathrm{Sp} 6 / \mathrm{T} 7) & 2 \mathrm{U} / \mu \mathrm{l}\end{array}$

\section{“cold" transcription}

5x selfmade transcription buffer

$\begin{array}{ll}\text { Template } & 0.05-0.1 \mu \mathrm{g} / \mu \mathrm{l} \\ \text { Selfmade transcription buffer } & 1 \mathrm{x} \\ \text { rNTPs } & 2.5 \mathrm{mM} \text { each } \\ \text { RNasin (Promega) } & 2 \mathrm{U} / \mu \mathrm{l} \\ \text { Pyrophosphatase (NEB) } & 0.02 \mathrm{U} / \mu \mathrm{l} \\ \text { RNA polymerase (Sp6/T7) } & 2 \mathrm{U} / \mu \mathrm{l}\end{array}$

$200 \mathrm{mM} \quad$ Tris $\mathrm{pH} 8.0$

$150 \mathrm{mM} \quad \mathrm{MgCl}_{2}$

$10 \mathrm{mM} \quad$ Spermidine

$50 \mathrm{mM} \quad$ DTT

The transcription reactions were incubated at $37^{\circ} \mathrm{C}$ for $2 \mathrm{~h}$ and subsequently purified by gel electrophoresis (2.2.1.6). Therefore, the designated RNA bands were cut from the gel and were eluted overnight at $4^{\circ} \mathrm{C}$ with RNA elution buffer (500 mM NaOAc pH 5.0, $1 \mathrm{mM}$ EDTA pH 8.0, 2.5\% phenol/chloroform/isoamylalcohol, pH 7.5-8.0, 25:24:1 from Roth). The next day, the gel pieces were separated from the elution buffer and the RNA was precipitated using 3 volumes of absolute ethanol. The pellet was resuspended in $\mathrm{ddH}_{2} \mathrm{O}$ and the concentration of the "cold” RNA was determined by UV spectroscopy (2.2.1.1), while the concentration of the "hot" RNA was calculated from its specific activity according to the following formula: 


$$
R N A(\text { pmol })=\frac{\text { total cpm }}{2.2 \times 10^{6} \mathrm{cpm}} \times \frac{2+(\text { age of } 32 P)}{2 \times S A 32 P\left(\mu \frac{C i}{p m o l}\right)} \times \frac{[U T P(\mu M)]}{[32 P U T P(\mu M)] \times(\# \text { of Us })}
$$

Age of ${ }^{32} \mathrm{P}$ is in weeks; $\mathrm{SA}{ }^{32} \mathrm{P}=$ specific activity of ${ }^{32} \mathrm{P}$, usually $3 \mu \mathrm{Ci} / \mathrm{pmol}$;

\# of Us = number of $U$ residues per transcript.

\subsubsection{Radioactive 5'-end labeling of oligonucleotides}

To label DNA oligonucleotides at their 5'-end, the T4 polynucleotide kinase (T4 PNK) was used which transfers the $\gamma$-phosphate of a nucleotide to the free 5'-hydroxy group of a DNA oligonucleotide. The composition of a typical reaction mixture is shown below:

\section{Reaction mix:}

$\begin{array}{ll}\text { DNA oligomer } & 1 \mathrm{pmol} / \mu \mathrm{l} \\ \text { PNK buffer (NEB) } & 1 \mathrm{x} \\ {\left[\gamma^{32} \mathrm{P}\right] \text { ATP }(6000 \mathrm{Ci} / \mathrm{mmol})} & 6 \mu \mathrm{l} / 10 \mu \mathrm{l} \text { reaction } \\ \text { T4 PNK (NEB) } & 0.1 \mathrm{U} / \mu \mathrm{l}\end{array}$

The reaction was incubated for $1 \mathrm{~h}$ at $37^{\circ} \mathrm{C}$. Subsequently, the reaction volume was adjusted to $50 \mu \mathrm{l}$ and the DNA oligomers were separated from unincorporated free nucleotides using G-25 or G-50 spin columns (Amersham). The samples were PCI extracted and ethanol precipitated (2.2.1.5).

\subsubsection{Protein-biochemistry standard methods}

\subsubsection{Concentration determination of proteins}

To determine the concentration of proteins mainly the Bradford protein assay was used. This method involves the binding of Coomassie Brilliant Blue G-250 dye to proteins (Valadkhan \& Jaladat, 2010). The dye exists in three forms: cationic (red), neutral (green), and anionic (blue). Under acidic conditions, the dye is predominantly in the cationic form with an absorption maximum at $470 \mathrm{~nm}$. When the dye binds to protein, it is converted to the blue form and the absorption maximum shifts to $595 \mathrm{~nm}$. Using a protein standard, it is possible to 
determine the concentration of a protein solution. During this work the Bradford protein assay kit from Biorad was used, according to the manufacturer's instructions.

\subsubsection{Denaturing Polyacrylamide Gel Electrophoresis (PAGE)}

To analyze proteins via denaturing PAGE either pre-casted NuPAGE® Bis-Tris gels (4-12\%) or self-casted polyacrylamide gels were used according to the procedure established by Laemmli (1970). Commercial gels were used according to the manufacturer's instructions. For self casted gels typical gel compositions are listed below:

\section{stacking qel}

$\begin{array}{ll}\text { 4x stacking gel buffer (2.1.8) } & 375 \mu \mathrm{l} \\ \text { Rotiphorese Gel 30 } & 250.5 \mu \mathrm{l} \\ \mathrm{H}_{2} \mathrm{O} & 874.5 \mu \mathrm{l} \\ \text { APS } & 10 \mu \mathrm{l} \\ \text { TEMED } & 1 \mu \mathrm{l}\end{array}$

\section{8\% separating gel}

$\begin{array}{ll}\text { 4x separating gel buffer (2.1.8) } & 1250 \mu \mathrm{l} \\ \text { Rotiphorese Gel 30 } & 1332.5 \mu \mathrm{l} \\ \mathrm{H}_{2} \mathrm{O} & 2417.5 \mu \mathrm{l} \\ \text { APS } & 16.75 \mu \mathrm{l} \\ \text { TEMED } & 16.75 \mu \mathrm{l}\end{array}$

Protein samples were dissolved in protein loading dye and heated up to $95^{\circ} \mathrm{C}$ for 5 min prior to loading. Electrophoresis was typically performed at $150-200 \mathrm{~V}$ for 45 min using Biorad mini gel systems. The gels were stained either with Coomassie Brilliant Blue or with silver.

\subsubsection{Coomassie staining of protein gels}

Coomassie Brilliant Blue R-250 is a triphenylmethane dye forming strong non covalent complexes with proteins. Coomassie staining of protein gels was essentially performed as described in (Sambrook et al, 1989).

Protein gels were incubated in Coomassie staining solution for 5-15 min, the staining solution was removed and the gel was treated with destaining solution until protein bands became clearly visible. To stop the destaining the solution was changed with $5 \%$ (v/v) acetic acid.

\section{Coomassie staining solution:}

$50 \%$ (v/v) Methanol

$10 \%(\mathrm{v} / \mathrm{v})$ Acetic acid

0.25\% (w/v) Coomasie Brillant Blue R-250

\section{Destaining solution:}

50\% (v/v) Methanol

10\% (v/v) Acetic acid 


\subsubsection{Silver Staining of Protein Gels}

Silver staining of protein gels was performed according to Blum (1987). First, the gel was fixed in a solution of $50 \%(\mathrm{v} / \mathrm{v})$ Methanol/ 12\% (v/v) acetic acid for at least $30 \mathrm{~min}$ or overnight. Subsequently, the gel was washed twice with $50 \%(\mathrm{v} / \mathrm{v})$ ethanol and once with $30 \%(\mathrm{v} / \mathrm{v})$ ethanol for $20 \mathrm{~min}$ each. The gel was then treated with a solution of $0.8 \mathrm{mM}$ $\mathrm{Na}_{2} \mathrm{~S}_{2} \mathrm{O}_{3}$ for $60 \mathrm{~s}$ and briefly rinsed with water. Afterwards, the gel was stained with a solution of $12 \mathrm{mM} \mathrm{AgNO}_{3} / 0.026 \%$ formaldehyde for $20 \mathrm{~min}$. The staining solution was removed and the gel was rinsed with water, before adding the developing solution (56 mM $\mathrm{Na}_{2} \mathrm{CO}_{3}, 0.0185 \%$ formaldehyde, $16 \mu \mathrm{M} \mathrm{Na} \mathrm{S}_{2} \mathrm{O}_{3}$ ). To stop developing, the gel was transferred in a solution of 50\% (v/v) Methanol/ 12\% (v/v) acetic acid.

\subsubsection{Western blot analysis}

For western blot analysis, proteins were transferred to a nitrocellulose membrane (Protan BA83 nitrocellulose, $0.2 \mu \mathrm{m}$ by Schleicher \& Schuell) by a wet blot procedure. A Biorad Mini Trans-Blot cell was used according to the manufacturer's instructions. The transfer usually was performed at $250 \mathrm{~mA}$ for $2 \mathrm{~h}$ and a Slab4, methanol, $\mathrm{H}_{2} \mathrm{O}$ mixture (in a ratio of 5:2:3) was used as transfer buffer. After the blot, the membrane was stained with Ponceau S to check for a proper transfer. The stain was removed by washing with a TBS-Tween solution (1x TBS, $0.1 \%$ Tween) 2-3 times for 5 min each. Next, the membrane was incubated for $1 \mathrm{~h}$ at RT in a TBS-Tween solution containing 5\% fat free milk powder, to block unspecific interactions between the antibody and the membrane. The antibody was then added to the blocking solution in the designated dilution and incubated at RT for 1h. Afterwards, the membrane was briefly rinsed with TBS-Tween twice, and then 2 times with TBS-Tween for 20 min each. If a second antibody was needed, it was added after this step and the previous steps were repeated. However, in this work mostly the PAP complex (anti-peroxidase antiperoxidase complex) was used to detect the TAP-tag, and therefore no secondary antibody was required.

The PAP complex bound to the TAP-tag was visualized on the membrane using the ECL western blot detection kit (GE Healthcare, UK). The principle of the detection kit is based on a chemiluminescence reaction. The peroxidase of the PAP complex catalyses the oxidation of luminol in the presence of hydrogen peroxide, resulting in the emission of light, which can be detected by a film or camera. 


\subsubsection{Purification of recombinant proteins}

In the course of this work different proteins, recombinantly expressed in E.coli and subsequently purified were used. The cloning and some of the purifications were done by Dr. Jana Schmitzová, MPI-BPC Göttingen.

The genes, coding for the proteins to be expressed were cloned as described in Warkocki et al (2009). Full length CWC2, PRP2 and CWC25, the N-terminally truncated form of SPP2 (aa 36-185) and a truncation of CWC2 lacking the C-terminus (CwC2 $\triangle \mathrm{CTD}$, amino acids 1-234) were amplified by standard PCR and ligated into the following vectors: PRP2, SPP2 into pET21a (Novagen) and CWC2, CWC2 $\triangle C T D$ into pET22b(+) resulting in fusion proteins with a C-terminal hexahistidine tag. CWC25 was ligated into pETM11, resulting in an N-terminal hexahistidine tagged fusion protein. The constructs were sequenced and transformed into $E$. coli BL21 cells (Novagen) carrying the Rosetta plasmid (Novagen). E. coli cultures were grown in 2xYT medium or in autoinducing medium containing antibiotics for selection of the plasmids (Studier, 2005). In the case of 2xYT medium, expression was induced by adding $0.6 \mathrm{mM}$ IPTG. After $20 \mathrm{~h}$ (or $48 \mathrm{~h}$ in the case of auto-inducing medium) at $17^{\circ} \mathrm{C}$, the cells were harvested, the pellets were washed and stored at $-80^{\circ} \mathrm{C}$.

For cell lysis, the pellet was resuspended in $5 \mathrm{ml}$ lysis buffer per gram of cells and processed with a microfluidiser (Microfluidics) at 80 psi for 2-3 times. The lysate was separated from cell debris by centrifugation ( $\left.12000 \mathrm{x} \mathrm{g}, 4^{\circ} \mathrm{C}, 40 \mathrm{~min}\right)$ and applied to liquid chromatography using the ÄKTA system (GE Healthcare). In a first chromatography step His Trap HP FF columns (GE Healthcare) were used to selectively purify to His-tagged proteins. The column was equilibrated with lysis buffer and after sample loading it was washed with wash buffer according to the manufacturer's instructions. In case the protein interacted strongly with RNA an additional washing step with $2 \mathrm{M} \mathrm{LiCl}$ was included. The sample was eluted using elution buffer containing imidazole and eluted proteins were dialyzed against lysis buffer. Subsequently, the tags were cleaved by the addition of TEV or Prescission proteases and the proteases were removed by affinity chromatography, retaining the proteases and the tag on the matrix, while the purified proteins went in the flow-through. Using Centricon concentrators (Millipore) the protein samples were concentrated and subsequently processed by a gelfiltration. After gelfiltration, the obtained protein solution was pure to $97 \%$ judging by SDS-PAGE. The sample concentration was determined by Bradford protein assay (2.2.2.1) and aliquots were taken and frozen at $-80^{\circ} \mathrm{C}$. 
Lysis buffer for His-tagged proteins

20 mM HEPES pH 7.5

$600 \mathrm{mM} \mathrm{NaCl}$

$2 \mathrm{mM} \beta$-Mercaptoethanol

$15 \%$ glycerol

15 mM Imidazole

\section{Elution buffer for His-tagqed proteins}

20 mM HEPES $\mathrm{pH} 7.5$

$600 \mathrm{mM} \mathrm{NaCl}$

$2 \mathrm{mM} \beta$-Mercaptoethanol

$15 \%$ glycerol

250 mM Imidazole

\section{Wash buffer for His-tagqed proteins}

20 mM HEPES pH 7.5

$600 \mathrm{mM} \mathrm{NaCl} / 2 \mathrm{M} \mathrm{LiCl}$

2 mM $\beta$-Mercaptoethanol

$15 \%$ glycerol

15 mM Imidazole

\section{Buffer for gelfiltration of His-tagged proteins}

20 mM HEPES pH 7.5

$200 \mathrm{mM} \mathrm{NaCl}$

2 mM DTT

5\% glycerol

\section{MS2-MBP purification}

The MS2-MBP fusion protein used for the purification of spliceosomal complexes was expressed and subsequently purified from E. coli cells. Cells containing the plasmid encoding the MS2-MBP protein were grown to an $\mathrm{OD}_{600}=0.3-0.6$ at $37^{\circ} \mathrm{C}$ in $\mathrm{LB}$ medium supplemented with the respective antibiotics. To induce the expression, IPTG was added to a final concentration of $0.1 \mathrm{mM}$ and the cells were incubated further until they reached an $\mathrm{OD}_{600}=2-2.5$. The cultures were harvested by centrifugation and the cell pellets were subsequently washed with $\mathrm{ddH}_{2} \mathrm{O}$. For cell lysis, the pellet was resuspended in $5 \mathrm{ml}$ lysis buffer (20 mM Tris-HCl, pH 7.6, $200 \mathrm{mM} \mathrm{NaCl,} \mathrm{complete} \mathrm{EDTA-free} \mathrm{protease} \mathrm{inhibitors}$ from Roche according to the manufactures instructions) per gram of cells and processed with a microfluidiser (Microfluidics) at 80 psi for 2-3 times. The lysate was separated from cell debris by centrifugation ( $12000 \mathrm{x} \mathrm{g}, 4^{\circ} \mathrm{C}, 40 \mathrm{~min}$ ) and incubated head-over-tail with $500 \mu \mathrm{l}$ of amylose resin per $10 \mathrm{ml}$ of lysate for $2 \mathrm{~h}$. Afterwards, the suspension was transferred into a Bio-Spin chromatography column (Biorad) and the resin was washed with 10 column 
volumes (CV) of wash buffer (20 mM HEPES, pH 7.9, $150 \mathrm{mM} \mathrm{NaCl,} \mathrm{0.05 \%} \mathrm{NP-40).} \mathrm{To}$ decrease the salt concentration in view of the next purification step the amylose resin was washed with $5 \mathrm{CV}$ of $5 \mathrm{mM} \mathrm{Na} \mathrm{HPO}_{4}$, pH7.0 before the protein was eluted with $5 \mathrm{mM}$ $\mathrm{Na}_{2} \mathrm{HPO}_{4}$ containing $20 \mathrm{mM}$ maltose. The eluate was loaded onto a heparin agarose column equilibrated with $5 \mathrm{mM} \mathrm{Na}_{2} \mathrm{HPO}_{4}$, pH7.0. After washing with $10 \mathrm{CV}$ of $5 \mathrm{mM} \mathrm{Na}_{2} \mathrm{HPO}_{4}$, pH7.0, the MS2-MBP protein was eluted using a higher salt concentration within the elution buffer (20 mM HEPES/KOH, pH 7.9, $100 \mathrm{mM} \mathrm{KCl,} \mathrm{15 \%} \mathrm{Glycerol,} 0.5 \mathrm{mM}$ DTT). The protein was shock frozen in liquid nitrogen and stored at $-80^{\circ} \mathrm{C}$.

\subsubsection{Cell culture and extract preparation}

\subsubsection{Cultivation of bacteria}

E. coli cells were grown in lysogeny broth (LB) medium (Sambrook et al, 1989), 2xYT medium or in autoinducing medium (Studier, 2005). The medium was autoclaved for 15 min at $121^{\circ} \mathrm{C}$. For the selection of antibiotic resistances the medium contained Ampicillin (100 $\mu \mathrm{g} / \mathrm{ml})$, Chloramphenicol $(30 \mu \mathrm{g} / \mathrm{ml})$ or Kanamycin $(30 \mu \mathrm{g} / \mathrm{ml})$. Cells were stored for long term at $-80^{\circ} \mathrm{C}$ by adding $15 \%$ glycerol as a cryopreservative.

\subsubsection{Cultivation of yeast cells}

Yeast cells were grown in Yeast Extract Peptone Dextrose (YPD) medium, either on plates or in liquid culture. The medium was autoclaved for $15 \mathrm{~min}$ at $121^{\circ} \mathrm{C}$ and sterile glucose was added afterwards to avoid a caramelizing effect of the sugar.

\section{$\underline{\text { YPD-medium }}$}

$2 \%(\mathrm{w} / \mathrm{v})$ Bacto peptone

$1 \%(\mathrm{w} / \mathrm{v})$ Yeast extract

$2 \%(\mathrm{w} / \mathrm{v})$ Glucose (filter sterilized)

$1 \%(\mathrm{w} / \mathrm{v})$ Bacto agar in the case of YPD-plates

Usually, a single yeast colony was used to inoculate a liquid pre-culture which was then used to inoculate larger amounts of medium in Erlenmeyer flasks or a fermenter. Depending on the 
phenotype of the strain the cells were cultivated at a temperature between $25-30^{\circ} \mathrm{C}$. Cells were stored for long term at $-80^{\circ} \mathrm{C}$ by adding $15 \%$ glycerol as a cryopreservative.

\subsubsection{Preparation of yeast whole cell extracts and immunodepletion}

The preparation of yeast whole cell extracts for subsequent use during in vitro splicing reactions was performed essentially as described by Gottschalk et al (1999). Cells were grown to the middle logarithmic phase $\left(\mathrm{OD}_{600}=3-5\right)$ and harvested by centrifugation at 5600 $\mathrm{x}$ g for $10 \mathrm{~min}$. The pellet was washed twice with cold $\mathrm{H}_{2} \mathrm{O}$ and subsequently resuspended in cold AGK buffer (20 mM HEPES/KOH pH 7.9, $200 \mathrm{mM} \mathrm{KCl,} 1.5 \mathrm{mM} \mathrm{MgCl}$, 8\% (v/v) glycerol) supplemented with $0.5 \mathrm{mM}$ DTT, $0.5 \mathrm{mM}$ PMSF, $2 \mathrm{mM}$ benzamidine, $1 \mu \mathrm{M}$ leupeptin, $2 \mu \mathrm{M}$ pepstatin A, $4 \mu \mathrm{M}$ chymostatin, and $2.6 \mu \mathrm{M}$ aprotinin. The volume of the suspension was measured and the concentration of KCL was adjusted to $200 \mathrm{mM}$ again. To obtain yeast beads $2-5 \mathrm{~mm}$ in diameter, the cell suspension was dripped into liquid nitrogen, using a separating funnel. For cell lysis, these beads were ground in liquid nitrogen at 18000 rpm using a centrifugal mill (Retsch). The powder formed during the grinding process was slowly thawed at RT, and the cell debris were separated from the extract by centrifugation ( $25000 \mathrm{x} \mathrm{g}, 4^{\circ} \mathrm{C}, 30 \mathrm{~min}$ ). A second centrifugation step at high speed was used in order to clarify the extract $\left(100000 \mathrm{x} \mathrm{g}, 4^{\circ} \mathrm{C}, 1 \mathrm{~h}\right)$. During the centrifugation the extract was separated into three phases. The upper phase contained lipids and liposomes, the middle phase was clear and the pellet contained ribosomes, DNA and fine cell debris. The middle phase was recovered and dialyzed twice against 50-100 volumes of buffer D (20 mM HEPES/KOH pH 7.9, $50 \mathrm{mM} \mathrm{KCl,} 0.2 \mathrm{mM}$ EDTA, $0.4 \mathrm{mM} \mathrm{MgCl}_{2}$, 20\% (v/v) glycerol, $0.5 \mathrm{mM}$ DTT, $0.5 \mathrm{mM}$ PMSF, 2 mM benzamidine) for 1.5h each. After dialysis, the extract was centrifuged at 17000 $\mathrm{x} g$ for $5 \mathrm{~min}$ and subsequently frozen in liquid nitrogen. The extract was stored for long term at $-80^{\circ} \mathrm{C}$.

If the extract originated from a strain in which a spliceosomal factor was fused to a TAP-tag, it was possible to deplete this factor just before the dialysis step, by incubation of the extract with IgG-beads (GE Healthcare). To the recovered middle phase, 0.25 volumes of IgG-beads were added and incubated slowly rotating head-over-tail at $4{ }^{\circ} \mathrm{C}$ for 1.5 hours. By passing the extract through a Polyprep column (Biorad) it was separated from the beads and could be processed further. 


\subsubsection{Special methods}

\subsubsection{In vitro splicing reactions}

In vitro splicing reactions were performed essentially as described by Fabrizio et al (1989). A splicing reaction usually contained $40 \%$ total yeast extract, $1 \mathrm{x}$ splice cocktail (see below) and $4000 \mathrm{cpm} / \mu \mathrm{l}(\sim 400 \mathrm{pmol} / \mu \mathrm{l})$ of radioactively labeled Actin WT pre-mRNA. The reactions were incubated at $23^{\circ} \mathrm{C}$ for $0-60 \mathrm{~min}$ and aliquots were taken at several time points. The reactions were stopped by storing them on ice. Afterwards, Proteinase K digestion was used to strip off completely the proteins of the RNA. A typical Proteinase K reaction included the sample to be digested, 2\% SDS, $300 \mathrm{mM} \mathrm{NaCl}, 25 \mathrm{mM}$ EDTA and $200 \mathrm{mM}$ Tris-HCl pH 7.5. The reactions were incubated at $42^{\circ} \mathrm{C}$ for $30 \mathrm{~min}$ and were followed by PCI extraction and ethanol precipitation (2.2.1.5). The RNAs were separated by denaturing PAGE and the gels were analyzed by autoradiography.

\section{$\underline{5 x \text { splicing cocktail: }}$}

$300 \mathrm{mM}$ phosphate buffer, $\mathrm{pH}$ 7.3*

$15 \%(\mathrm{w} / \mathrm{v})$ PEG 8000

$10 \mathrm{mM}$ ATP

$12.5 \mathrm{mM} \mathrm{MgCl} 2$

$10 \mathrm{mM}$ spermidine

*phosphate buffer at $\mathrm{pH} 7.3$ was prepared by mixing solutions of $\mathrm{K}_{2} \mathrm{HPO}_{4}$ and $\mathrm{KH}_{2} \mathrm{PO}_{4}$ according to Sambrook et al (1989).

\subsubsection{Purification of spliceosomal complexes}

The purification of spliceosomal yeast complexes was essentially performed according to Fabrizio et al (2009). First, the pre-mRNA substrate was bound to the MS2-MBP fusion protein by incubating a 30 times molar excess of MS2-MBP with the designated pre-mRNA and $20 \mathrm{mM}$ HEPES-KOH, pH 7.9 on ice for $30 \mathrm{~min}$. Subsequently, the pre-mRNA was mixed with $40 \%$ extract (2.2.3.3) and 1x splicing cocktail (2.2.4.1) and splicing was carried out at $23^{\circ} \mathrm{C}$ for $50 \mathrm{~min}$. During preparative in vitro splicing reactions the final concentration of pre-mRNA usually was $2 \mathrm{nM}$. After the incubation at $23^{\circ} \mathrm{C}$, the splicing reaction was chilled on ice and then loaded on top of a 10-30\% (v/v) glycerol gradient, containing G150 
buffer (20 mM HEPES-KOH, pH 7.9; $1.5 \mathrm{mM} \mathrm{MgCl}_{2}$; $150 \mathrm{mM} \mathrm{KCl).} \mathrm{Sedimentation} \mathrm{was}$ carried out at $90000 \mathrm{x} \mathrm{g}$ at $4^{\circ} \mathrm{C}$ for $18 \mathrm{~h}$. Afterwards, the gradients were fractionated from top to bottom and the fractions were analyzed by Cherenkov counting in a scintillation counter. The fractions containing the spliceosomal complexes were pooled and loaded on an amylose column, equilibrated with G150 buffer beforehand. The column was washed with 10 column volumes (CV) of G150 buffer supplemented with 5\% glycerol and $0.01 \%$ NP40, and spliceosomal complexes were eluted using G150 buffer containing $12 \mathrm{mM}$ maltose, 5\% glycerol and $0.01 \%$ NP40.

After the elution from the amylose column the spliceosomal complexes were used either for UV crosslinking/structure probing experiments, for reconstitution of B* or C-complexes, or a second gradient centrifugation was carried out as a third step purification.

In case of complex $\mathrm{C}$ purification, the splicing reaction was followed by an RNase $\mathrm{H}$ digestion. For this purpose, a DNA oligo complementary to nts 13-24 of the intron was added to the reaction, followed by an additional incubation at $30^{\circ} \mathrm{C}$ for $10 \mathrm{~min}$. In this way, the endogenous RNase $\mathrm{H}$ present in the extract digests the RNA intron of early spliceosomal complexes whose presence would otherwise complicate the purification.

\subsubsection{UV-crosslinking of spliceosomal complexes}

UV crosslinking was used to characterize sites of direct protein-RNA interactions within native spliceosomal complexes. In general, the irradiation of RNP particles results in the generation of covalent interactions between proteins and RNA if they are in a favorable arrangement (Urlaub et al, 2005).

UV crosslinking of spliceosomal complexes was essentially performed as described by Urlaub et al (2005). Approximately 1-4 pmol of purified yeast complexes were pipetted onto pre-cooled 10-well multitest slides and then irradiated for $60 \mathrm{~s}$ with UV light at $254 \mathrm{~nm}$ on ice. To the irradiated and non-irradiated control samples of spliceosomal complexes, SDS was added to a final concentration of $1 \%$ and incubated for $10 \mathrm{~min}$ at $70{ }^{\circ} \mathrm{C}$ to destroy all non covalent interactions. The samples were chilled at room temperature before the addition of Triton X-100 to a final concentration of 5\%, then diluted with 5-6 volumes of NET-150 buffer (50 mM Tris- $\mathrm{HCl} \mathrm{pH}$ 7.4, $150 \mathrm{mM} \mathrm{NaCl}$ ) and subjected to immunoprecipitation. 


\subsubsection{Immunoprecipitation of protein-RNA crosslinks}

To enrich for crosslinks to one specific protein, immunoprecipitation was used. Spliceosomes were assembled from extract in which one factor was fused to the TAP tag (Puig et al, 2001). The TAP-tag consists of a CBP part separated from a Protein A part by a TEV cleavage site. In this work, the strong interaction of Protein A with the Fc fragment of IgGs was used to affinity select tagged protein factors. The immunoprecipitation was performed under denaturing conditions. In this way, RNAs were co-precipitated with the tagged protein only if they were covalently attached to it.

Protein A or IgG Sepharose (GE Healthcare) resins were washed with NET-150 buffer and incubated at $4{ }^{\circ} \mathrm{C}$ with UV-crosslinked or non-crosslinked yeast complexes prepared as above (2.2.4.3). After washing with NET-150 buffer, beads were incubated with PK-mix (0.5-1 $\mathrm{mg} / \mathrm{ml}$ Proteinase K, $50 \mathrm{mM}$ EDTA pH 8.0, 1\% SDS) for $20 \mathrm{~min}$ at $42{ }^{\circ} \mathrm{C}$ followed by PCI extraction and ethanol precipitation. The pellet was dried and dissolved in water.

\subsubsection{Chemical modifications of RNA}

In order to analyze the impact of the absence of Cwc2 from the spliceosome on the spliceosomal RNA network, different chemicals were used to assess RNA structural features. These reagents modify unpaired nucleotides, while base-paired nucleotides or those bound by protein remain unmodified.The modification reagents used were dimethylsulfate (DMS; Riedel-de Haën), and 1-cyclohexyl-3-(2-morpholinoethyl) carbodiimide metho-p-toluene sulfonate (CMCT; Fluka).

DMS primarily reacts with N7-G, N1-A and N3-C at a neutral $\mathrm{pH}$ and therefore only modifications at A and C should be detectable by primer extension (Ehresmann et al, 1987), since these positions are required for Watson-Crick basepairing (Figure 2.1). CMCT on the other hand primarily reacts with N3-U and N1-G at pH 8.0. Thus, with CMCT only modifications at $\mathrm{U}$ and $\mathrm{G}$ should be detectable by primer extension.

For the modification reactions, $500 \mathrm{fmol}$ of $\mathrm{B}^{\text {act }}$ complex were incubated with modification reagents in the presence of $10 \mu \mathrm{g}$ E. coli tRNA, essentially as described by others (Ehresmann et al, 1987). In brief, $1 \mu \mathrm{l}$ DMS was added per $200 \mu \mathrm{l}$ reaction and incubated at $20{ }^{\circ} \mathrm{C}$ for $8 \mathrm{~min}$. The reaction was stopped by the addition of $50 \mu \mathrm{l}$ DMS stop buffer ( $1 \mathrm{M}$ Tris-HOAc pH 7.5, 2 M $\beta$-mercaptoethanol, 12.5 mM EDTA). CMCT modifications were 


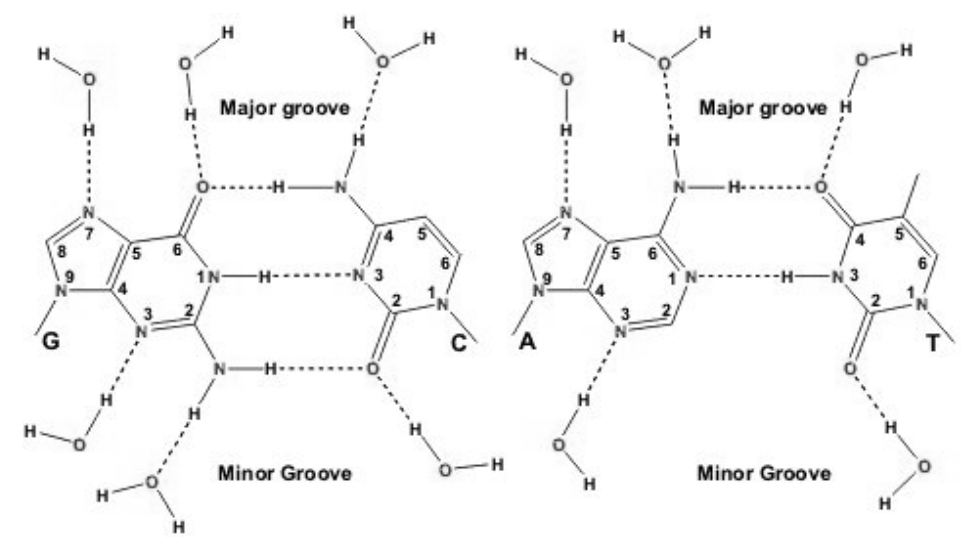

\section{Figure 2.1: Watson-Crick basepairing}

DMS primarily modifies N7-G, N1-A and N3-C and CMCT primarily reacts with N3-U and N1-G.

Picture taken from http://www.lsbu.ac.uk/water/nucleic.html

performed at $20^{\circ} \mathrm{C}$ for $30 \mathrm{~min}$ in the presence of $8 \mathrm{mg}$ of CMCT per $200 \mu \mathrm{l}$ reaction. To recover the RNA, samples were first ethanol-precipitated and then digested with proteinase $\mathrm{K}$ and PCI-extracted. Following ethanol precipitation, samples were diluted with water and used for primer extension analysis.

\subsubsection{Primer extension analysis}

Primer extension analysis was used to detect crosslinks of protein to RNA or modifications of RNA by different modifying reagents. The reverse transcriptase cannot read through nucleotides whose Watson-Crick base pairing is blocked, either by crosslinked peptide or by other means of chemical modification. Therefore, the elongation of the nascent transcript is aborted, resulting in a truncated DNA product. Separating the DNA fragments on a denaturing gel together with a sequencing reaction, allows the identification of the nucleotides whose Watson-Crick base pairing was blocked.

Oligodeoxynucleotide primers complementary to nts 94-112 of the U6 snRNA and 254-269 of the M3Act pre-mRNA were labelled with ${ }^{32} \mathrm{P}$ at their 5' end by $\mathrm{T} 4$ polynucleotide kinase (2.2.1.11), and $\sim 1$ to $2 \times 10^{5} \mathrm{cpm}$ of primer was used for one reverse transcription reaction. The samples were denatured by heating at $96^{\circ} \mathrm{C}$ for $1 \mathrm{~min}$, annealed by cooling to room temperature, and reverse-transcribed with $1.5 \mathrm{U}$ of AMV reverse transcriptase (USB) for $45 \mathrm{~min}$ at $43^{\circ} \mathrm{C}$. Sequencing ladders were obtained from U6 RNA and M3Act pre-mRNA 
prepared by in vitro transcription (2.2.1.10) under identical conditions, except that $0.05 \mathrm{mM}$ dideoxynucleoside triphosphates were included. Reverse transcripts were separated on a 9.6\% polyacrylamide sequencing gel containing $8.3 \mathrm{M}$ urea and visualized by autoradiography.

\subsubsection{Mass spectrometry}

For Mass spectrometry, proteins recovered from purified spliceosomal complexes (usually between 100-400 fmol), were separated by SDS-PAGE using a 4-12\% Bis-Tris-HCL (pH 7.0) NUPAGE polyacrylamide gel (Invitrogen) and stained with Coomassie. Entire lanes were cut into 23 slices and proteins were digested in-gel with trypsin and extracted as described by described Shevchenko et al (1996). Resulting peptides were analyzed in an LCcoupled ESI Q-ToF (QToF Ultima, Waters) and/or OrbitrapXL (ThermoFisher Scientific) mass spectrometer under standard conditions. Proteins were identified by searching fragment spectra against the NCBI nonredundant (nr) database using Mascot as search engine. 


\section{Results}

As pointed out above, there are many indications for the hypothesis that the mechanism of splicing between group II self-splicing introns and the spliceosome might be very similar. Especially DV of group II introns shares important evolutionary conserved features with the U6-ISL and both of these elements, DV and the U6-ISL are crucial components of the catalytic core within their respective splicing machinery. For DV however it was demonstrated that it only adopts its active conformation within the huge scaffold of DI where plenty of tertiary RNA interactions are required to position and even bend its RNA structure. Based on the similarities between DV and the U6-ISL it is assumed that analogous mechanisms could be required to position the U6-ISL within the catalytic center of the spliceosome. Since introns of nuclear pre-mRNA most likely do not adopt a 3 dimensional fold -comparable to the one of group II introns- which could play a role in shaping the catalytic core of the spliceosome, most likely spliceosomal factors are needed to position the U6-ISL properly. To identify possible interaction partners of U6 snRNA and to characterize their role during catalytic activation of the spliceosome a crosslinking approach was applied.

\subsection{Cwc2 can be crosslinked to U6 RNA and the pre-mRNA in activated spliceosomes}

To discover spliceosomal factors which might fulfill a function analogous to DI within group II introns a crosslinking approach was applied to identify proteins possibly interacting with U6 snRNA within purified spliceosomal complexes.

A prerequisite for these crosslinking experiments was the purification of spliceosomal complexes in their native state. The purification procedure was essentially performed as described by Fabrizio et al (2009). Spliceosomes were assembled in vitro under splicing conditions in the presence of different pre-mRNA substrates containing three RNA stem loop structures (MS2 loops), known to interact tightly with a coat protein of the MS2 phage. In this way, the pre-mRNA substrates could be bound to a fusion protein consisting of the MS2 coat protein and the maltose binding protein (MBP), allowing affinity selection on an amylose matrix. 


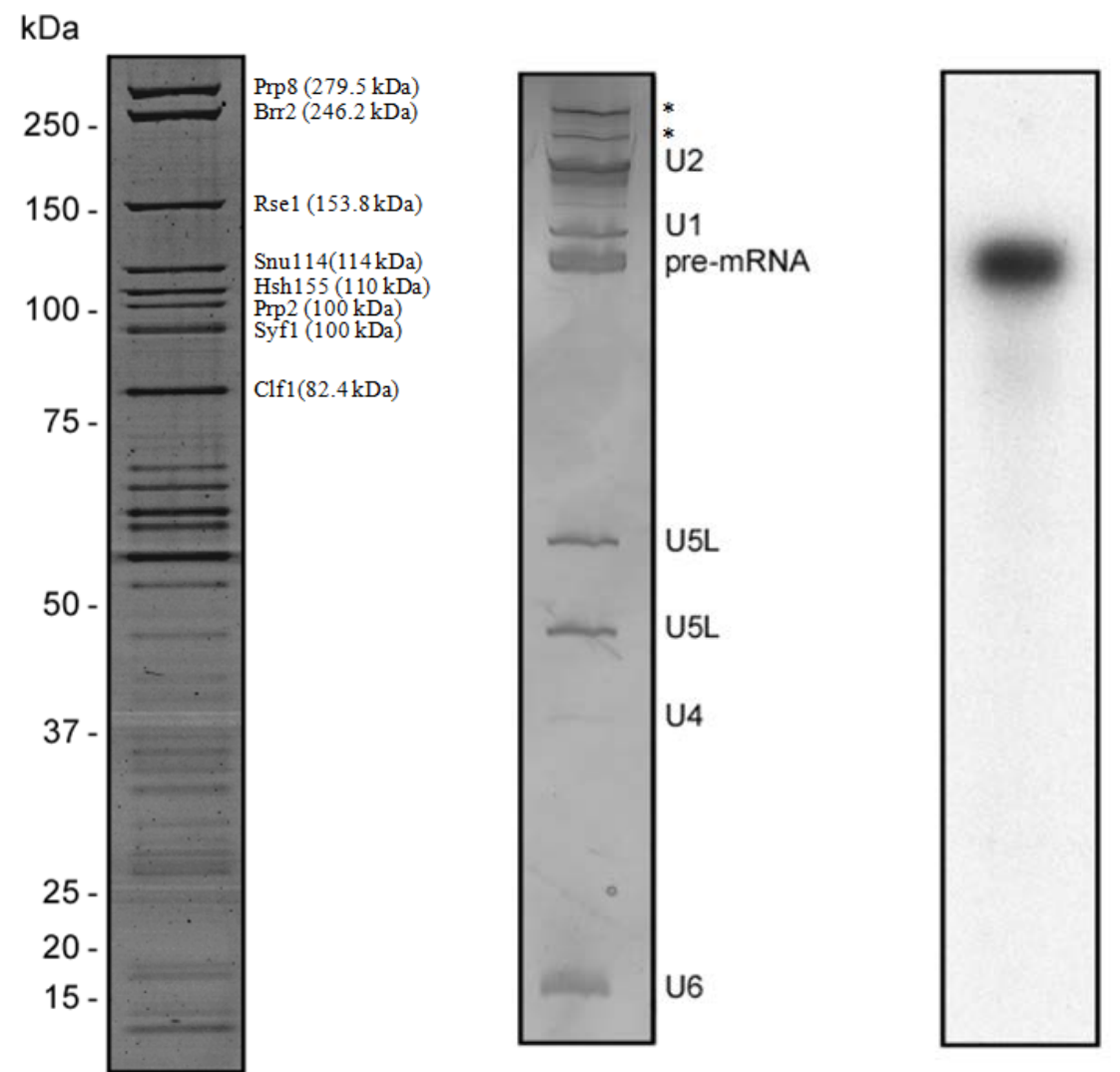

Figure 3.1: Analytics of spliceosomal complexes by gel electrophoresis

The composition of $\mathrm{B}^{\text {act }}$ complexes , purified by glycerol gradient centrifugation and affinity chromatography, was analyzed by SDS-PAGE (panel 1) and subsequent staining with Coomassie Brilliant Blue in case of protein samples, or by denaturing PAGE and subsequent staining with silver for RNA samples (panel 2). The autoradiogram of the RNA silver gel is shown in panel 3. Contaminations, most probably by ribosomal RNAs are marked with an asterisk.

After assembly, the reactions were initially separated on a glycerol gradient in which the spliceosomal complexes migrated in the 40S - 45S region, depending on the type of the complex. The complex containing fractions were combined and loaded onto an amylose matrix for the MS2-MBP affinity chromatography step. The complexes were eluted with buffer containing maltose and then used for crosslinking or structure probing experiments.

To monitor the purity and the functional status of the purified complexes usually a denaturing gel electrophoresis of the RNA and protein components was performed. Figure 3.1 shows an example of such an analysis for a $\mathrm{B}^{\text {act }}$ complex assembled on M3Act $\Delta 6$ pre-mRNA. The left panel represents a protein gel stained with Coomassie Brilliant Blue where the typical protein 
pattern for $\mathrm{B}^{\text {act }}$ complexes is clearly visible. The factors above $75 \mathrm{kDa}$ in size were assigned by their molecular weight, as determined by mass spectrometry and quoted on the right. Almost no contamination with non spliceosomal factors was found, indicating that the purification of spliceosomal complexes was close to homogeneity. The RNA composition was analyzed by staining the RNAs with silver (panel 2) and shows mainly U2 snRNA, premRNA, U5L snRNA, U5S snRNA and U6 snRNA. Only minor contaminations of U1 snRNA and most probably ribosomal RNAs (indicated on the right with asterisks) are visible. The autoradiography (panel 3) confirms the identity of the pre-mRNA. All RNAs are intact and show almost no degradation, indicating that the spliceosomal complexes are largely intact and free from contaminating RNases.

1. UV-crosslinking

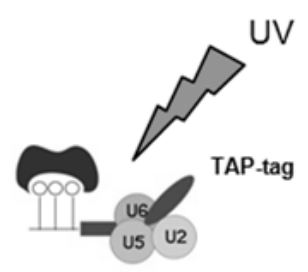

purified spliceosomal complexes

2. Disassembly

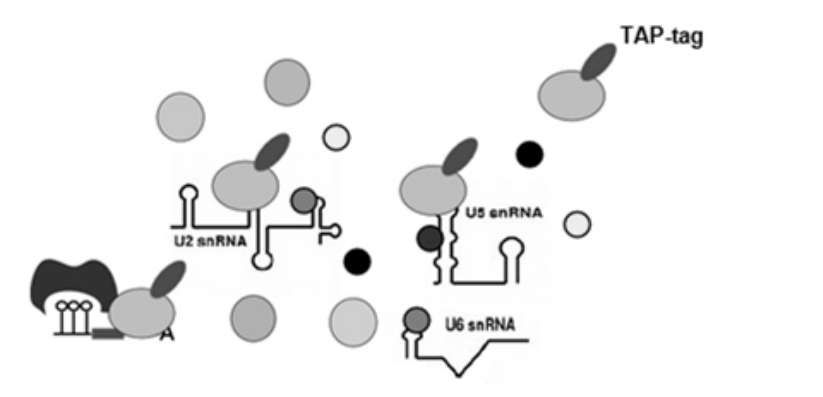

3. Pulldown

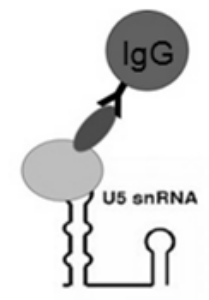

4. Proteinase K digestion

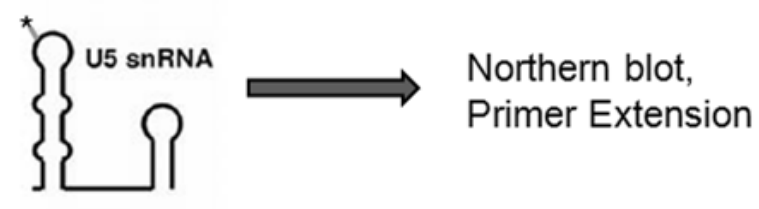

Figure 3.2: Schematic overview of the crosslinking and immunoprecipitation procedures

Purified spliceosomal complexes were UV irradiated (1.), disassembled under denaturing conditions (2.) and subsequently subjected to immunoprecipitation (3.). Co-precipitated RNA species were extracted (4.) and further analyzed.

To induce covalent protein-RNA crosslinks purified $\mathrm{B}^{\text {act }}$ complexes were exposed to UV light at a wavelength of $254 \mathrm{~nm}$ for $1 \mathrm{~min}$ and subsequently subjected to denaturing conditions in 
order to disrupt protein-protein and non-covalent RNA-protein interactions (see also Figure 3.2). Immunoprecipitation was used to assess if RNAs were specifically crosslinked to the factor under investigation. The sample was therefore incubated with IgG Sepharose, allowing the selective immunoprecipitation of RNA species crosslinked to the protein factor carrying a TAP-tag. After extensive washing, the beads were digested with Proteinase K (2.2.4.1) and the RNA was PCI extracted and precipitated with ethanol (2.2.1.5). Co-precipitated RNAs were identified by Northern blot analysis.

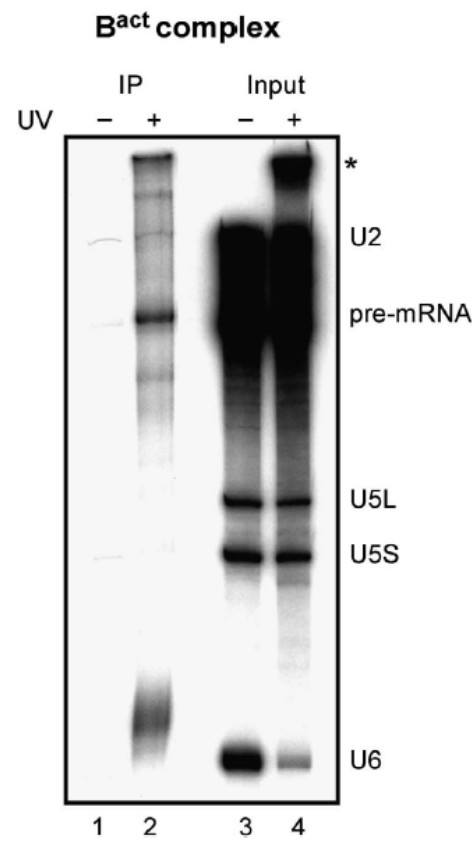

Figure 3.3: Cwc2 crosslinks to yeast U6 snRNA and pre-mRNA within activated spliceosomes.

Northern blot analysis of the RNAs derived from UV-irradiated $\mathrm{B}^{\text {act }}$ complexes carrying Cwc2 tagged with the TAP tag (lane 4) and after immunoprecipitation of $B^{\text {act }}$ complexes with IgG Sepharose beads (IP, lane 2). Lanes 1 and 3 are controls without UV irradiation. RNA was analysed on an 8\% polyacrylamide gel and visualized by autoradiography. The positions of the snRNAs and M3Act $\Delta 6$ pre-mRNA are indicated on the right. Asterisk: high-molecular weight crosslinked product.

Proteins used for the crosslinking experiments were chosen on the basis of different circumstances. They were either implicated in interactions with U6 snRNA before or they belong to the group of proteins joining the spliceosome during the transition from $\mathrm{B}$ to $\mathrm{B}^{\text {act }}$ complex, when almost all other known U6 snRNA interaction partners are released from the spliceosome (see also Figure 1.7). Prp8 for example, one of the largest and most highly conserved nuclear proteins, occupies a central position in the catalytic core of the spliceosome (Grainger \& Beggs, 2005), and it has been shown to crosslink not only to U6 snRNA (Vidal et al, 1999), but also to U5 snRNA within the tri-snRNP (Dix et al, 1998) and 
to multiple regions of the pre-mRNA within spliceosomes (Vijayraghavan et al (1986), Whittaker and Beggs (1991), Turner et al (2006)). Snu114, an important spliceosomal GTPase which is involved in the regulation of Brr2 could likewise be crosslinked to U5 snRNA and might also be contacting U6 snRNA (Dix et al, 1998; Frazer et al, 2008). Another factor, the NTC related protein Ecm2 has been shown to be involved in the formation of U2/U6 helix II during the activation of the spliceosome and contains known RNA binding domains (Xu \& Friesen, 2001). Also Cwc2 belongs to the group of NTC related proteins, contains a zinc finger and an $\underline{R} N A$ recognition motif (RRM) and it has been implicated in U6 snRNA binding under splicing conditions (McGrail et al, 2009).
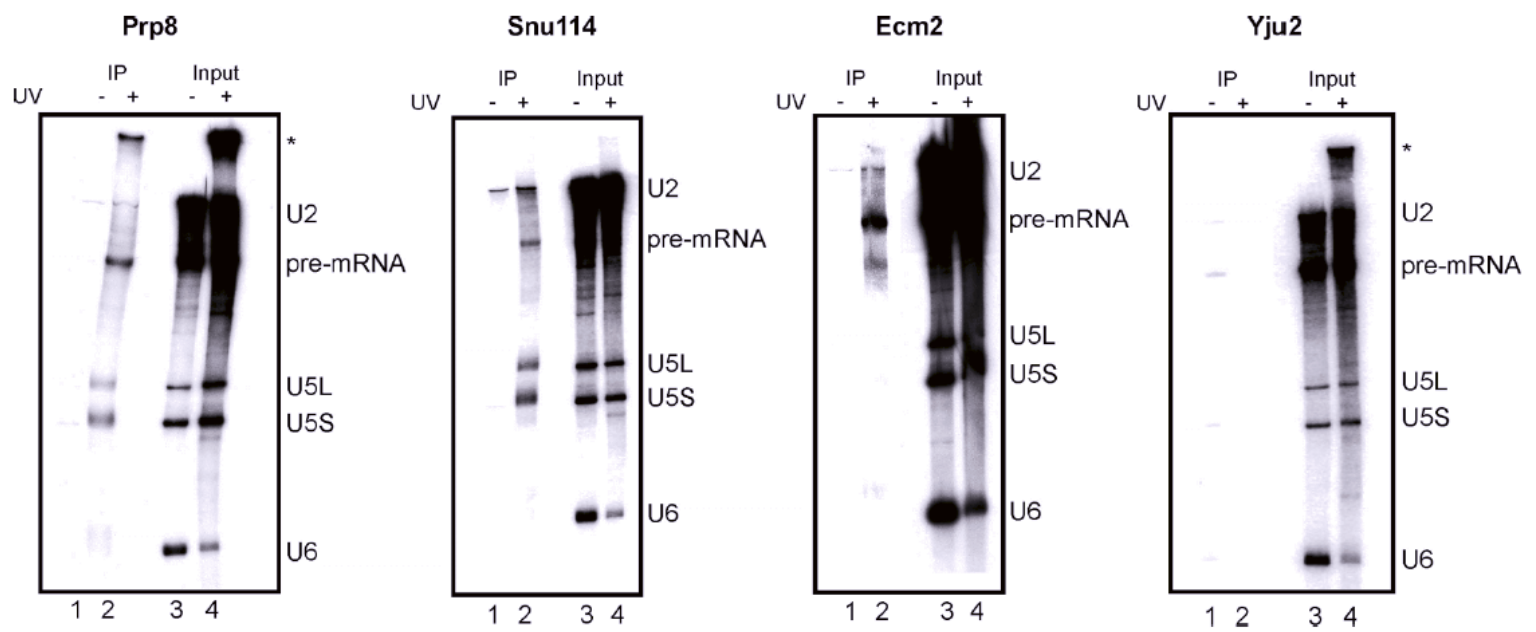

Figure 3.4: Crosslinking of Prp8, Snu114, Ecm2 and Yju2 to pre-mRNA and snRNAs within affinity-

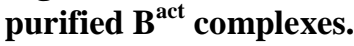

Northern blot analysis of the snRNAs derived from UV-irradiated $\mathrm{B}^{\text {act }}$ complexes carrying Prp8 or Snu114 or Ecm2 or Yju2 tagged with the TAP-tag (lanes 4) and after immunoprecipitation of denatured B ${ }^{\text {act }}$ complexes with IgG Sepharose beads (IP, lanes 2). Lanes 1 and 3 are controls without UV irradiation. RNAs were analyzed on an $8 \%$ polyacrylamide gel and visualized by autoradiography. The positions of the snRNAs and M3Act $\Delta 6$ pre-mRNA are indicated on the right. Prp8 crosslinks to U5 snRNA and to pre-mRNA. Snu114 crosslinks to U5 snRNA, to the pre-mRNA and also to U2 snRNA. Ecm2 crosslinks to the pre-mRNA, while Yju2 showed no RNA-protein crosslinks at all in the $\mathrm{B}^{\text {act }}$ complex. Asterisks: high-molecular-weight crosslinked product.

Within $\mathrm{B}^{\text {act }}$ complexes however, among these factors, only Cwc2 could be crosslinked to U6 snRNA under the conditions used here (Figure 3.3, note that the ${ }^{32} \mathrm{P}$-labelled pre-mRNA used for complex formation is also visible in the autoradiogram). Upon UV irradiation of purified $\mathrm{B}^{\text {act }}$ complexes some loss of U6 snRNA was observed, while the other RNA signals remained largely unchanged (Figure 3.3, compare lanes 3 and 4). In the absence of UV irradiation, no RNA was co-immunoprecipitated together with Cwc2 (lane 1), confirming that all non- 
covalent RNA-protein interactions were disrupted under the immunoprecipitation conditions used. In contrast, upon UV irradiation solely the U6 snRNA and the pre-mRNA were coprecipitated. The crosslinked U6 snRNA migrated more slowly than non UV irradiated U6 snRNA, presumably due to a bound residual oligopeptide (digestion fragment) of Cwc2. These data indicate that in the purified $\mathrm{B}^{\text {act }}$ complex, Cwc2 can be crosslinked specifically not only to U6 snRNA but also to the pre-mRNA.

Figure 3.4 gives an overview of the crosslinks found for the other factors under investigation. Prp8, as expected, crosslinked to pre-mRNA and to U5 snRNA, but however, no U6 snRNA could be co-precipitated together with Prp8 under these conditions (Prp8, lane 2). Also Ecm2, which was suspected to interact with U6 snRNA and/or U2 snRNA, could not be crosslinked to neither of them, but nevertheless, unexpectedly precipitated pre-mRNA (Ecm2, lane2), an interaction unknown till now. Likewise, the crosslinks of Snu114 to pre-mRNA and U2 snRNA (Snu114, lane 2) were not reported up to now and are therefore interesting. The interaction of Snu114 to U5 however has been described before by Dix et al (1998) and therefore, it can be considered, together with the U5 snRNA and pre-mRNA crosslinks of Prp8 a proof of concept of the crosslinking procedure. The NTC related factor Yju2 did not crosslink to any spliceosomal RNA, indeed demonstrating a very selective crosslinking behavior of the five proteins tested here.

\subsection{Cwc2 interacts with the U6-ISL and a region upstream of the U6 ACAGAGA box}

To map the crosslinking sites of Cwc2 on U6 snRNA and the pre-mRNA, primer extension analysis was performed (Ehresmann et al, 1987). During the reverse transcription of crosslinked RNA, the reverse transcriptase cannot read through nucleotides whose WatsonCrick base pairing is blocked, e.g. by a crosslinked amino acid. Therefore, the elongation of the nascent transcript is aborted one nucleotide prior to the crosslink, resulting in a truncated DNA product. Separating the DNA fragments on a denaturing gel together with a sequencing reaction allows the identification of the nucleotides whose Watson-Crick base pairing was blocked. To distinguish between reverse transcriptase stops reflecting a protein crosslink and stops caused simply by RNA damage (e.g. UV irradiation induced strand breaking, thymine dimers etc.), in vitro transcribed U6 snRNA and pre-mRNA, respectively, were included as 


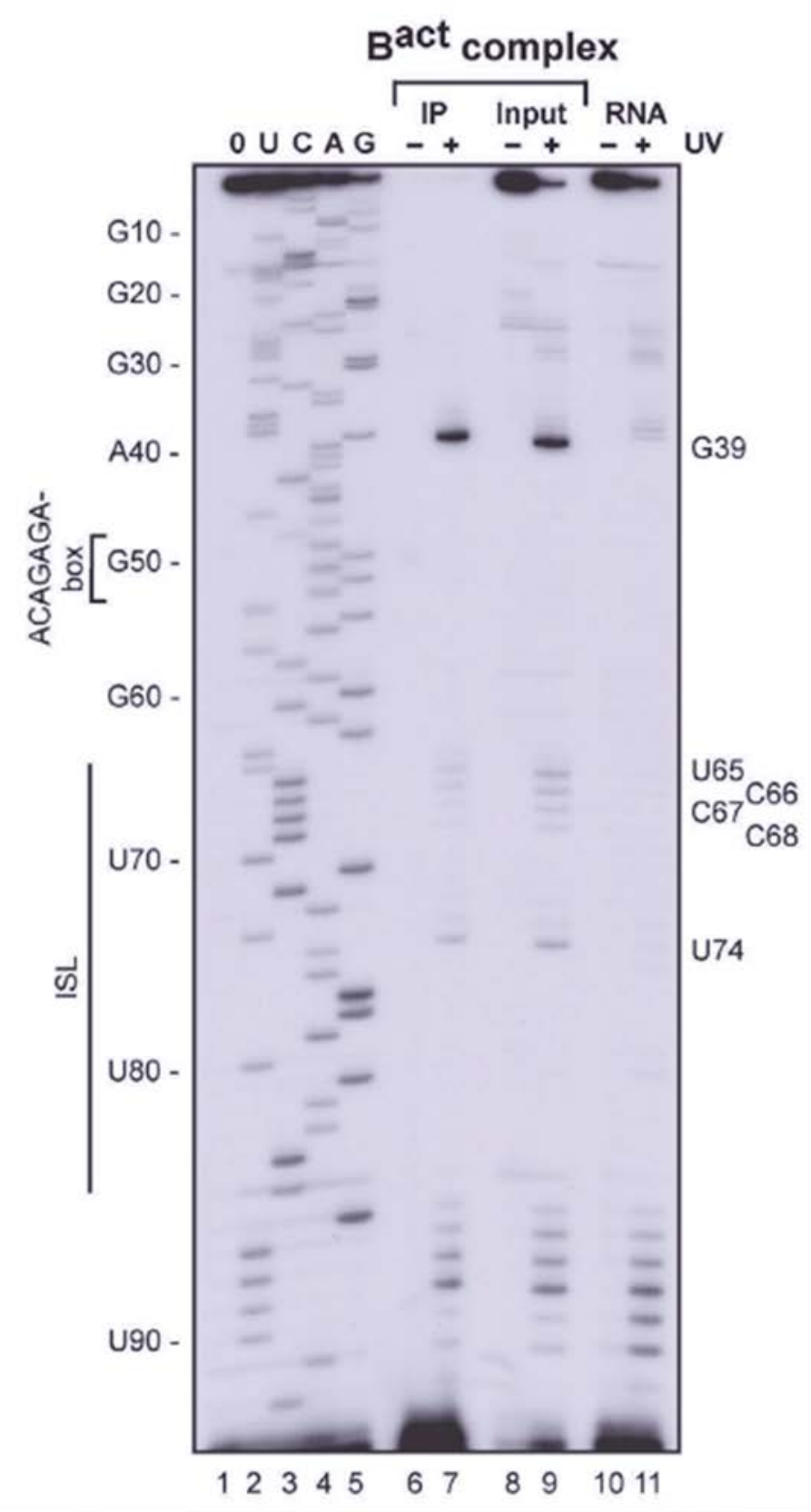

Figure 3.5: Cwc2 interacts with the U6-ISL and a region upstream of the ACAGAGA box in yeast $B^{\text {act }}$ complexes.

Primer-extension analysis of U6 snRNA derived from UV irradiated $\mathrm{B}^{\text {act }}$ complexes containing TAP-tagged Cwc2, after immunoprecipitation with IgG Sepharose beads (IP, lane 7), or without immunoprecipitation (input, lane 9). Lane 11, analysis of UV-irradiated in vitro transcribed U6 snRNA, lanes 6, 8, and 10 are controls without UV irradiation. U, C, A, and G are dideoxy sequence markers (' 0 ', no ddNTP). Regions corresponding to the U6-ACAGAGA and ISL sequences are marked on the left. Reverse transcriptase stops that are due to RNA-protein crosslinks are denoted on the right.

controls (Figure 3.5, Figure 3.6 and Figure 3.9 lanes 10 and 11). Thus, identical stops appearing within the in vitro transcribed RNAs and in the input samples, likely would not 


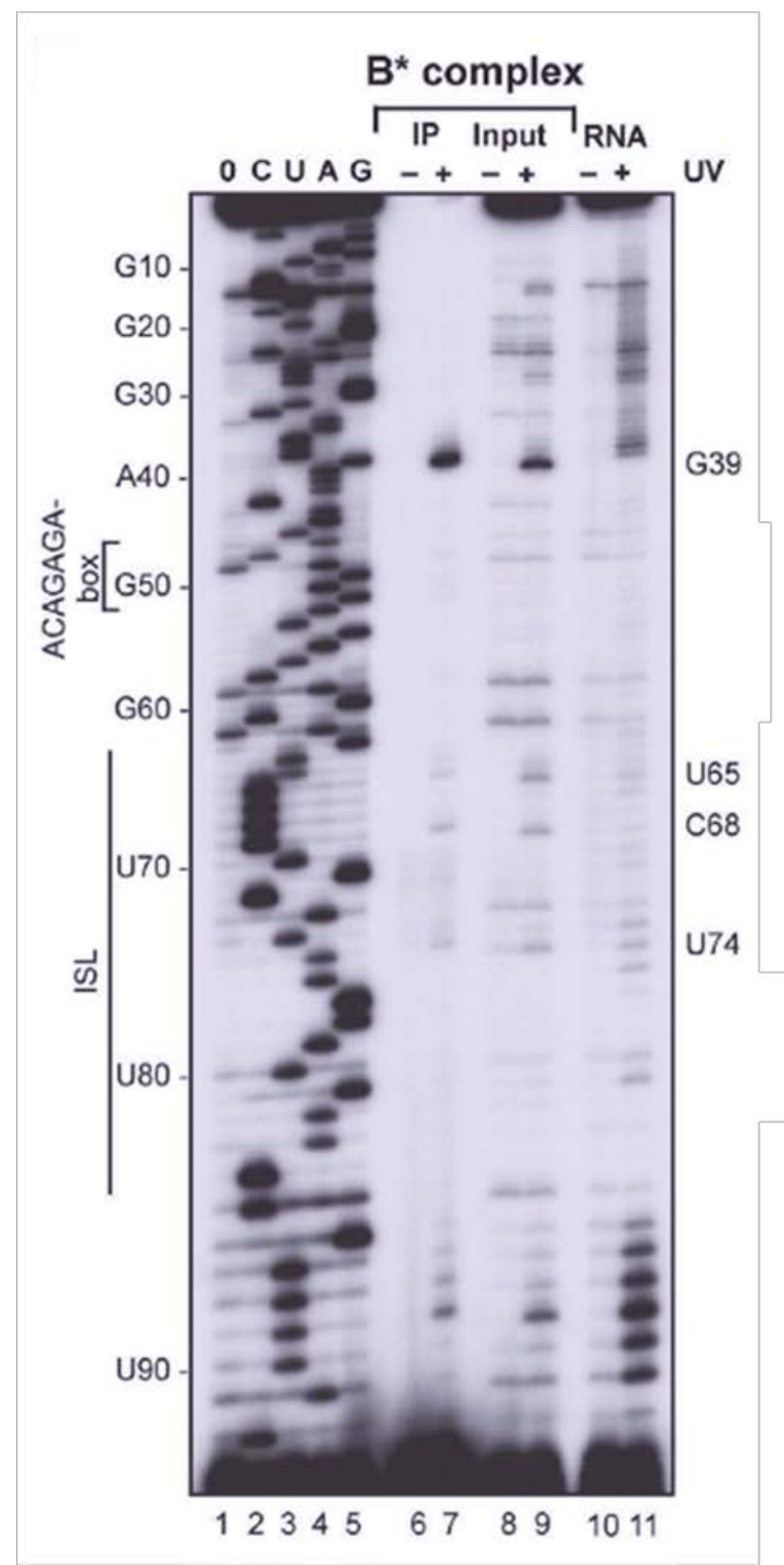

Figure 3.6: Cwc2 interacts with the U6-ISL and a region upstream of the ACAGAGA box in yeast B* complexes.

Primer-extension analysis of U6 snRNA derived from UV irradiated B* complexes containing TAP-tagged Cwc2, after immunoprecipitation with IgG Sepharose beads (IP, lane 7), or without immunoprecipitation (input, lane 9). Lane 11, analysis of UV-irradiated in vitro transcribed U6 snRNA, lanes 6, 8, and 10 are controls without UV irradiation. U, C, A, and G are dideoxy sequence markers (' 0 ', no ddNTP). Regions corresponding to the U6-ACAGAGA and ISL sequences are marked on the left. Reverse transcriptase stops that are due to RNA-protein crosslinks are denoted on the right.

represent protein-RNA crosslinks. However, it cannot be ruled out that a strong signal appearing upon UV irradiation of the RNA, masks a weaker signal induced by a protein crosslink in the same spot within the RNP sample. 


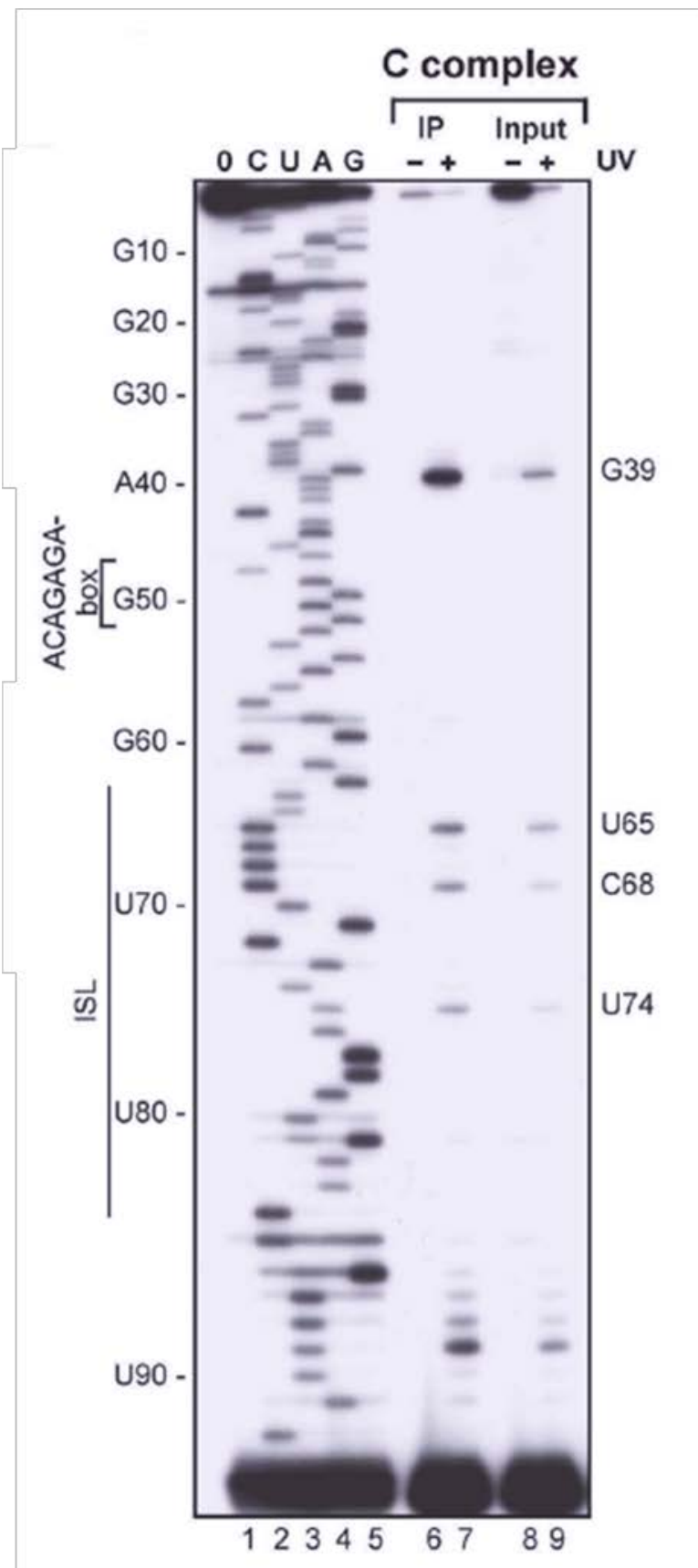

Figure 3.7: Cwc2 interacts with the U6-ISL and a region upstream of the ACAGAGA box in yeast C complexes.

Primer-extension analysis of U6 snRNA derived from UV irradiated C complexes containing TAP-tagged Cwc2, after immunoprecipitation with IgG Sepharose beads (IP, lane 7), or without immunoprecipitation (input, lane 9). Lane 11, analysis of UV-irradiated in vitro transcribed U6 snRNA, lanes 6, 8, and 10 are controls without UV irradiation. U, C, A, and G are dideoxy sequence markers ('0', no ddNTP). Regions corresponding to the U6ACAGAGA and ISL sequences are marked on the left. Reverse transcriptase stops that are due to RNA-protein crosslinks are denoted on the right.

The input lanes (Figure 3.5, Figure 3.6, Figure 3.7 and Figure 3.9 lanes 9) reflect crosslinks found in U6 snRNA or in the pre-mRNA within the respective complex (i.e. $\mathrm{B}^{\text {act }}, \mathrm{B}^{*}$ or $\mathrm{C}$ complex). To identify crosslinks specific for Cwc2, RNAs co-precipitated together with 
Cwc2 during the immunoprecipitation (see 3.1) were analyzed in parallel (lanes 7). In these samples, stops induced by Cwc2 crosslinks should be heavily enriched. In all cases, as controls also non UV irradiated samples were analyzed in parallel (lanes 6, 8 and 10).

The crosslinking sites of Cwc2 on U6 snRNA were mapped at different stages of spliceosome assembly, namely the $\mathrm{B}^{\text {act }}$, the $\mathrm{B}^{*}$ and the $\mathrm{C}$ complex (Figure 3.5, Figure 3.6 and Figure 3.7) while crosslinks of Cwc2 on the pre-mRNA were only localized at the stage of the $\mathrm{B}^{\text {act }}$ complex (Figure 3.9).

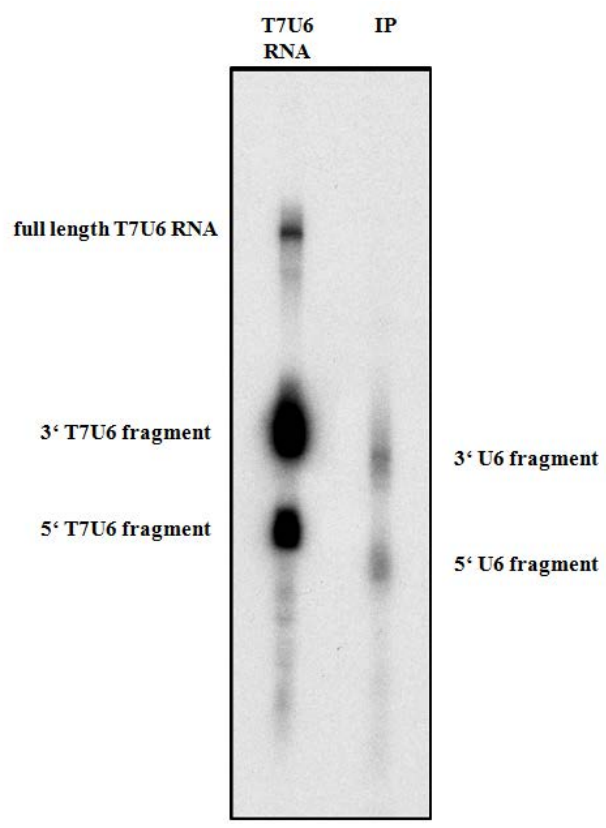

Figure 3.8: RNase $H$ cleavage and immunoprecipitation of Cwc2-TAP after UV crosslinking of the spliceosomal C complex

Digestion of U6 snRNA after DNA oligonucleotide-directed RNase H cleavage of in vitro transcribed U6 snRNA (lane 1) and U6 snRNA from purified C complexes after crosslinking and immunoprecipitation with Cwc2 (lane 2). Note that the T7U6 RNA transcript contains additional nucleotides at the 3' and 5' ends.

In all three complexes, a strong reverse transcriptase stop was observed at U6 snRNA nucleotide G39 (located just upstream of the U6 ACAGAGA box), four weaker stops at nucleotides U65-C68 (in the stem of the U6-ISL), and one at U74 (in the loop of the U6ISL)(see below for a summary). All of them were dependent on UV irradiation of spliceosomes (lanes 6-9 in Figure 3.5, Figure 3.6 and Figure 3.7) and were not observed after UV irradiation of in vitro transcribed U6 snRNA (lanes 10 and 11). All of these spliceosome-dependent reverse transcriptase stops were observed exclusively when crosslinked TAP-Cwc2-RNA species were specifically precipitated with IgG Sepharose under denaturing conditions, indicating that the protein contacting these nucleotides in native 
$\mathrm{B}^{\text {act }}$ complexes was indeed Cwc2 (lanes 6 and 7, Figure 3.5). While the Cwc2 crosslink to G39 appeared to be equally strong in all three complexes, there were differences in the intensity of the weaker stops. In the C complex, significant stops were observed at nucleotides U65, C68, and U74 but not at nucleotides C66 and C67, while in complex B* the stops at nucleotides U65, C68, and U74 were less intense than in complex C. These minor differences observed in crosslinks in the loop and stem of the U6-ISL, suggest changes in the interaction between Cwc2 and the ISL during the catalytic phase of the spliceosome cycle, which could in turn suggest the possibility of conformational changes in the ISL at this stage of splicing. The signals from nucleotides C85 to A90 were seen in the RNP samples (lanes 7 and 9) and also in UV irradiated in vitro transcribed U6 snRNA (lane 11), indicating that these were reverse transcriptase stops due to RNA-RNA crosslinks between adjacent nucleotides or, alternatively, UV induced RNA damage.

To obtain additional, independent experimental evidence that the crosslinks detected to the U6-ISL in the C complex were due to Cwc2 and not to a different protein, the purified crosslinked TAP-Cwc2-U6 RNA species was specifically cut into two pieces by oligodirected RNase H cleavage (Figure 3.8). RNase H is a non specific endonuclease, catalyzing the cleavage of RNA within an RNA- DNA duplex. For this purpose a DNA oligonucleotide was used that hybridized to nucleotides 42-61 of U6 snRNA. The sample was incubated with IgG Sepharose, allowing the selective immunoprecipitation of the 5' and/or the 3' portion of U6 snRNA (e.g., containing the U6-ISL) crosslinked to Cwc2-TAP. Co-precipitated RNAs were identified by Northern blotting using a probe that hybridizes to U6 snRNA. This experiment showed that both portions of U6 snRNA were precipitated, thereby demonstrating that the crosslinking sites detected in the U6-ISL at the stage of C complex were due to Cwc2 (Figure 3.8).

The localization of Cwc2 crosslinks on the pre-mRNA was carried out in an identical manner as described for U6 snRNA above. Primer extension analysis revealed a crosslink of Cwc2 to U222 of the M3Act $\Delta 6$ pre-mRNA which corresponds to uridine +15 of the intron (Figure 3.9 lane 7). $U+15$ was assigned as crosslink to Cwc2 among the other stops appearing in the IP manly for the following reasons. First, compared to the other signals, $U+15$ is strongly enriched after the precipitation (compare the intensities of signals between lanes 7 and 9). While in the input lane the intensity of the signal at $U+16$ is equal to $U+15$ and the intensities at nucleotides $U+29$ and $U+30$ are much higher, within the IP lane the intensities of these signals drop significantly, whereas the signal for $U+15$ does not. Second, the signal 


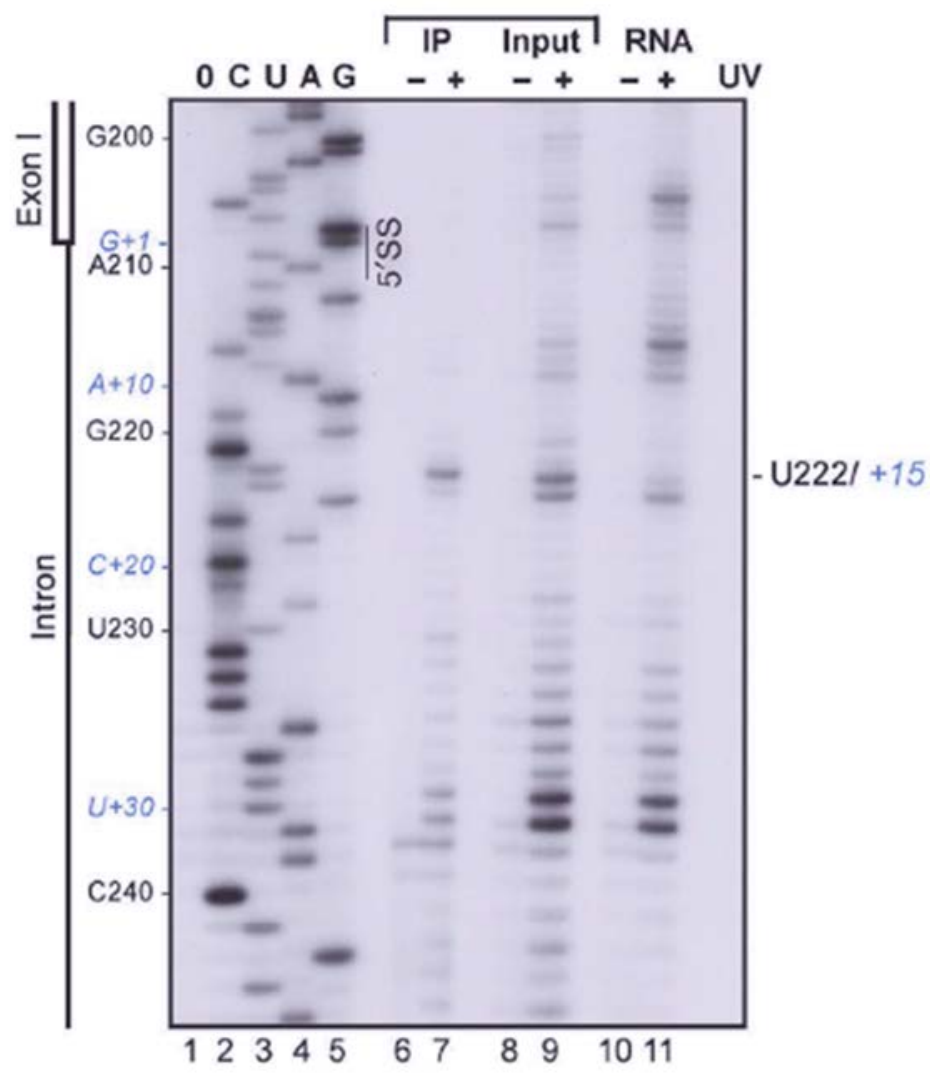

Figure 3.9: Cwc2 interacts with the pre-mRNA intron 15 nucleotides downstream of the 5'SS.

Primer-extension analysis of M3Act $\Delta 6$ pre-mRNA derived from UV irradiated $\mathrm{B}^{\text {act }}$ complex, after immunoprecipitation with IgG sepharose (IP, lane 7) or without immunoprecipitation (input, lane 9). Analysis of UV irradiated M3Act $\triangle 6$ RNA prepared by transcription in vitro (lane 11). The primer used was complementary to positions 254-269 of yeast M3Act $\Delta 6$ pre-mRNA. The reverse-transcriptase stop that is due to an RNA- Cwc2 crosslink is denoted on the right.

at this position within the RNA control (lane 11) is very weak compared to the RNP samples, an indication of a stop caused by crosslinked protein. Third, no signals are observed after the stop at $U+15$. If the pre-mRNA is precipitated via a crosslink of $U+15$ to Cwc2, all bound pre-mRNA will contain this crosslink since the non-crosslinked RNA is washed away. Therefore, the reverse transcriptase can never read through this nucleotide, while this is possible within the input (lane 9). Generally, during primer extension analysis of UV irradiated pre-mRNA a high background was observed, which was due to those additional signals.

The crosslinking results are summarized in Figure 3.10 for $\mathrm{B}^{\text {act }}$ and $\mathrm{C}$ complexes, in the context of the U6/U2/pre-mRNA interaction network proposed for the catalytic center. The existence of crosslinks between Cwc2 and U6 G39, on the one hand, and between Cwc2 and $\mathrm{U}+15$ of the pre-mRNA intron, on the other hand, suggests that these two nucleotides 

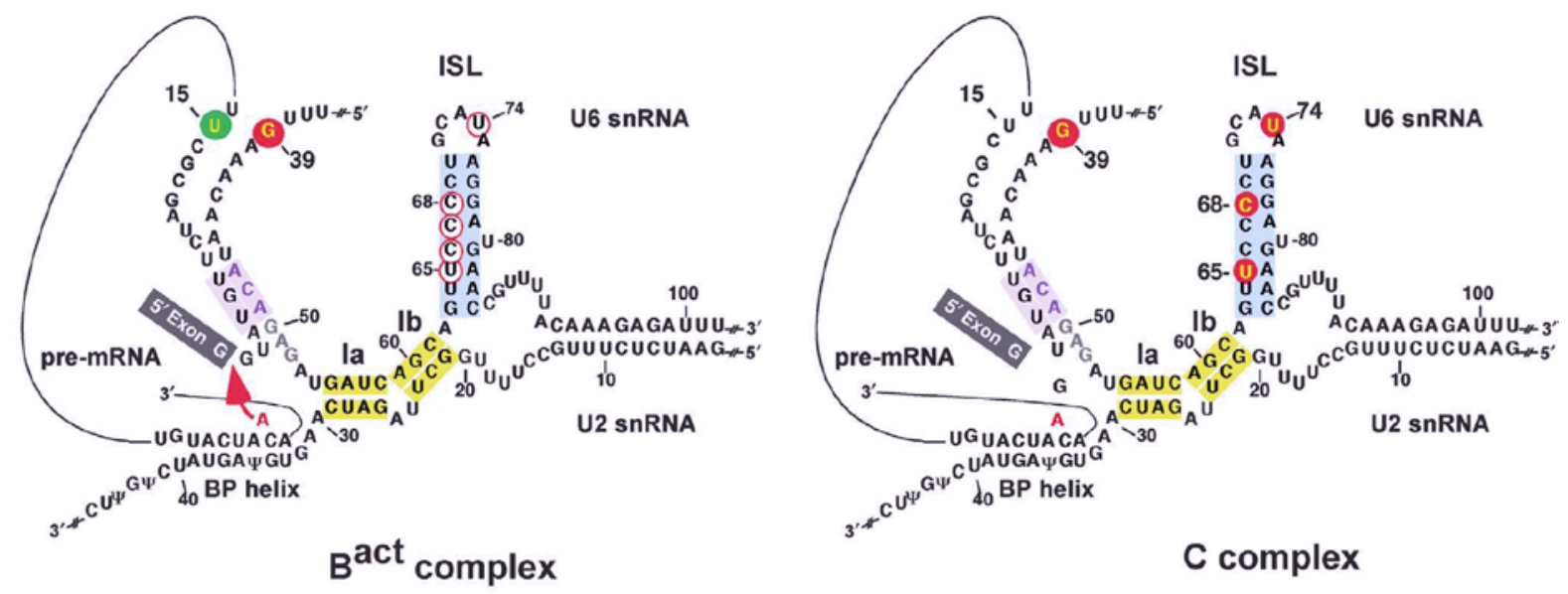

Figure 3.10: Crosslinks of $C w c 2$ in yeast $B^{\text {act }}$ and $C$ complexes

Secondary-structure models of U2/U6/pre-mRNA before ( $\mathrm{B}^{\text {act }}$ complex) and after (C complex) step 1 of splicing according to Madhani and Guthrie (1992). The attack of the branchpoint adenosine at the 5' SS is indicated by an arrow in the $\mathrm{B}^{\text {act }}$ complex. Sites in U6 snRNA crosslinked to Cwc2 are indicated by red circles, open circles indicate weak, and closed circles indicate strong crosslinks, respectively. Green circle: site in the pre-mRNA intron crosslinked to Cwc2.

simultaneously contact Cwc2, and thus are in close proximity in the spliceosome. As Cwc2 also contacts the U6 ISL, one possible function of Cwc2 might be to orient and/or juxtapose the ISL region of U6 snRNA and the ACAGAGA/5' SS RNA element (see Discussion).

\subsection{Structure probing of native and Cwc2-depleted $B^{\text {act }}$ complexes}

The UV crosslinking experiments described above provide important information about the interaction sites of Cwc2 on U6 snRNA and the pre-mRNA. To get a better understanding of the whole interaction surface of Cwc2 within the spliceosomal RNA network, additionally, structure probing experiments were performed in cooperation with Dr. Olexandr Dybkov (Department of Cellular Biochemistry, MPI-BPC). During the course of these experiments, the reactivity of U6 snRNA within native spliceosomal complexes towards dimethylsulfate (DMS) and 1-cyclohexyl-3- (2- morpholinoethyl) carbodiimide metho-p-toluene sulfonate (CMCT) was assessed. For this purpose, purified $\mathrm{B}^{\text {act }}$ complexes either containing Cwc2, depleted of Cwc2 or depleted and supplemented with recombinant Cwc2, where treated with the probing chemicals. The extracted U6 snRNA was subsequently analyzed by primer 


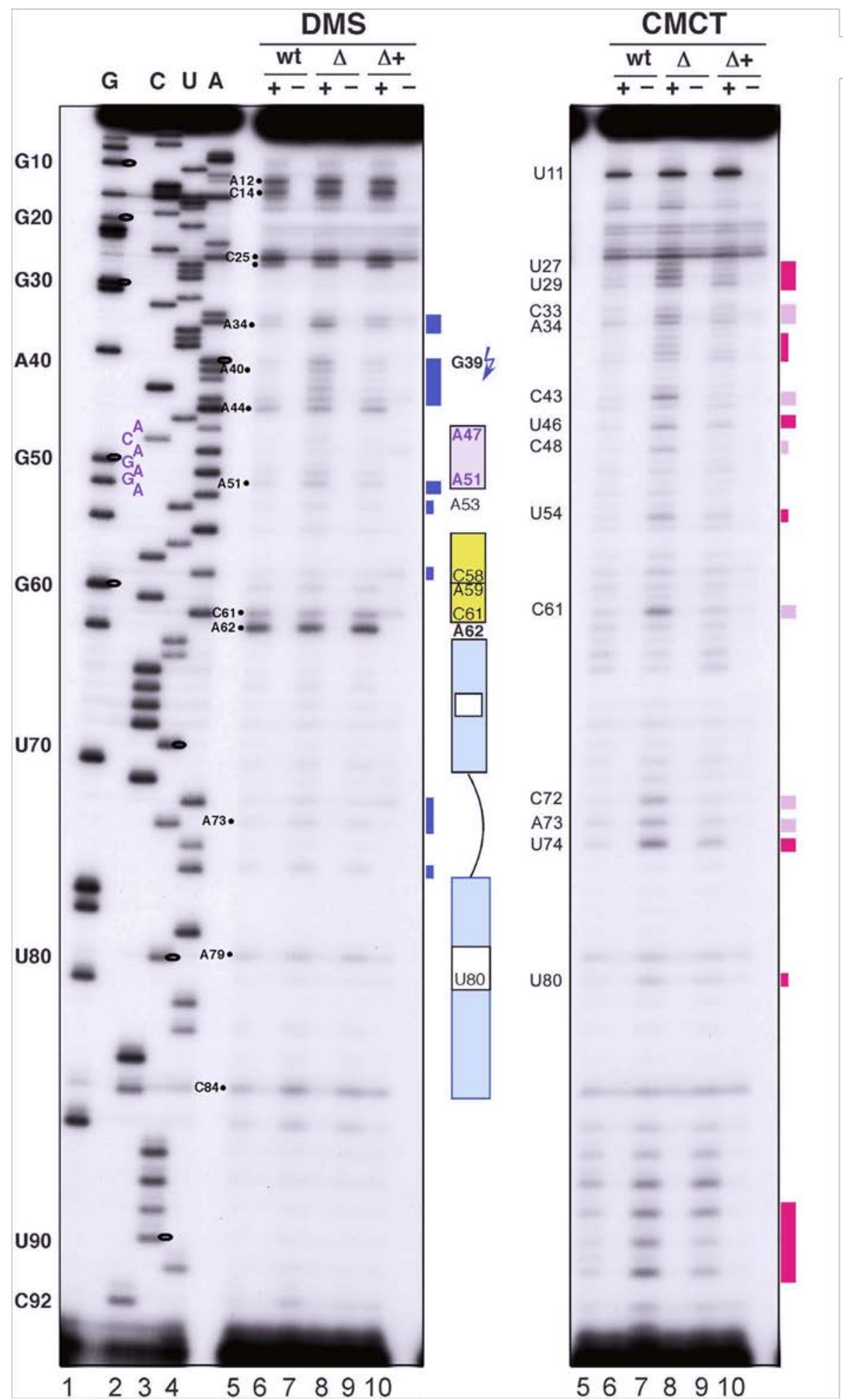

Figure 3.11 Structure probing in native and $\Delta \mathrm{Cwc} 2 \mathrm{~B}^{\text {act }}$ complexes.

Structure probing with DMS and CMCT. Lanes 5 and 6 (wt) 'wild-type' $\mathrm{B}^{\text {act }}$ complex, lanes 7 and $8(\Delta) \mathrm{B}^{\text {act }}$ complex assembled in $\Delta$ Cwc2 extract, and lanes 9 and $10(\Delta+) \mathrm{B}^{\text {act }}$ complex assembled in $\Delta$ Cwc2 extract supplemented with $1 \mu \mathrm{M}$ recombinant Cwc2. In lanes 5,7 , and 9 ('+'), the reaction mixture was complete, while in lanes 6,8 , and 10 ('-'), the chemical reagent was omitted. G, C, U, A are sequencing ladders. The arrow indicates the U6 snRNA G39 nucleotide crosslinked to Cwc2. The positions of protected nucleotides in native purified complexes are shown on the right with blue stripes for DMS and red stripes for CMCT. Pink stripes indicate cytidine and adenosine residues unusually modified by CMCT. 


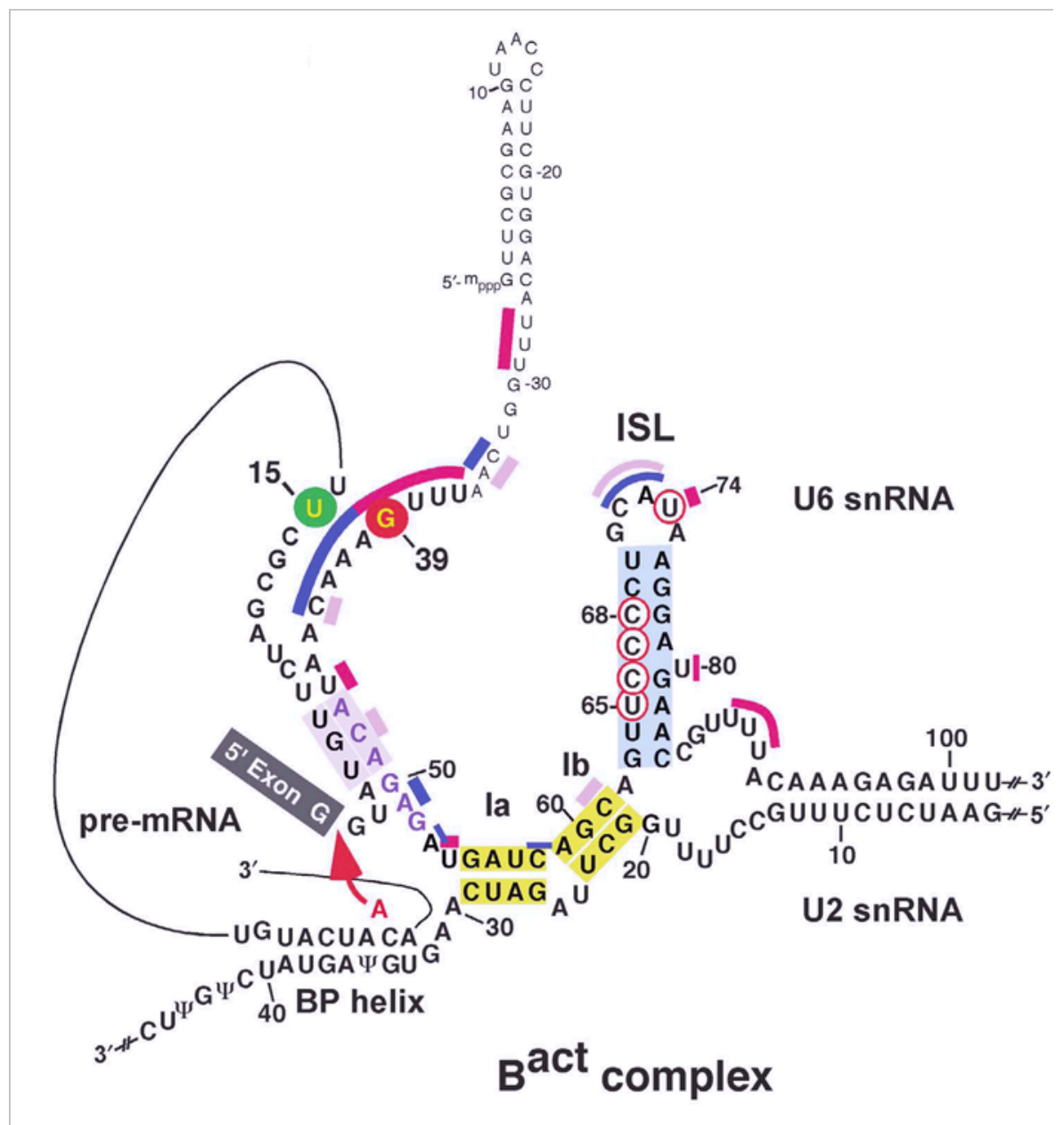

Figure 3.12: Summary of the results obtained from structure probing in native and $\Delta \mathrm{Cwc} 2 \mathrm{~B}^{\text {act }}$ complexes

Secondary-structure model of U2/U6/pre-mRNA before step 1 of splicing. The attack of the branch point adenosine at the 5' SS is indicated by an arrow. Bases in U6 snRNA protected from modifications towards DMS and CMCT, respectively, in the presence of Cwc2, are represented by blue, red, and pink stripes superimposed on the secondary-structure models of the U6 snRNA. U6 snRNA crosslinks to Cwc2 are indicated by red circles, open circles indicate weak, and closed circles indicate strong crosslinks, respectively. Green circle: site in the pre-mRNA intron crosslinked to Cwc2.

extension. At a neutral $\mathrm{pH}$, DMS primarily reacts with for Watson-Crick base pairing relevant positions of adenosine and cytidine, while CMCT on the other hand, at $\mathrm{pH} 8.0$, primarily modifies uridine and guanine (Ehresmann et al, 1987). Under the buffer conditions used here, however, CMCT also modified to some extent adenosine and cytidine.

In native $\mathrm{B}^{\text {act }}$ complexes, only a few nucleotides of the U6 snRNA were highly accessible towards modifications by DMS and CMCT (Figure 3.11 lanes 5). In case of DMS, these nucleotides were located primarily in the loop of the 5' stem-loop (i.e., A12 and C14) and the regions around nucleotides C25 and A62, the latter one connecting U6/U2 helix Ib with the 
U6-ISL. The strongest signals observed for CMCT were at U11, which is located in the loop of the 5' stem-loop as well, and signals in the region between nucleotides C16 and A26. Importantly, the nucleotides flanking G39 and the loop of the U6-ISL, where the Cwc2 crosslinks were mapped, are poorly or not at all accessible (lane 5 in both panels). In contrast, both regions became heavily accessible to DMS as well as to CMCT when Cwc2 was not present in the complex (lanes 5 and 7 in both panels), indicating that Cwc2 does not only interact with the nucleotides found to be crosslinked, but also with the nucleotides surrounding them. Additional nucleotides of U6 snRNA that became more accessible in $\Delta \mathrm{Cwc} 2 \mathrm{~B}^{\text {act }}$ complexes compared to native $\mathrm{B}^{\text {act }}$ complexes include U80, the bulged out nucleotide within the U6-ISL coordinating a catalytically important $\mathrm{Mg}^{2+}$ ion, and several nucleotides within or flanking the ACAGAGA box such as U46, A51, U54 and nucleotides U88-U91 downstream of the U6-ISL (see Figure 3.12 for a summary of the U6 snRNA sequences that are protected in the presence of Cwc2). Importantly, the modification pattern of U6 snRNA in $\mathrm{B}^{\text {act }}$ complexes purified from Cwc2-depleted splicing extract which was supplemented with recombinant Cwc2 prior to spliceosome assembly, resembles closely the one observed with native purified $\mathrm{B}^{\text {act }}$ complexes (compare lane 9 with lanes 5 and 7 in both panels). This is particularly true for the regions around G39, the ACAGAGA box and the ISL loop and therefore indicates that the observed gain of accessibility in certain regions of U6 snRNA upon depletion of Cwc2 is really due to the lack of Cwc2.

Taken together with the crosslinking experiments these results clearly imply that within the $\mathrm{B}^{\text {act }}$ complex Cwc2 contacts the region upstream of the ACAGAGA box motif around G39 and the U6-ISL. The increased accessibility of the region around the ACAGAGA box towards DMS and CMCT in the absence of Cwc2 indicates that these might also be interaction sites of Cwc2 with U6 snRNA. On the other hand, it might well be that in the absence of Cwc2 this whole area is somehow destabilized since Cwc2 seems to be a major scaffolding factor reinforcing the catalytic center of the spliceosome.

\subsection{Cwc2 is essential for step 1 of splicing in vitro}

To gain a better understanding of the role of Cwc2 in pre-mRNA splicing, in vitro splicing was performed with standard yeast splicing extracts depleted of Cwc2 ( $\Delta$ Cwc2 extracts). For this purpose, a yeast strain was used (SC1887) expressing Cwc2 fused to the Tandem 
Affinity Purification tag (TAP-tag) at its C-terminus (Puig et al, 2001). Yeast extracts were incubated either with IgG Sepharose, or (for mock depletion) with Protein A Sepharose.
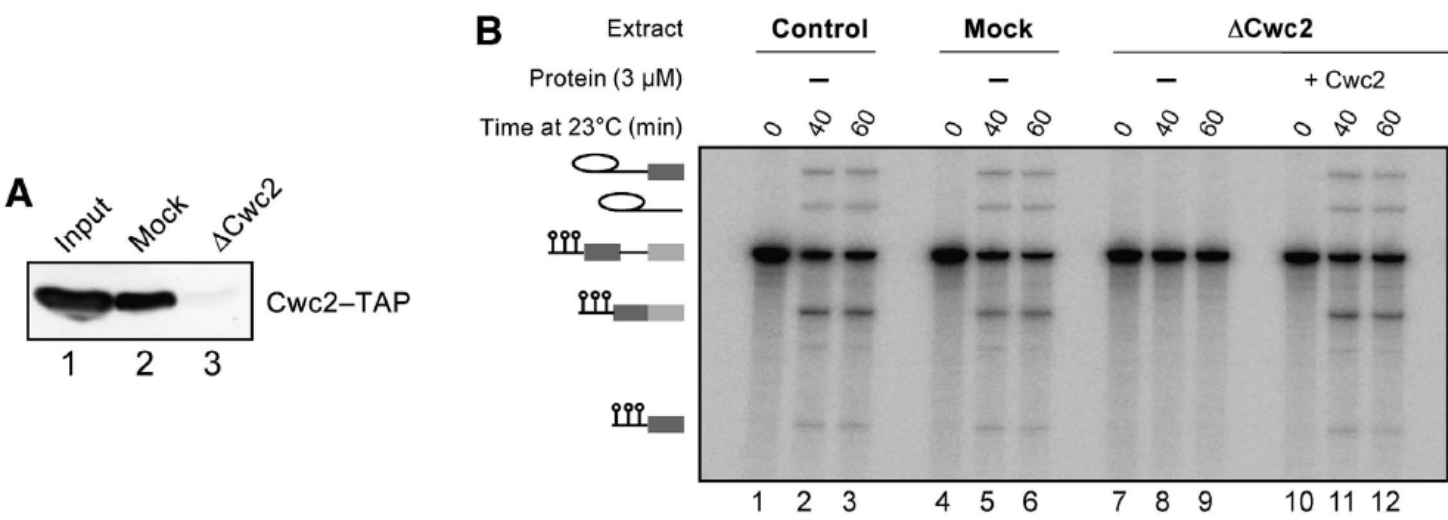

Figure 3.13 Cwc2 is essential for step 1 of splicing in vitro

(A) Western blot analysis of yeast splicing extracts carrying Cwc2 tagged with the TAP tag before (lanes 1 and 2) and after depletion of Cwc2 (lane 3). (B) A uniformly radiolabelled M3Act pre-mRNA was incubated in yeast whole-cell extract (lanes 1-3), either mock- (lanes 4-6) or Cwc2-depleted (lanes 7-12), under standard splicing conditions. Recombinant Cwc2 was added to a final concentration of $3 \mu \mathrm{M}$ (lanes 10-12). The splicing mixtures were incubated at $23{ }^{\circ} \mathrm{C}$ and stopped at the time indicated. RNA was analyzed on an $8 \%$ polyacrylamide gel and visualized by autoradiography. The pre-mRNAs, the splicing intermediates and products are indicated on the left.

Subsequently, Western blot analysis using the PAP complex (peroxidase anti-peroxidase complex), which recognizes the TAP-tag, demonstrated that Cwc2 was efficiently depleted from the extract, while it was still present in the mock treated extract (Figure 3.13A, compare lanes 2 and 3). Yeast extracts depleted of Cwc2 were then assayed for their ability to splice Actin WT pre-mRNA. As shown in Figure 3.13, the mock depleted extract (lanes 4-6) spliced with an efficiency comparable to that of the control (1-3), while no splicing products or intermediates were observed in the reactions where the $\Delta \mathrm{Cwc} 2$ extract was used. Since the depletion was performed under mild salt conditions (200 mM KCl, 2.2.3.3), it was important to prove that the observed effect on splicing was really due to the lack of Cwc2 and not caused by the co-depletion of some other factors, tightly interacting with Cwc2. Therefore, $\Delta$ Cwc2 extract was supplemented with recombinant Cwc2, expressed in E. coli and subsequently purified, to test for its ability to reconstitute the splicing activity of the depleted extract. Since the activity of $\Delta \mathrm{Cwc} 2$ extract (lanes 10-12) could be restored to a level comparable to that of the control extracts (lanes 1-6) by adding only recombinant Cwc2, it is evident that Cwc2 is essential for in vitro splicing. The purity of the recombinant protein was checked by SDS-PAGE and subsequent Coomassie staining (Figure 3.14:). 


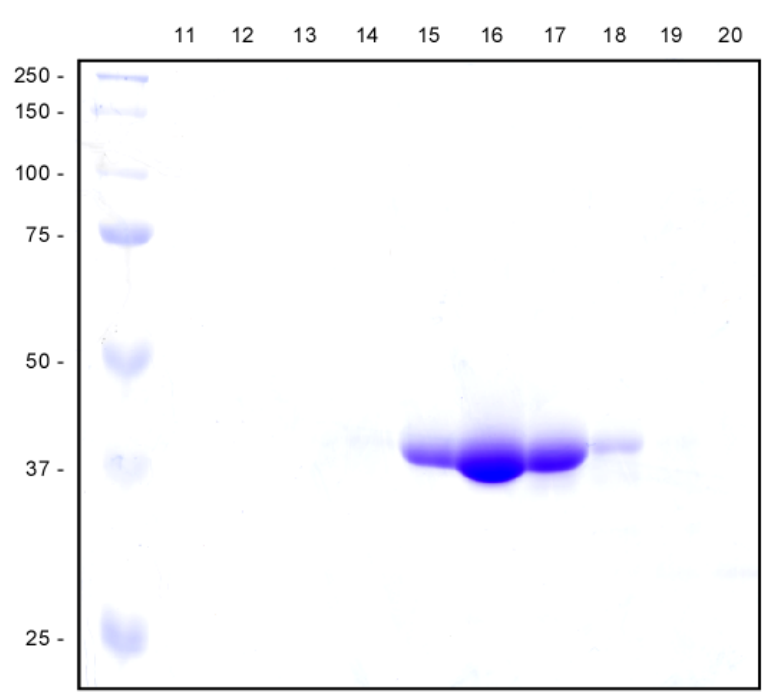

\section{Figure 3.14: Purification of recombinant Cwc2}

After overexpression, recombinant Cwc2 was purified from E. coli cell lysate by Ni-NTA affinity chromatography and subsequent size exclusion chromatography. Fractions eluted after size exclusion chromatography were loaded on a SDS-polyacrylamide gel and visualized by Coomassie-staining. Shown are fractions 11-20. Cwc2 usually was eluted in fractions 15-17.

Shown are analyzed aliquots taken from fractions collected after size exclusion chromatography. No significant impurities were detected and for the reconstitution assay only the peak fractions 16 and 17 were used. To assess the influence of the Cwc2 depletion on complex formation and to get further proof that no other spliceosomal factors were codepleted during the depletion, spliceosomal complexes lacking Cwc2 ( $\Delta$ Cwc2 $\mathrm{B}^{\text {act }}$ complexes) were purified and analyzed.

$\Delta \mathrm{Cwc} 2 \mathrm{~B}^{\text {act }}$ complexes were purified essentially as described above only that yeast cell extract depleted of Cwc2 ( $\Delta$ Cwc2 extract) was used for the in vitro assembly. In this way it was possible to obtain spliceosomal complexes stalled at the stage of the $\mathrm{B}^{\text {act }}$ complex, just prior to the first catalytic step, which showed a sedimentation behavior similar to native $\mathrm{B}^{\text {act }}$ complexes and also had the respective snRNAs stably integrated (see also 3.3). To analyze the impact of the Cwc2 depletion on the spliceosomal proteome, mass spectrometry analysis with $\triangle \mathrm{Cwc} 2 \mathrm{~B}^{\text {act }}$ and native $\mathrm{B}^{\text {act }}$ complexes was performed. Table 3.1 shows one representative result of such an analysis in form of a direct comparison between the peptide

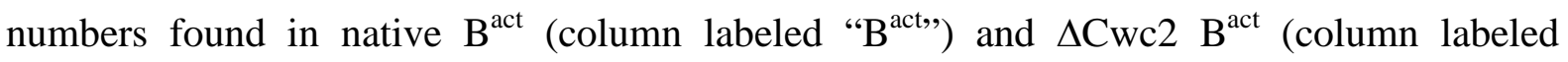
“ $\triangle$ Cwc2”) complexes, respectively. These data indicate that apart from the significantly 

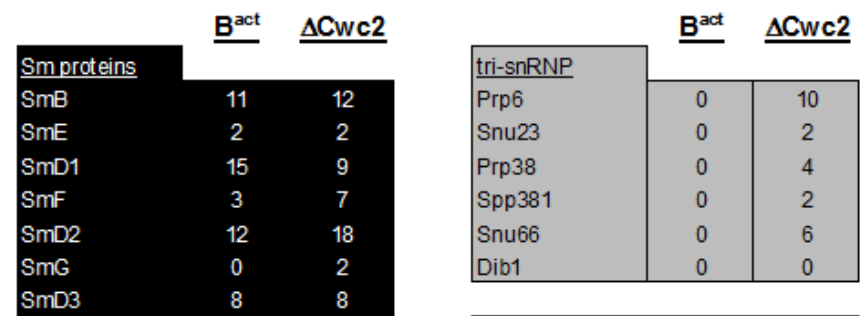

\begin{tabular}{|l|c|c|}
\multicolumn{1}{c}{} & \multicolumn{1}{c}{$\boldsymbol{B}^{\text {act }}$} & \multicolumn{1}{c|}{$\boldsymbol{\Delta C}$ wc2 } \\
\hline Yju2/Cwc16 & 11 & 7 \\
Cwc21 & 4 & 0 \\
Cwc22 & 28 & 26 \\
Cwc24 & 6 & 4 \\
Cwc27 & 3 & 11 \\
Cwc25 & 0 & 0 \\
Cwc23 & 0 & 0 \\
\hline
\end{tabular}

\begin{tabular}{|l|c|c|}
\hline U1 snRNP & \multicolumn{2}{|c|}{} \\
\cline { 2 - 3 } Snu71 & 0 & 9 \\
Prp40 & 0 & 4 \\
Prp39 & 4 & 10 \\
Prp42 & 0 & 7 \\
Snp1 & 0 & 2 \\
Luc7 & 0 & 0 \\
Nam8 & 0 & 0 \\
Mud1 & 0 & 0 \\
U1C & 0 & 0 \\
Snu56 & 0 & 4 \\
\hline
\end{tabular}

\begin{tabular}{|l|c|c|}
\hline U5 snRNP & \multicolumn{2}{|c|}{} \\
\cline { 2 - 3 } Prp8 & 105 & 202 \\
Brr2 & 108 & 163 \\
Snu114 & 76 & 68 \\
\hline
\end{tabular}

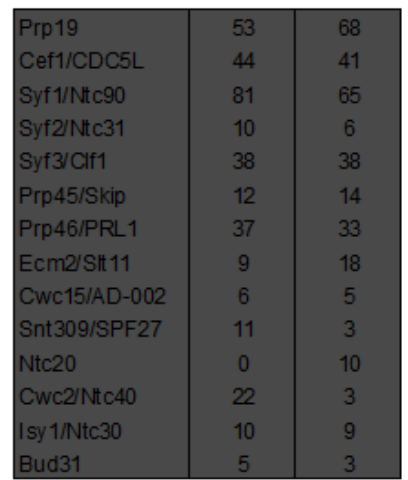

\begin{tabular}{|l|c|c|}
\hline U2 snRNP & \multicolumn{2}{|c}{} \\
\cline { 3 - 3 } Rse1 & 91 & 96 \\
Lea1 & 10 & 9 \\
Cus1 & 19 & 29 \\
Hsh49 & 11 & 6 \\
Hsh155 & 43 & 47 \\
Ysf3 & 0 & 3 \\
Rds3 & 6 & 0 \\
Msl1 & 8 & 5 \\
Prp43 & 0 & 2 \\
\hline
\end{tabular}
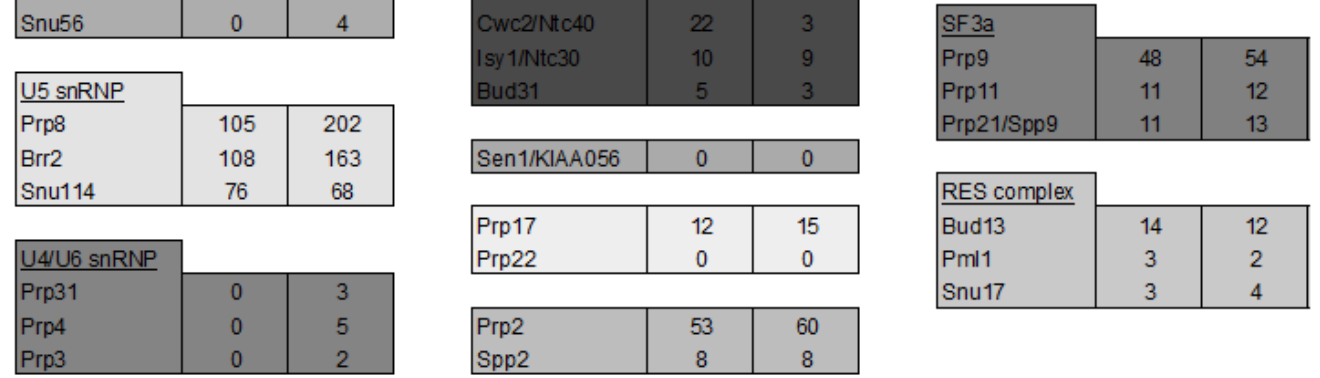

\begin{tabular}{|l|l|l|}
\hline Lsm proteins & \multicolumn{2}{|c}{} \\
\cline { 3 - 3 } Lsm4 & 0 & 0 \\
LsmR & 0 & 0 \\
Lsm8 & 0 & 0 \\
Lsm7 & 0 & 0 \\
Lsm6 & 0 & 0 \\
Lsm6 & 0 & 0 \\
\hline
\end{tabular}

\section{Table 3.1: MS analysis of native $\mathrm{B}^{\text {act }}$ and $\Delta \mathrm{Cwc2} \mathrm{B}^{\text {act }}$ complexes}

Proteins were separated by SDS-PAGE and stained with Coomassie. Each lane of the gel cut into 23 slices and proteins therein were digested with trypsin. The received peptides were extracted and then analyzed by LCMS/MS. The absolute number of peptides sequenced is shown for each identified protein

reduced amounts of Cwc2, the protein composition of $\Delta \mathrm{Cwc} 2 \mathrm{~B}^{\text {act }}$ complexes is qualitatively identical to that of the native $\mathrm{B}^{\text {act }}$ complexes. 


\subsection{Cwc2 is not required for the activation of the spliceosome or for its remodelling by Prp2}

It was previously shown that Cwc2 is recruited to the spliceosome during its activation step, i.e. during the transition from complex B to $\mathrm{B}^{\text {act }}$, when $\mathrm{U} 1$ and $\mathrm{U} 4$ snRNAs are dissociated. Therefore, it was investigated whether Cwc2 is required for this transition. To monitor this transition, the fact was exploited that complex B has a Svedberg (S) value of 40, while complex $\mathrm{B}^{\text {act }}$ to which it is transformed, has an $\mathrm{S}$ value of 45 (see also Figure 3.15 and Fabrizio et al (2009)). For this experiment a yeast strain was used containing a temperaturesensitive Prp2 helicase (prp2-1) and also expressing Cwc2 with a C-terminal TAP tag (strain YNR1). Splicing extracts of these cells were depleted of endogenous Cwc2 (2.2.3.3), and the mutated Prp2 was heat inactivated prior to the in vitro splicing reaction by 30 min incubation at $35^{\circ} \mathrm{C}$. The heat inactivation was necessary to block spliceosome assembly at the $\mathrm{B}^{\text {act }}$ stage (i.e. $\mathrm{B}^{\text {act } \triangle \mathrm{Prp} 2}$ complex). Splicing was then initiated by adding ${ }^{32} \mathrm{P}$-labelled Actin WT premRNA that carried three MS2 RNA aptamers at its 5'end (M3Act pre-mRNA) and the splicing reaction was further incubated for $50 \mathrm{~min}$ at $23^{\circ} \mathrm{C}$. The resulting spliceosomal complexes were purified via glycerol gradient centrifugation and MS2-MBP-based affinity chromatography (Fabrizio et al (2009), Warkocki et al (2009)) and subsequently examined by analytical ultracentrifugation in a second glycerol gradient. Figure 3.15 shows that most of the purified complex $\Delta \mathrm{CwC} 2 \mathrm{~B}^{\mathrm{act} \Delta \operatorname{Prp} 2}$ had an $\mathrm{S}$ value of about 45 . A parallel experiment using Cwc2 mock-depleted splicing extracts, but otherwise identical to the first, gave a very similar result (Figure 3.15, $\mathrm{B}^{\text {act } \Delta \mathrm{Prp} 2}$ ). These results imply that the transition from complex B (40S) to $\mathrm{B}^{\text {act }}$ (45S) took place in both cases, implying that Cwc2 is not required for this process. This inference is supported by an RNA analysis of the isolated spliceosomal complexes (Figure 3.16A): while 40S B complexes contain, as expected, all of the snRNPs U1, U2, U4, U5 and U6 in similar molar quantities (lane 1), the 45S spliceosomal complexes assembled in $\Delta \mathrm{CwC} 2$ splicing extracts show only small quantities of U1 and U4 snRNAs, while U2, U5 and U6 snRNAs are represented in quantities similarly to those found in the B complex, confirming the identity of the $45 \mathrm{~S}$ particles as $\mathrm{B}^{\text {act }}$ (lane 2 compare with lane 3 ).

These results further show that Cwc2, apart from being not needed for the activation of the spliceosome, is also not needed for the stable integration of the U5 and U6 snRNAs into the spliceosome during the $\mathrm{B}$ to $\mathrm{B}^{\text {act }}$ transition. Thus, Cwc2 clearly has a function distinct from that of the core NTC complex. It was previously shown that Prp2 triggers a major remodeling 


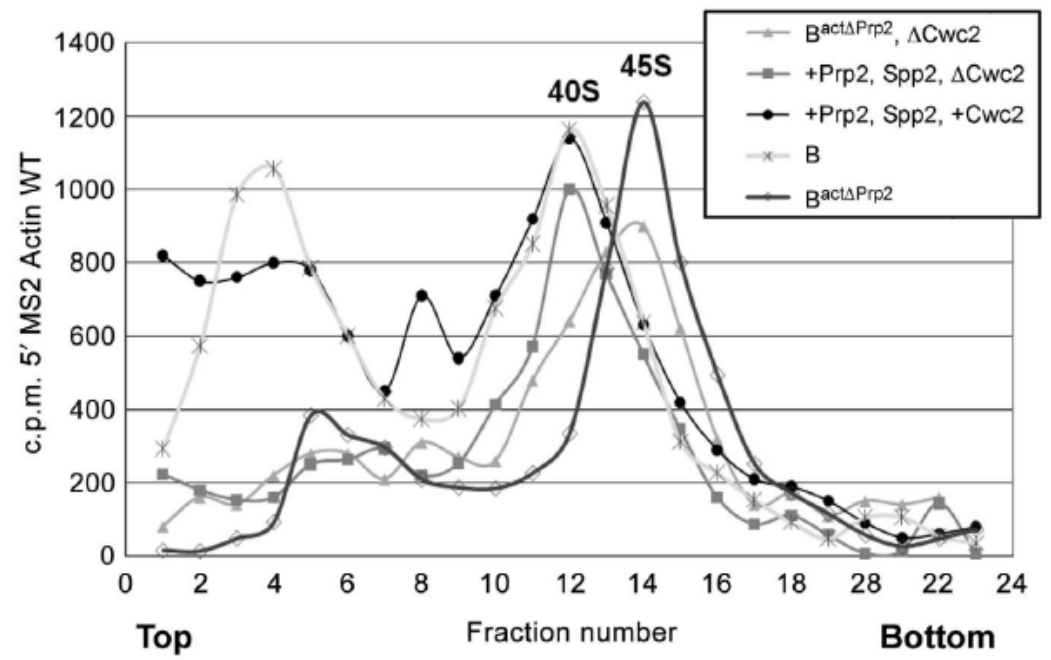

Figure 3.15: Cwc2 is not required for the Prp2-mediated remodelling step

Profiles of affinity-purified $\mathrm{B}^{\text {act }}$ spliceosomes depleted of Cwc2 (B $\left.{ }^{\text {act }} \Delta \mathrm{Cwc} 2\right), \mathrm{B}^{\text {act } \Delta \mathrm{Prp} 2} \Delta \mathrm{Cwc} 2$ spliceosomes after incubation with Prp2/Spp2/ATP (+Prp2, Spp2 $\Delta$ Cwc2) and after incubation with Prp2/Spp2/ATP plus recombinant Cwc2 (+Prp2, Spp2 + Cwc2). Profiles of purified B complexes and $\mathrm{B}^{\text {act } \Delta \mathrm{Prp} 2}$ spliceosomes mockdepleted of Cwc2 are also shown. Spliceosomes were separated on a glycerol gradient containing $75 \mathrm{mM}$ $\mathrm{KCl}$. The radioactivity contained in each gradient fraction was determined by Cherenkov counting. Sedimentation coefficients were determined by comparison with the UV absorbance profile of a reference gradient containing prokaryotic ribosomal subunits.

of the activated spliceosome in an ATP-dependent step as a prerequisite for catalytic activation of the spliceosome (i.e., transition from the $\mathrm{B}^{\text {act }}$ to $\mathrm{B}^{*}$ complex). This remodelling step results in a decrease in the $S$ value of the spliceosome from $45 \mathrm{~S}\left(\mathrm{~B}^{\text {act }}\right)$ to $40 \mathrm{~S}\left(\mathrm{~B}^{*}\right)$, a process which also involves the destabilization of the interaction of the U2 SF3a and SF3b proteins (Kim and Lin (1996); Warkocki et al (2009)). To investigate whether Cwc2 is involved in this Prp2- mediated remodeling step, we incubated affinity-purified 45S $\Delta \mathrm{Cwc} 2$ $\mathrm{B}^{\text {act } \Delta \operatorname{Prp} 2}$ spliceosomes with Prp2, Spp2, and ATP for $30 \mathrm{~min}$ at $23^{\circ} \mathrm{C}$ and then analyzed their sedimentation behavior in a glycerol gradient. Figure 3.15 shows that the majority of these spliceosomes now sediment with an S value of $\sim 40 \mathrm{~S}$ (+Prp2, +Spp2, $\Delta \mathrm{Cwc} 2)$. Thus, efficient ATP-dependent Prp2 remodeling of the spliceosome can also occur in the absence of Cwc2. While the Prp2-remodelled $\Delta$ Cwc2 B $^{\text {act }}$ complex (+Prp2, +Spp2, $\Delta$ Cwc2) exhibits a similar S value as a wild-type $\mathrm{B}^{*}$ complex, it is catalytically inactive. This was shown by the following experiment (Figure 3.16A). Affinity-purified 45S $\Delta \mathrm{Cwc} 2 \mathrm{~B}^{\text {act } \Delta \mathrm{Prp} 2}$ spliceosomes were incubated with Prp2, Spp2, ATP, and Cwc25 for 45 min at $23^{\circ} \mathrm{C}$ (lane 7). As a control, the 

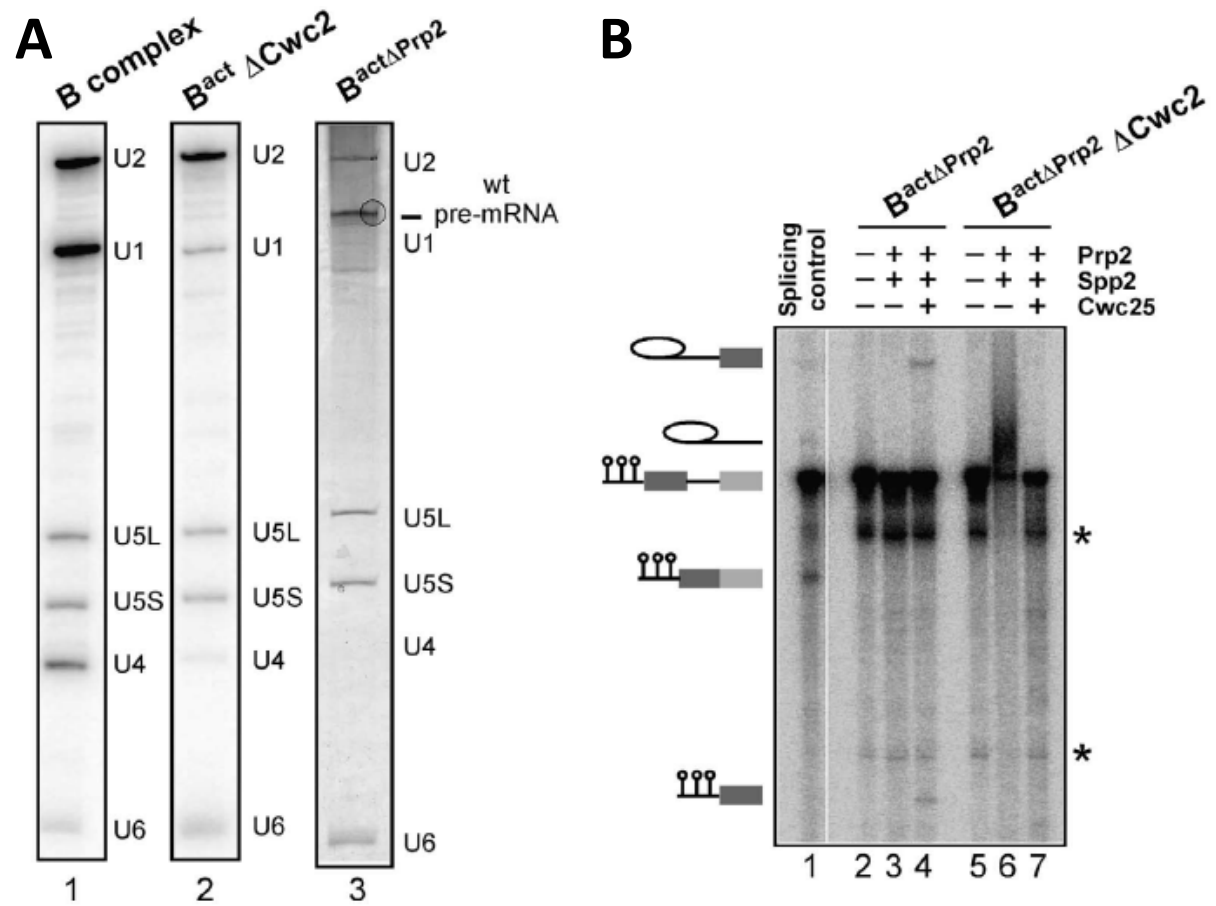

Figure 3.16:

(A) RNAs isolated from the $\mathrm{B}$ and the $\Delta \mathrm{Cwc} 2 \mathrm{~B}^{\text {act }}$ complex (lanes 1 and 2) were visualized by northern blot analysis. Lane 3, RNAs isolated from complex $\mathrm{B}^{\text {act } \triangle \mathrm{P} \text { rp2 }}$ (visualized by silver staining). RNA identities are indicated on the right. (B) Affinity-purified $B^{\text {act } \triangle P r p 2}$ spliceosomes mock-depleted of Cwc2 (lane 4) and $\triangle \mathrm{Cwc} 2$ $\mathrm{B}^{\text {act } \Delta \mathrm{Prp2}}$ spliceosomes were incubated with Prp2, Spp2, ATP, and Cwc25 for 45 min at $23^{\circ} \mathrm{C}$ (lane 7).

Asterisks: uncharacterized pre-mRNA-derived bands.

same experiment was carried out except that purified $45 \mathrm{~S} \mathrm{~B}^{\text {act } \Delta \operatorname{Prp} 2}$ spliceosomes were Cwc2 mock-depleted (lane 4). Only the Cwc2 containing spliceosomes were capable of carrying out catalytic step 1 of splicing (lane 4 ), while $\Delta \mathrm{Cwc} 2 \mathrm{~B}^{\mathrm{act}}$ spliceosomes were catalytically inactive (lane 7), despite the fact that they can undergo the Prp2 mediated remodeling step.

\subsection{Cwc2 contains three potential RNA binding sites}

To gain a better understanding of how Cwc2 might be capable of interacting with several distinct RNA elements within the spliceosome and possibly even bring and hold them in close proximity to each other, mutational studies on Cwc2 have been performed in collaboration with Dr. Jana Schmitzová (Macromolecular Crystallography Group, MPIBPC). 


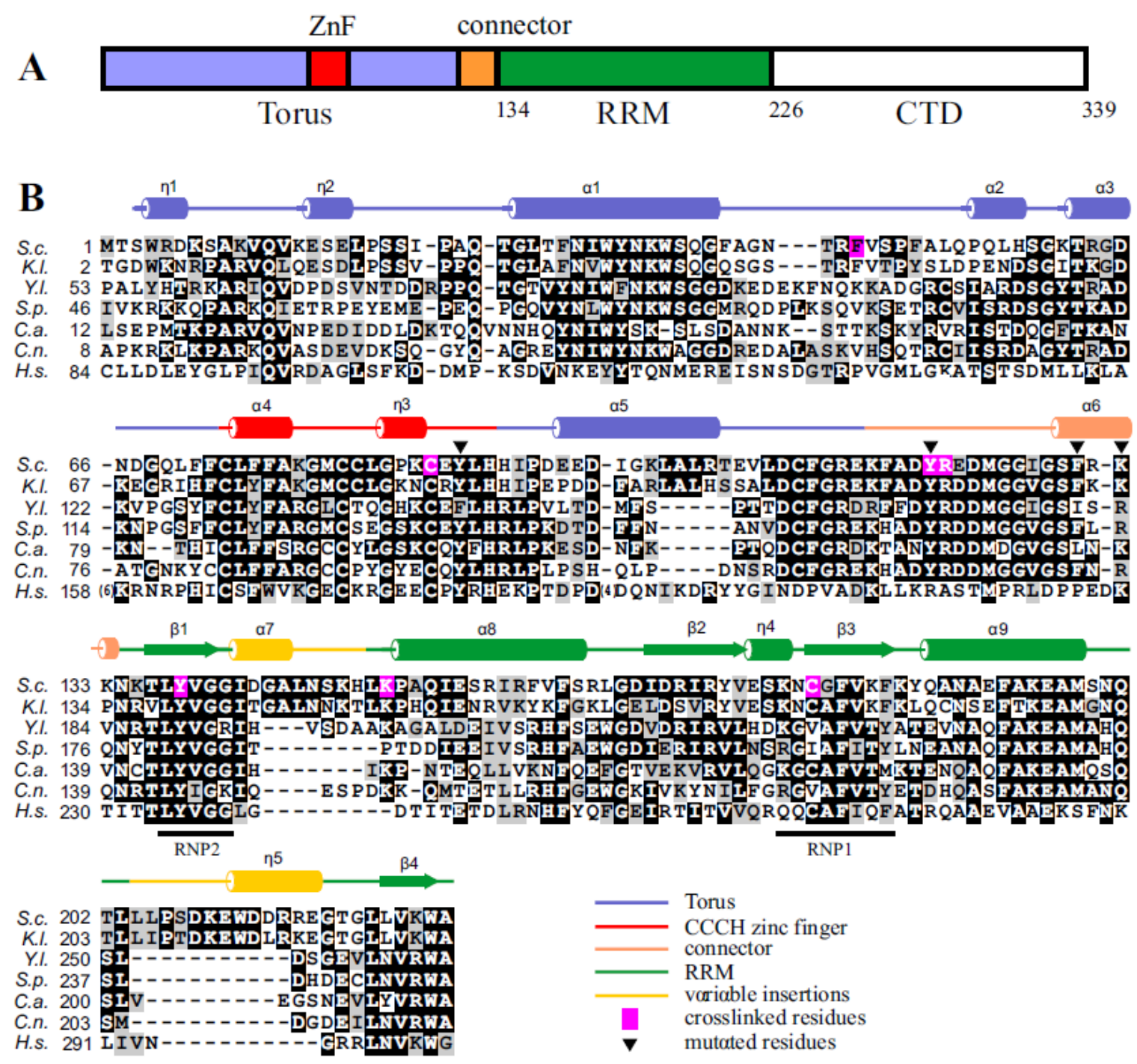

Figure 3.17: Domain structure and sequence alignment of Cwc2 (adapted from Schmitzova et al (2012)).

(A) Schematic representation of domains and structural motifs in Cwc2. (B) Multiple sequence alignment of Cwc2 orthologs. S.c - Saccharomyces cerevisiae; K.l - Kluyveromyces lactis; Y.l - Yarrowia lipolytica; S.p Schizosaccharomyces pombe; C.a - Candida albicans; C.n - Cryptococcus neoformans; H.s. - Homo sapiens. Darker background corresponds to higher sequence conservation. Icons above indicate secondary structure elements from the Cwc2 crystal structure. Magenta background corresponds to the RNA-crosslink sites. The triangles indicate positions of the point mutations tested in complementation assays.

Recent high resolution crystal structures and sequence homology analysis have shown that Cwc2 consists of a conserved CCCH-type ZnF (zinc finger) and a conserved RRM (RNA recognition motif), both domains linked by a connector loop (Lu et al (2012); Schmitzova et al (2012), see also Figure 3.17). Cwc2 also contains an intrinsically disordered region at its C-terminus which has been described before as the interaction surface of Cwc2 with Prp19 (Ohi and Gould (2002), Vander Kooi et al (2010)). While the RRM and the ZnF were obvious candidates for possible RNA recognition sites on Cwc2 also the connector loop was 
considered to be involved in RNA interactions because it consists of a stretch of at least eight positively charged amino acids exposed to the solvent (Lu et al (2012),Schmitzova et al (2012)). To investigate the functional significance of these selected structural elements, point and truncation mutants of Cwc2 were expressed in E.coli and purified to homogeneity and their activity was analyzed by in vitro splicing.
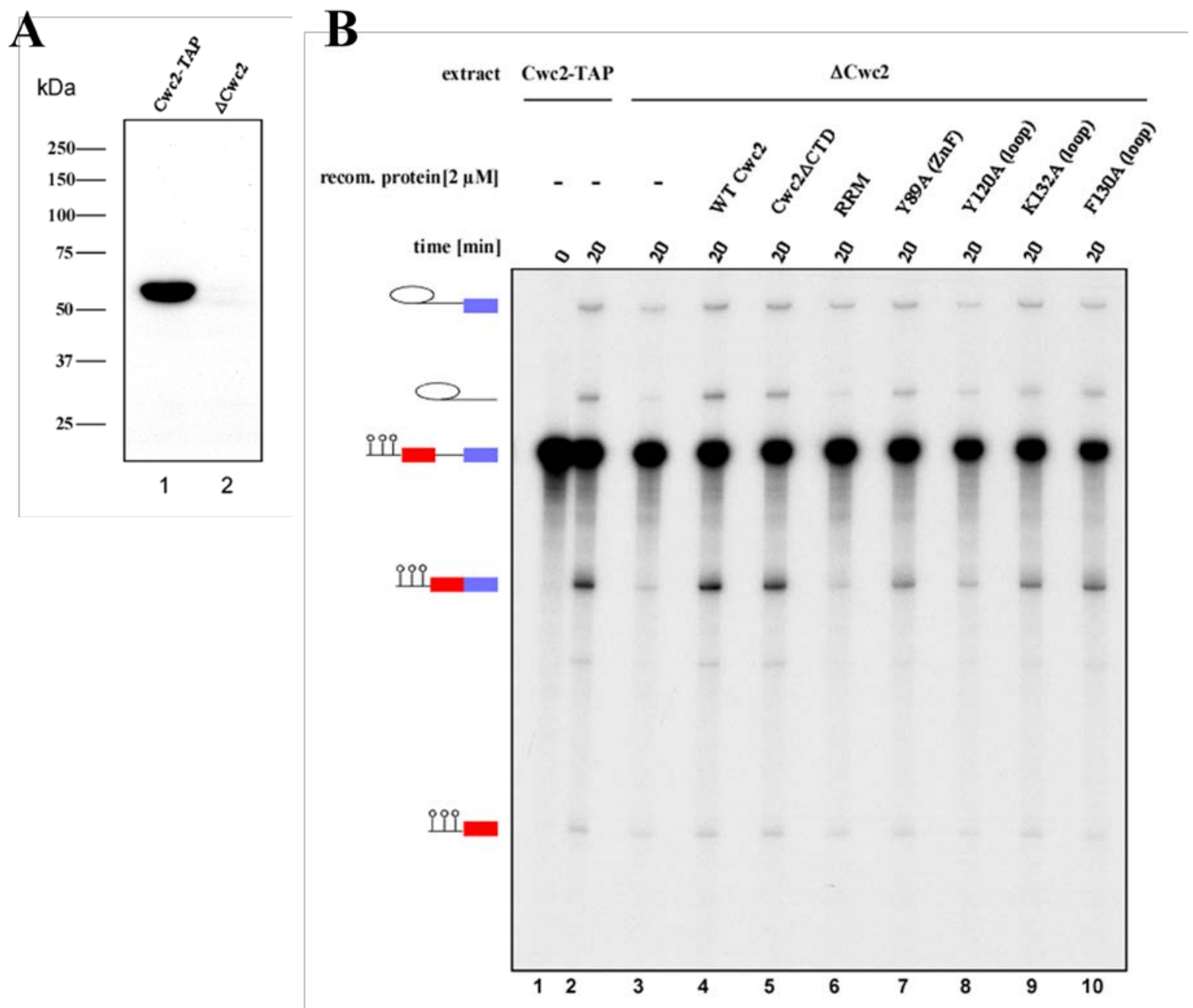

Figure 3.18: Effects of Cwc2 mutagenesis on its splicing activity.

(A) Western blot analysis of yeast splicing extracts carrying TAP-tagged Cwc2 before depletion (lane 1) and after depletion of Cwc2 (lane 2). (B) Uniformly radiolabelled M3-ActWT pre-mRNA (0.4 nM) was incubated in 20\% yeast whole-cell extract, which was either mock- (lanes 1,2) or Cwc2-depleted (lanes 3-10), under standard splicing conditions. Recombinant WT Cwc2 and mutant proteins indicated above each lane, were then added to a final concentration of $2 \mu \mathrm{M}$ (lanes 4-10). The splicing reactions were incubated at $23^{\circ} \mathrm{C}$ for the indicated time points. RNA was analyzed on an $8 \%$ urea-polyacrylamide gel and visualized by autoradiography. The positions of the pre-mRNA, the splicing intermediates and products are indicated on the left. The intensities of the mRNA product signals were quantified using Quantity One. The signal of the Cwc2TAP extract (lane 2) was used as $100 \%$, and relative to it the amount of mRNA produced was calculated. $\Delta$ Cwc2 extract shows a residual level of mRNA of $16 \%$ (lane3) compared to $109 \%$ for $\Delta$ Cwc2 extract supplemented with WT Cwc2 (lane 4), 97\% with Cwc2 $\Delta$ C (lane 5), 16\% with RRM (lane 6), 50\% with Y89A (lane 7), 21\% with Y120A (lane 8), 58\% with K132A (lane 9) and 69\% with F130A (lane 10). 
First, it was determined whether individual domains of Cwc2 alone were able to complement yeast extract depleted of Cwc2. Unfortunately, it was not possible to obtain a soluble fragment of Cwc2 spanning only the ZnF-Torus module. The RRM domain (residues 124234) on the other hand could be expressed and purified, but it did not have any impact on the splicing activity (Figure 3.18, lane 6). The Cwc2 structure, and crosslinking experiments of binary U6 snRNA-Cwc2 complexes formed in vitro, show that the two RNP motifs of the RRM are exposed to the solvent and able to bind RNA (Schmitzova et al, 2012).

According to McGrail et al (2009), however, single-point mutations in amino acids Y138 and F183 (both of which are located in the RNP2 and RNP1 motifs of Cwc2, respectively) are not lethal. These results imply that the binding of RNA to the Cwc2-RRM is complex in nature and may involve cooperation with neighbouring regions of Cwc2. For this reason, the focus of the following mutational studies is directed more towards the $\mathrm{ZnF}$ and especially to the connector loop. The ZnF belongs to the TIS11d protein domain family ( $\mathrm{Lu}$ et al, 2012). In this type of $\mathrm{ZnF}$ two conserved aromatic residues are usually required for stacking interactions with RNA. However, only one of these amino acids is conserved and exposed to the solvent in Cwc2, namely Y89 (Lu et al (2012), Schmitzova et al (2012)). When standard yeast splicing extract depleted of Cwc2 ( $\Delta \mathrm{Cwc} 2$ extract) was supplemented with the point mutant Cwc2-Y89A, the splicing activity of the depleted extract could be restored only to a low level (35\% activity, compared with the wild type Cwc2 protein; Figure 3.18, lane 7), supporting the concept of a significant role of residue Y89 and, accordingly, of the entire $\mathrm{ZnF}$ for the function of Cwc2. To assess the importance of the connector element, also point mutations of Y120, K132 and F130 to alanine were analyzed for their ability to complement $\Delta \mathrm{Cwc} 2$ extract. The substitution of Y120 completely abolished the ability of Cwc2 to restore the splicing activity of the depleted extract (Figure 3.18, lane 8), while the mutations at K132 and F130 led to a significant decrease of activity (mRNA formation levels of ca. $60 \%$ and $50 \%$, respectively, compared to complementation with the wild type protein (Figure 3.18, lanes 9-10). These results illustrate a major role of the connector element during in vitro splicing. Taken together with the crosslinking results obtained from the binary U6 snRNACwc2 complexes in which Y120/R121 were found to crosslink to U6 snRNA (Schmitzova et al, 2012) this loop might have a pivotal role in RNA binding.

A Cwc2 truncation (Cwc2 $\Delta \mathrm{C}$, residues 1-234) lacking the C-terminal part, the region of Cwc2 required for interactions with Prp19, was also assessed for its ability to restore the splicing activity of $\Delta \mathrm{CwC} 2$ extract. Almost no difference between the activity of the extract 
complemented with WT Cwc2 or Cwc2 $\Delta$ C, respectively, could be observed (Figure 3.18, compare lanes 4 and 5), indicating that Cwc2 $\Delta \mathrm{C}$ represents the functional core of Cwc2 and the interaction of Cwc2 with Prp19 is not essential for in vitro splicing.

\subsection{RBM22, the human homologue of Cwc2, interacts with U6 snRNA at sites equivalent to those contacted by Cwc2 in yeast spliceosomes}

As Cwc2 is essential for step 1 of splicing in yeast, it is highly likely that its interaction with U6 snRNA (and potentially also with the pre-mRNA) is a prerequisite for step 1 . If such a centrally positioned RNA-protein interaction is indeed of functional importance, it should be highly conserved through evolution. To address this question, the observed interactions of Cwc2 with the spliceosomal RNA network were compared to those of RBM22 within the human spliceosome. RBM22 is the human homologue of Cwc2 (McGrail et al, 2009)(see also Figure 3.19). Although sequence comparisons between both proteins show only an overall similarity of $27 \%$, the central region comprising the $\mathrm{ZnF}$ and the $\mathrm{RRM}$ is conserved as shown also above (39\% similarity, 26\% identity, see Figure 3.19). RBM22 has also been classified as NTC-related protein being an integral component of human spliceosomal complexes B and C (Bessonov et al, 2008; Deckert et al, 2006). In previous work (Bessonov et al, 2008; Deckert et al, 2006), the yeast protein Ecm2 was considered as the homologue of RBM22 and a closer look at the sequence revealed that this conservation is mainly restricted to the N-terminal part of RBM22 spanning amino acids $21-145$ (51\% similarity and 37\% identity, Figure 3.19). Therefore, different regions of RBM22 show homology to two different proteins from $S$. cerevisiae. Like for Cwc2, it was also shown that RBM22 is required for pre-mRNA splicing in vitro and that it can be crosslinked to U6 snRNA and premRNA in purified human $B^{\text {act }}$ and $C$ complexes (Rasche et al, 2012). Interestingly, the crosslinks of RBM22 to U6 snRNA within the $\mathrm{B}^{\text {act }}$ complex were mapped to nucleotides upstream of the ACAGAGA box motif and to a lesser extend also to the U6-ISL (Figure 3.20). The contact sites of RBM22 therefore are located approximately in the same regions of U6 snRNA as those observed for Cwc2. Upon the transition to the C complex, the RBM22 

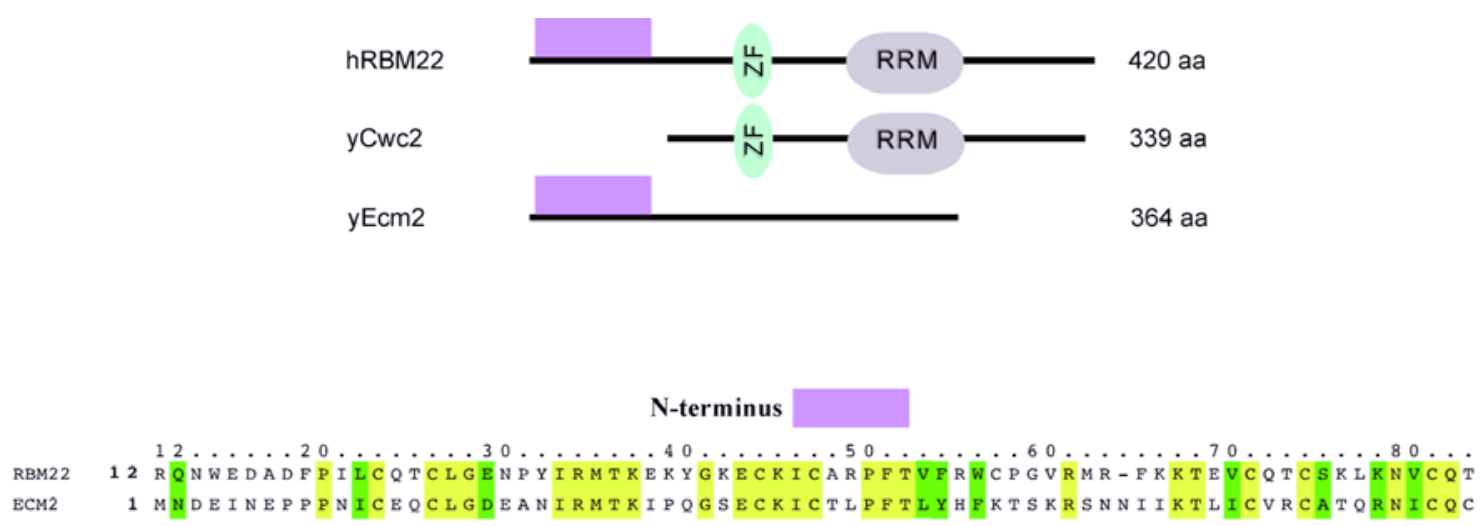

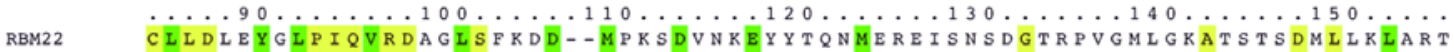
ECM2 CMLDSRHIPIQLRDHLISLVNEENVMTEEAKNDMMRFLSLKNVKLGGAQITSDPSEADNVDKLKNILR

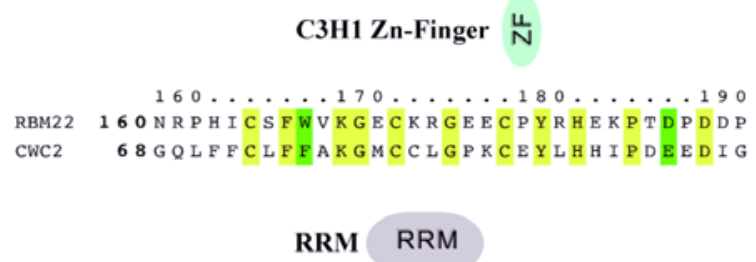
CWC2 135 KTLYVGGIDGALNSKHLKPAQIESRIRFVFSRLGDIDRIRYVESKNCGFVKFKYQANAEFAKEAMSNQTLLLPSDKEWDDRREGTGLLVKWANEDPDPAAQR

Figure 3.19: The N-terminal portion of RBM22, the human homolog of Cwc2, shares homology with $S$. cerevisiae Ecm2.

A database search with the human protein RBM22 sequence retrieved both Ecm2 and Cwc2 from $S$. cerevisiae and revealed that the N-terminal part of RBM22 (amino acids (aa) 21-145) is highly evolutionarily conserved (51\% similarity, 37\% identity) to that of Ecm2 (aa 10-128). The central and Cterminal part of RBM22 (aa 164-303), which includes Zn-fingers and RRM, is in turn homologous to Cwc2 (aa 72-226) (39\% similarity, 26\% identity). Identical amino acids are shown in yellow and similar amino acids are shown in green.

crosslinks to the U6-ISL accumulated. Also in case of Cwc2 an increased crosslinking yield was observed after step one of splicing.

The crosslinks of RBM22 to the pre-mRNA were mapped to intron nucleotides +26 to +28 upstream of the 5'SS, again corresponding to a similar region where the Cwc2 crosslinks were found. In summary, RBM22 interacts with both the U6 snRNA and the pre-mRNA in the human spliceosome similarly to its yeast counterpart Cwc2, and its interaction sites on the U6 snRNA are conserved in both organisms. The evolutionarily highly conserved nature of these interactions strongly supports their functional importance during splicing. 


\section{Cwc2 (yeast)}
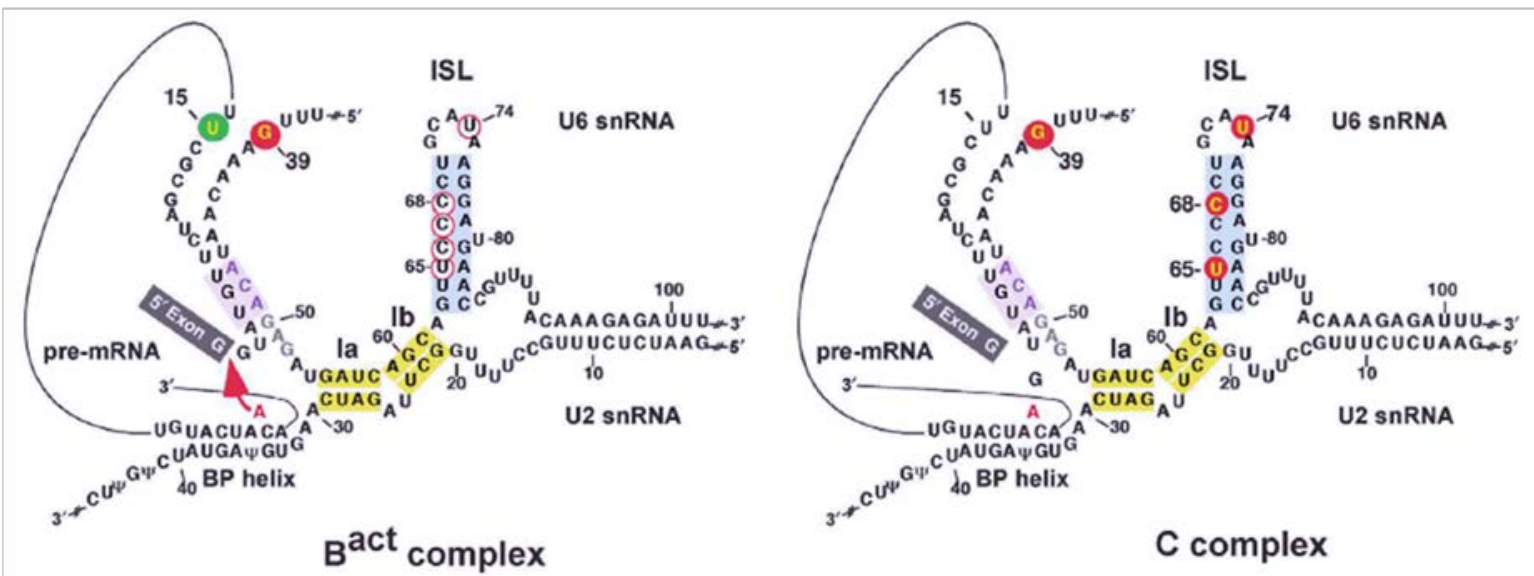

\section{RBM22 (human)}
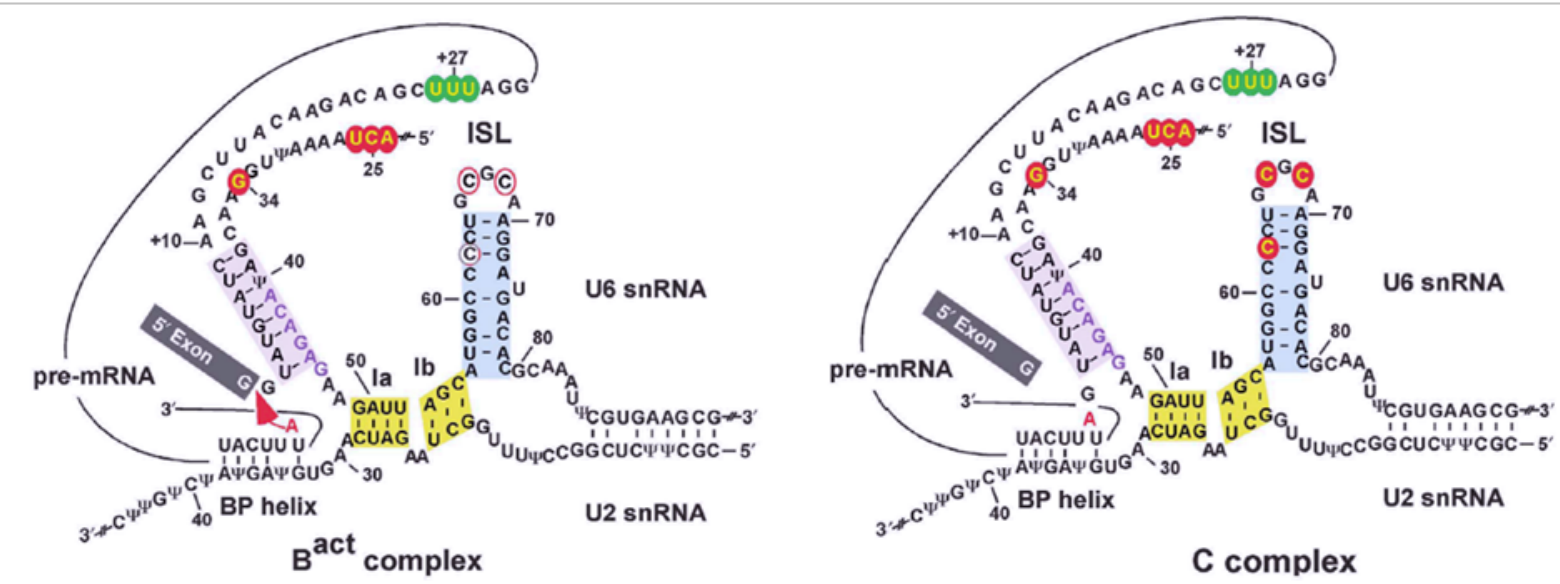

Figure 3.20: Comparison of Cwc2 and RBM22 crosslinks within yeast and human spliceosomes

Secondary-structure models of yeast (upper panel) and human (lower panel) U2/U6/pre-mRNA network before ( $\mathrm{B}^{\text {act }}$ complex) and after (C complex) step 1 of splicing. The attack of the branchpoint adenosine at the 5 ' $\mathrm{SS}$ is indicated by an arrow in the $\mathrm{B}^{\text {act }}$ complex. Sites in U6 snRNA crosslinked to Cwc2/RBM22 are indicated by red circles, open circles indicate weak, and closed circles indicate strong crosslinks, respectively. Green circle: sites in the pre-mRNA intron crosslinked to Cwc2/RBM22. 


\section{Discussion}

The recently published crystal structure of a self-splicing group IIC intron (Toor et al, 2008a) revealed that the central element of the group II catalytic center, stem-loop DV, is enclosed by a large RNA network consisting mainly of DI of the intron, which leads to the arrangement of DV in a specific, catalytically active conformation by several long-range interactions. Group II introns and the spliceosome are believed to have a common ancestor which is reflected in particular by the high similarity observed between DV of group II introns and the U6-ISL. Under the premise that both processes are related and the mechanism of catalysis is similar, the interactions described for DV and DI in group II introns may be accomplished by snRNAs or by protein factors within the spliceosome. This circumstance is of particular interest since it was shown, that during the transition from $\mathrm{B}$ to $\mathrm{B}^{\text {act }}$ complex almost all known U6 snRNA interaction partners are leaving the spliceosome (Fabrizio et al, 2009). To discover a possible interaction partner of U6 snRNA and to characterize its role during splicing a crosslinking approach was applied.

\subsection{Cwc2 interacts with catalytic RNA-structural elements in the spliceosome}

Several spliceosomal factors were previously implicated in interactions with U6 snRNA. Prp8 for example, one of the largest and most highly conserved nuclear proteins, occupies a central position in the catalytic core of the spliceosome (Grainger \& Beggs, 2005), and it has been shown to crosslink not only to U6 snRNA (Vidal et al, 1999), but also to U5 snRNA within the tri-snRNP (Dix et al, 1998) and to multiple regions of the pre-mRNA within spliceosomes (Vijayraghavan et al (1986), Whittaker and Beggs (1991), Turner et al (2006)). Likewise, also the NTC related protein Ecm2 has been shown to be involved in the formation of U2/U6 helix II during the activation of the spliceosome (Xu \& Friesen, 2001). Both factors were obvious candidates for initial crosslinking trials in activated spliceosomes. However, under the experimental conditions used during this work none of these factors could be crosslinked to U6 snRNA (Figure 3.4). Prp8 shows crosslinks to U5 snRNA and the pre- 
mRNA while Ecm2 could only be crosslinked to the pre-mRNA. Besides these two proteins, additional potential U6 snRNA interactions with Yju2, Cwc2 and the U5 component Snu114 were investigated. Snu114 could be crosslinked to U5 snRNA, to U2 snRNA and the premRNA while Ecm2 showed crosslinks to the pre-mRNA and Cwc2 to the pre-mRNA and U6 snRNA, demonstrating a very selective crosslinking behavior of the five proteins tested.

Cwc2, the only protein found here to be crosslinked to U6 snRNA, is a member of the group of NTC-related proteins that, along with the core NTC complex, are stably integrated into the $\mathrm{B}^{\text {act }}$ complex during the activation of the spliceosome. The results obtained during this work show that Cwc2 is essential for the formation of a catalytically competent spliceosome, but it does not act until the late spliceosome maturation phase, just prior or during step 1 of splicing.

An indication for a possible function of Cwc2 is provided by the data obtained through additional protein-RNA UV crosslinking studies conducted with purified yeast spliceosomes in the activation/catalytic phase $\left(\mathrm{B}^{\mathrm{act}}, \mathrm{B}^{*}\right.$, and $\left.\mathrm{C}\right)$. In all of these complexes, Cwc2 contacts two regions of U6 snRNA, namely nucleotides around G39, upstream of the ACAGAGA box, which is base paired with the 5' SS, and the left part of the U6-ISL including the ISL loop (Figure 3.5, Figure 3.6, Figure 3.7). It is instructive to examine the Cwc2-U6 snRNA interactions in more detail and to compare them between the various spliceosomal complexes analyzed. Crosslinking of Cwc2 to U6-G39 takes place already in complex B ${ }^{\text {act }}$, with an efficiency equal to that observed with $\mathrm{B}^{*}$ and $\mathrm{C}$ complexes (Figure 3.5, Figure 3.6, Figure 3.7). In contrast, the interaction of Cwc2 with the U6-ISL is more dynamic, in that the crosslinking pattern changes during the transition from $\mathrm{B}^{\text {act }}$ to $\mathrm{B}^{*}$ to $\mathrm{C}$ (Figure 3.5, Figure 3.6, Figure 3.7). In the $\mathrm{B}^{\text {act }}$ complex, only a low degree of crosslinking to U74 in the terminal loop and to U65-C68 on the 5' side of the stem is observed (Figure 3.5). While the intensity of the Cwc2 crosslink to U6-G39 is similar in all three complexes, the crosslinking of Cwc2 to the ISL is more pronounced in $\mathrm{B}^{*}$ and especially in the C complex, in which the greatest degree of Cwc2 crosslinking is observed for U65 and C68 with little or no crosslinks formed with C66 and C67. To gain additional proof for Cwc2 interacting with G39 of U6 snRNA and the ISL at the same time, a DNA-oligo-directed RNase $\mathrm{H}$ digestion was performed, demonstrating that Cwc2 indeed crosslinks to both parts of U6 snRNA (Figure 3.8). This observed change in crosslinking behavior suggests that the conformation of the U6-ISL is remodeled during the catalytic activation by $\operatorname{Prp} 2 / \operatorname{Spp} 2$ and also during the transition to the post-step 1 spliceosome C complex. 
To get a better understanding of the whole interaction surface of Cwc2 within the spliceosomal RNA network, additionally, structure probing experiments were performed. Upon depletion of Cwc2 from spliceosomal complexes indeed the regions around G39 and the U6-ISL loop, where the UV induced crosslinks are found, become more accessible towards chemical modifications (Figure 3.11). The enhanced accessibility of the U6 snRNA nucleotides $\mathrm{C} 33-\mathrm{C} 43$ in $\Delta \mathrm{Cwc} 2 \mathrm{~B}^{\text {act }}$ compared with native $\mathrm{B}^{\text {act }}$ complexes, suggests that Cwc2 probably contacts a longer stretch of the U6 snRNA, both upstream and downstream of G39.

Besides the areas where the crosslinking sites are located also other nucleotides of U6 snRNA became more accessible in $\Delta \mathrm{Cwc} 2 \mathrm{~B}^{\text {act }}$ complexes compared to native $\mathrm{B}^{\text {act }}$ complexes, including U80, the bulged out nucleotide within the U6-ISL coordinating a catalytically important $\mathrm{Mg}^{2+}$ ion, and several nucleotides within or flanking the ACAGAGA box such as U46, A51, U54 and nucleotides U88-U91 downstream of the U6-ISL. However, in these cases it is not clear if this is a matter of direct Cwc2-U6 interactions or an indirect destabilization effect induced by the absence of Cwc2.

Taken together, these data indicate that one function of Cwc2 in the spliceosome could be to bring, or to help to keep, two functionally important RNA-structural elements close to one another, namely the ACAGAGA box/5' SS element and the U6-ISL.

Interestingly, Cwc2 can also be crosslinked to a $U$ at intron position +15 (relative to the 5' SS, Figure 3.9), indicating that this region must be close to the G39-containing region of U6 snRNA, upstream of the ACAGAGA box. By binding simultaneously to both of these singlestranded regions (U6 snRNA and the intron), which are both close to the ACAGAGA/5' SS element, Cwc2 could play a role in tethering this entire region to the U6-ISL. It is also possible that the simultaneous binding of Cwc2 to the U6-G39 and intron U+15 region reinforces or modulates the interaction between the ACAGAGA box and the 5' SS. In this context, it is important to note that several nucleotides in and around the ACAGAGA box were found to be accessible to chemical reagents in the $\Delta$ Cwc2 $\mathrm{B}^{\text {act }}$, but not in the native $\mathrm{B}^{\text {act }}$ complex. The same is true for some U6 snRNA nucleotides in the U6/U2 helix I, especially for U6-C61 (Figure 3.11). This is consistent with the idea that Cwc2 also interacts with the ACAGAGA box/5' SS and helix I. However, in the absence of Cwc2 crosslinks in these regions, it cannot be excluded that one or more other proteins interact with these regions in a Cwc2-dependent manner. It is also possible that Cwc2 stabilizes a specific conformation of the active site of the spliceosome and that in the absence of Cwc2 the whole active site is 
destabilized or distorted, thus making the function of Cwc2 fundamental. Recently, it was shown that the U6 ACAGAGA box is dynamically base paired with the 5' SS, in a manner dependent upon the NTC complex (Chan \& Cheng, 2005). As Cwc2 interacts with at least two proteins of the core NTC complex (i.e. Isy1 and Prp19) (Ohi \& Gould, 2002), it is conceivable that the NTC together with Cwc2 modulates the interaction between the U6 snRNA and the 5' SS. In their RNA-RNA crosslinking study Chan and Cheng (2005) noted that U6-G39 was crosslinked to an unidentified protein; it seems very likely that this is the Cwc2 crosslink described in this work.

\subsection{Cwc2 is required for pre-mRNA splicing in vitro and it is not required for the Prp2-mediated remodeling of the activated spliceosome}

The crosslinking and structure probing experiments discussed above demonstrate that Cwc2 interacts with several important RNA elements close to the spliceosomal catalytic core. Therefore depletion and reconstitution experiments should provide additional information about the functional relevance of Cwc2 during splicing.

The depletion of Cwc2 from yeast splicing extracts leads to inhibition of splicing prior to step 1 of splicing (Figure 3.13). In the absence of Cwc2, however, a stable complex that (like a native $\mathrm{B}^{\text {act }}$ complex) has an $\mathrm{S}$ value of 45 , could be purified. This $\mathrm{B}^{\text {act }}$-like complex no longer contains U1 or U4 snRNAs and possesses stably integrated U5 and U6 snRNAs (Figure 3.16A) indicating that Cwc2 is not required for the formation of $\mathrm{B}^{\text {act }}$ complex. Additionally, mass spectrometry analysis of the isolated $\Delta \mathrm{Cwc} 2 \mathrm{~B}^{\text {act }}$ complexes revealed that their protein composition, apart from the absence of Cwc2, is qualitatively identical to that of the native $\mathrm{B}^{\text {act }}$ complexes demonstrating that Cwc2 is also not needed for the recruitment of the NTC (Table 3.1).

Further experiments showed that Cwc2 is not required for the Prp2/Spp2- and ATPdependent remodeling of the $\mathrm{B}^{\text {act }}$ complex from a $45 \mathrm{~S}$ to $40 \mathrm{~S}$ spliceosomal complex (Figure 3.15), a process that is accompanied by destabilization of the binding of the U2-SF3a and SF3b proteins (Warkocki et al, 2009). In addition, Cwc2 unlike other proteins, which dissociate after the first catalytic step, remains stably associated with the spliceosome during 
the entire catalytic phase. Thus, due to its close association with the catalytic RNA network, it is likely that Cwc2 is required not only for step 1, but also for step 2 of splicing.

\subsection{Structural requirements of Cwc2 for multiple RNA interactions}

A reductionist crosslinking approach in a binary system composed of recombinant Cwc2 and in vitro transcribed U6 snRNA suggested several interaction sites of Cwc2 with U6 snRNA (Schmitzova et al, 2012), which would be consistent with the results obtained during this work. Here it was shown that Cwc2 directly interacts with at least three different important RNA elements within the spliceosomal RNA network, the U6 snRNA upstream of the ACAGAGA box motif, the U6-ISL and the pre-mRNA just upstream of the 5'SS. Therefore, the structure of Cwc2 was analyzed to localize regions possibly involved in these RNA interactions.

Cwc2 adopts a compact, globular fold comprising nine $\alpha$-helices (a1-a9), five $3_{10}$ helices ( $\eta 1-\eta 5)$ and four $\beta$-strands ( $\beta 1-\beta 4$; Figure 4.1) and the two predicted RNA-binding motifs of Cwc2, the ZnF and the RRM domains are readily recognized in the crystal structure. The RRM domain (residues 134-226), accounts for about $40 \%$ of the whole structure and exhibits a typical topology, with a four-stranded $\beta$-sheet $(\beta 1-\beta 4)$ packed against two $\alpha$-helices $(\alpha 8$, $\alpha 9)$. The RRM domain contains two well-conserved sequence motifs commonly referred to as RNP1 and RNP2 which comprise two aromatic residues (Y138 of RNP2 and F183 of RNP1) that usually undergo stacking interactions with RNA bases. The crystal structure of Cwc2 demonstrates that all of the residues in general necessary for RNA binding by an RRM domain are exposed to the solvent, which is consistent with potential RNA-binding properties of this domain.

The CCCH type ZnF domain folds into a common circular conformation in which three cysteine residues (C73, C81, C87) and one histidine residue (H91) coordinate the zinc ion. The ZnF exhibits a fold that is similar to those observed in the crystal structures of TIS11d and MBNL1 (Hudson et al, 2004; Teplova and Patel, 2008). 


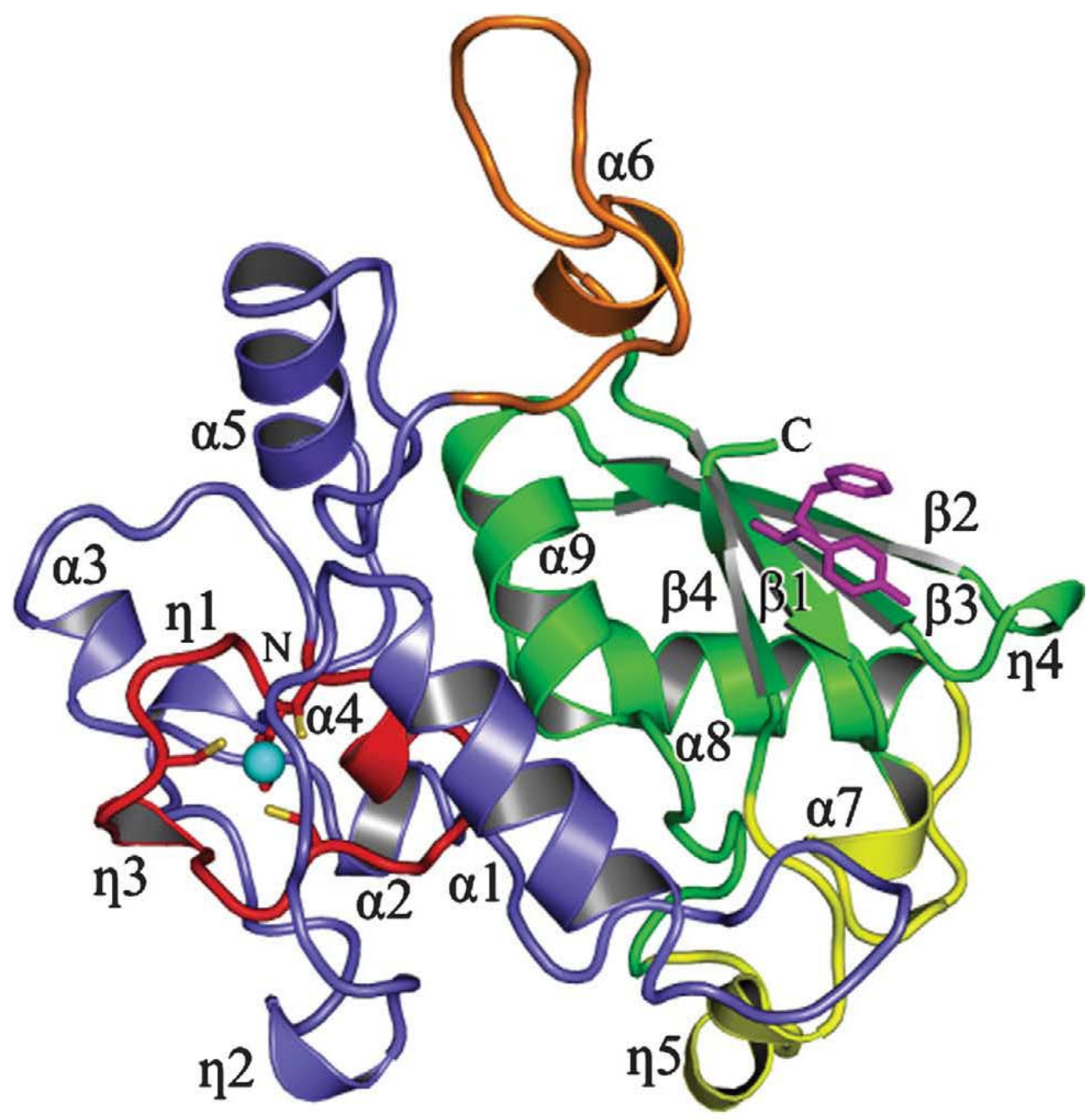

Figure 4.1: Overall crystal structure of Cwc2 (adapted from Schmitzova et al (2012))

Overall crystal structure of Cwc2 in a ribbon representation. Secondary structure elements and termini are labelled. Red, ZnF domain; blue, Torus domain; green, RRM domain; yellow, variable insertions; orange, connector element. Aromatic residues from the two canonical RNP motifs are shown as magenta sticks.

An interesting feature of the Cwc2 fold is a massive toroidal structure enclosing the ZnF. This enclosure is formed by the regions flanking the ZnF (3-72 and 92-115) and since it has a certain analogy to a ring on a finger, it is referred to as Torus domain. This Torus domain is anchored to the $\mathrm{ZnF}$ mainly through several conserved hydrophobic residues and it represents the integrating element of the whole assembly, connecting tightly the $\mathrm{ZnF}$ and the RRM domain in one folding unit.

At the sequence level, the C-terminal part of the Torus is connected to the N-terminal part of the RRM domain by a linker (residues 116-133), the connector element. Interestingly, this 
connector element contains three conserved aromatic and three conserved positively charged residues, suggesting a possible role of this element in RNA interactions. Using an in vitro complementation splicing assay, it could be shown that a point mutation in the ZnF (Y89A) inhibits Cwc2 splicing activity significantly (ca. 65\%), while a point mutation in the connector element (Y120A) abolishes activity almost completely (Figure 3.18B). Although based only on this assay it is not possible to directly link the reduction in splicing activity to a defect of Cwc2 in RNA-binding, it nevertheless seems to be the most plausible interpretation since aromatic residues of other $\mathrm{ZnF}$ domains corresponding to Y89 in Cwc2 are known to be crucial for RNA-binding (Hudson et al, 2004; Teplova \& Patel, 2008). The region around Y120 (residues Y120-R121) can even be directly crosslinked to U6 snRNA within the binary U6-Cwc2 complex and its mutation also affects RNA binding according to performed EMSA experiments (Schmitzova et al, 2012), indicating that a loss of splicing activity indeed reflects a defect of Cwc2 in RNA binding.

Besides the functional data provided by the mutational studies, a total of six crosslinking sites, which were located in the ZnF (C87), in the connector element (Y120-R121), in the RRM (K152, C181 from RNP1 and Y138 from RNP2) and in the Torus domain (F47), adjacent to the RNA binding side of the RRM domain could be identified by Schmitzova et al (2012) also providing strong support for the hypothesis that Cwc2 is indeed a multipartite RNA-binding protein, which exhibits the biophysical composition allowing it to organise several RNA elements.

\subsection{Evolutionary conservation of Cwc2 function in splicing}

That the interaction between Cwc2 and spliceosomal catalytic RNA elements described here is of functional importance is strongly supported by its striking evolutionary conservation. Like its yeast counterpart the human homologue of Cwc2, RBM22 (McGrail et al, 2009) is required for step 1 of splicing in vitro (Rasche et al, 2012). In isolated human $B^{\text {act }}$ and $C$ complexes, RBM22 also is crosslinked to the corresponding regions of the human U6 snRNA i.e., the region upstream of the ACAGAGA box (G34 and A24-U26) and to nucleotides in the terminal loop of U6-ISL and to C62 in its stem (see Figure 3.20). Furthermore, the differential yield of crosslinks between RBM22 and the U6-ISL in the $\mathrm{B}^{\text {act }}$ versus C complex is similar to what was detected in yeast spliceosomes. Moreover, RBM22 (like Cwc2) 
contacts intron nucleotides near the ACAGAGA/5' SS box interaction site, although the crosslinks are located somewhat further downstream than in the yeast spliceosome. Thus, also in higher eukaryotes, this protein appears to aid in tethering of the ACAGAGA/5' SS interaction elements to the U6-ISL. Close proximity between the ACAGAGA/5' SS element and the U6-ISL, as indicated by the crosslinks between both of these regions and Cwc2/RBM22, is supported by previous site-directed hydroxyl-radical footprinting experiments with the Fe-BABE (iron(S)-1-(p-bromoacetamidobenzyl) ethylenediaminetetraacetate) reagent placed at position +10 of the introns in human $\mathrm{B}^{\text {act }} / \mathrm{B}^{*}$ and C complexes. In both complexes, cleavages were detected not only 5' of the ACAGAGA box, but also in the upper region of the U6-ISL (Rhode et al (2006), see also Figure 4.2).
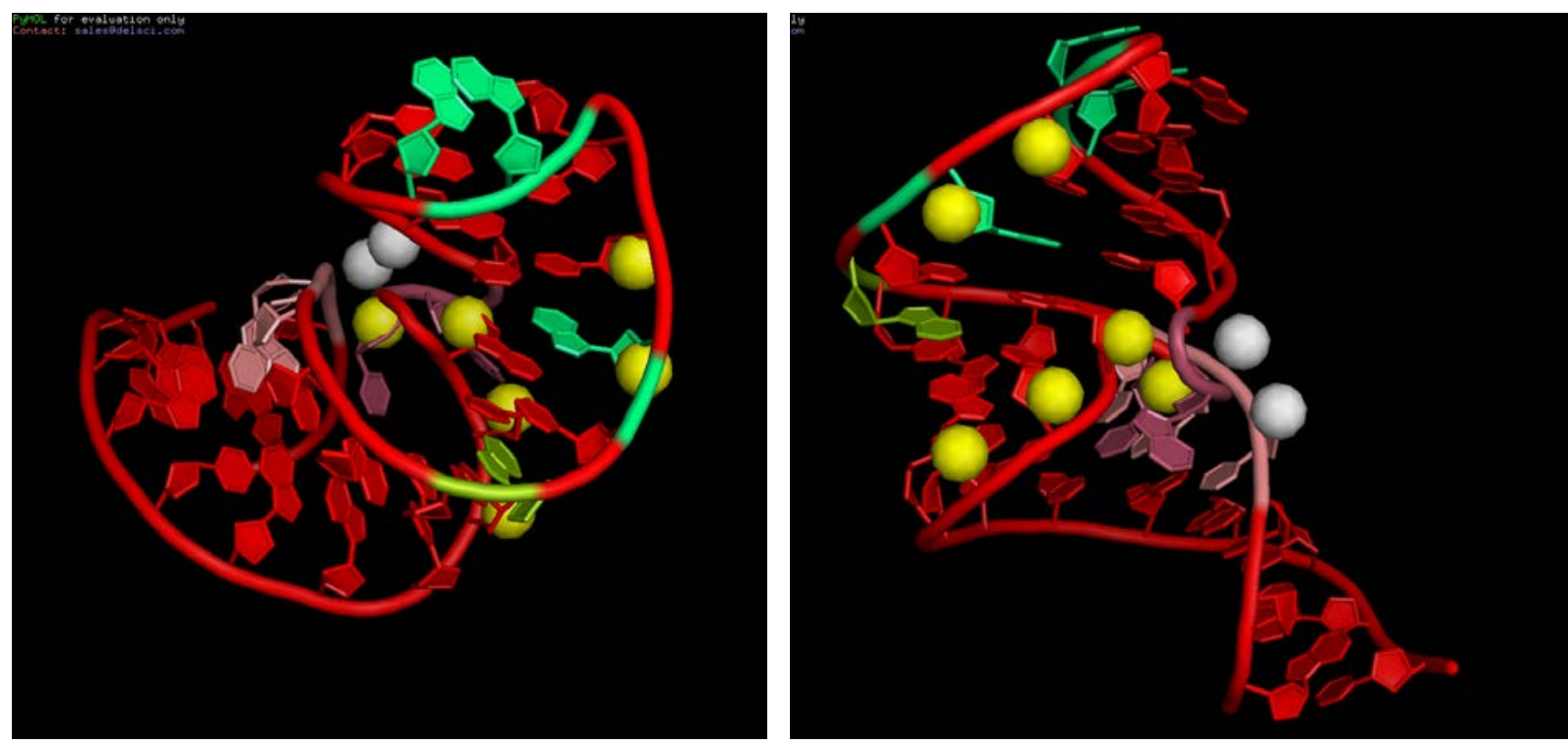

Figure 4.2: Hydroxyl-radical cleavages and RBM22 U6-ISL crosslinks projected onto the crystal structure of DV

Snapshots of DV taken from the crystal structure of the group IIC intron from O. iheyensis (Toor et al, 2008a). The left panel represents a top view, the right panel a side view of DV. Catalytic $\mathrm{Mg}^{2+}$ ions are shown as grey spheres. Crosslinks of RBM22 to the U6-ISL are marked at analogous positions in DV (green nucleotides). Hydroxyl radical cleavages found in the U6-ISL with the Fe-BABE reagent placed at position +10 of the introns in human $\mathrm{B}^{\text {act }} / \mathrm{B}^{*}$ and $\mathrm{C}$ complexes (Rhode et al, 2006), are represented at analogous positions in DV (yellow spheres). (This figure was kindly provided by Dr. Klaus Hartmuth, department of cellular biochemistry, MPI$\mathrm{BPC})$.

Contact between RNA and Cwc2/RBM22 in the spliceosome is consistent with the presence of at least two potential RNA binding domains in both proteins - an RRM and a zinc finger both of which are also conserved (Figure 3.17). Interestingly, RBM22 has an additional zinc 
finger-like sequence that, although absent in Cwc2, shows a clear sequence relationship with a zinc fingerlike sequence in yeast Ecm2 (Xu and Friesen (2001), Figure 3.17). No other human spliceosomal protein exhibits significant homology with yeast Ecm2. This raises the interesting possibility that RBM22 might represent a fusion protein of yeast Ecm2 and Cwc2, and thus functionally replace both proteins. Interestingly, Ecm2 was previously shown to play a role in the formation of the U2/U6 helix II during maturation of the spliceosome (Xu \& Friesen, 2001).

\subsection{Cwc2: a link between the RNA-catalytic center and the protein network of the spliceosome}

The multiple interactions between Cwc2 and the catalytic RNA network of the spliceosome together with its interactions with proteins of the core NTC complex such as Prp19 and Isy1 (Ohi and Gould, 2002) suggest that Cwc2 is an important link between the catalytic RNA network and factors that modulate the activity and the fidelity of the catalytic center (Hogg et al, 2010). On the basis of elegant genetic studies, a two-state model of the spliceosome has recently been proposed in which the conformations required for the first and second steps are in thermodynamic equilibrium (Konarska \& Query, 2005a; Konarska et al, 2006). Interestingly, the two states can be stabilized/destabilized by various proteins and U6 snRNA mutant alleles that affect the efficiency and fidelity of step 1 or step 2, respectively (Konarska and Query, 2005). How these conformational changes are achieved at a molecular level is at present unclear. Due to the high degree of connectivity among spliceosomal proteins, local changes in the structure of the spliceosome -caused by certain protein or RNA mutationscould also be transmitted to the catalytic RNA network via Cwc2, thereby modulating the activity and/or fidelity of the catalytic center. Consistent with this possibility is the observation that the deletion of the NTC protein Isy1, which appears to interact with Cwc2 (Ohi \& Gould, 2002), also influences the fidelity of step 1 (Villa \& Guthrie, 2005). 


\subsection{A potential role for $C w c 2 / R B M 22$ in promoting an active conformation of the spliceosome's catalytic RNA elements}

The recently published crystal structure of a self-splicing group IIC intron (Toor et al, 2008a) revealed how the central element of the group II catalytic center, stem-loop DV, is brought into a specific, catalytically active conformation by several long-range interactions. The upper and lower stems of DV are positioned at a $45^{\circ}$ angle (relative to each other), which distorts the conformation of the bulge separating these stems and moves it into the vicinity of the catalytic RGC triad at the foot of the lower stem of DV (Keating et al, 2010; Toor et al, 2010). At the same time, the nucleotides of the catalytic triad form a catalytic triple helix together with C377 of the DV bulge and the J2/3 GC dinucleotides (GA in group IIA and B introns), bringing together catalytically essential residues of the introns (Keating et al (2010), see also Figure 4.3 and Figure 4.4). In this constellation, the DV bulge and the triple helix together co-ordinate two $\mathrm{Mg}^{2+}$ ions in a configuration that is consistent with a two-metal-ion mechanism of splicing catalysis (Steitz \& Steitz, 1993).

An important feature of this is that formation of the catalytically active conformation of the DV stem-loop requires the entire group II intron structure. The U6-ISL together with the U6/U2 helix Ib -which contains the catalytic U6-AGC triad- possesses all the biophysical properties of the DV element of group II introns and is a central, catalytically essential RNA element of the spliceosome (see above). This idea is supported strongly by the demonstration that, in the minor spliceosome, a group II intron DV stem-loop can replace the U6atac-ISL without loss of splicing activity (Shukla \& Padgett, 2002). It has further been suggested that the catalytically important J2/3 GA dinucleotide may have a spliceosomal counterpart in the 3'-terminal GA of the U6 ACAGAGA box, which together with the U6-ISL bulge (U80 in yeast) could form a catalytic triplex with the AGC triad of the U6/U2 helix Ib (Keating et al, 2010). However, this would require that (i) the upper part of the ISL stem adopts a similarly angular, distorted conformation with respect to the bottom part and (ii) both the ACAGAGA box and the 5' SS are positioned in proximity to helix Ib and the ISL. As there are no obviously conserved RNA elements in the spliceosome that, analogous to the situation in group II introns, could induce a catalytically active conformation of the U6-ISL, this task must at least partly be performed by proteins. The results obtained during this work indicate that Cwc2 is an ideal candidate for performing such a task. By tethering the partially base paired ACAGAGA/5' SS element to the U6-ISL and by interacting either directly or 
A

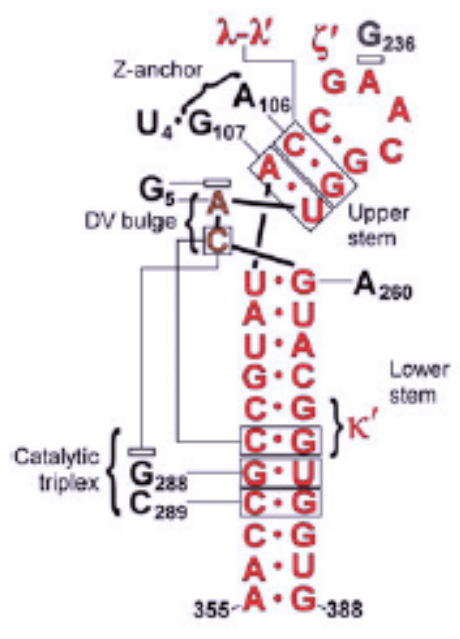

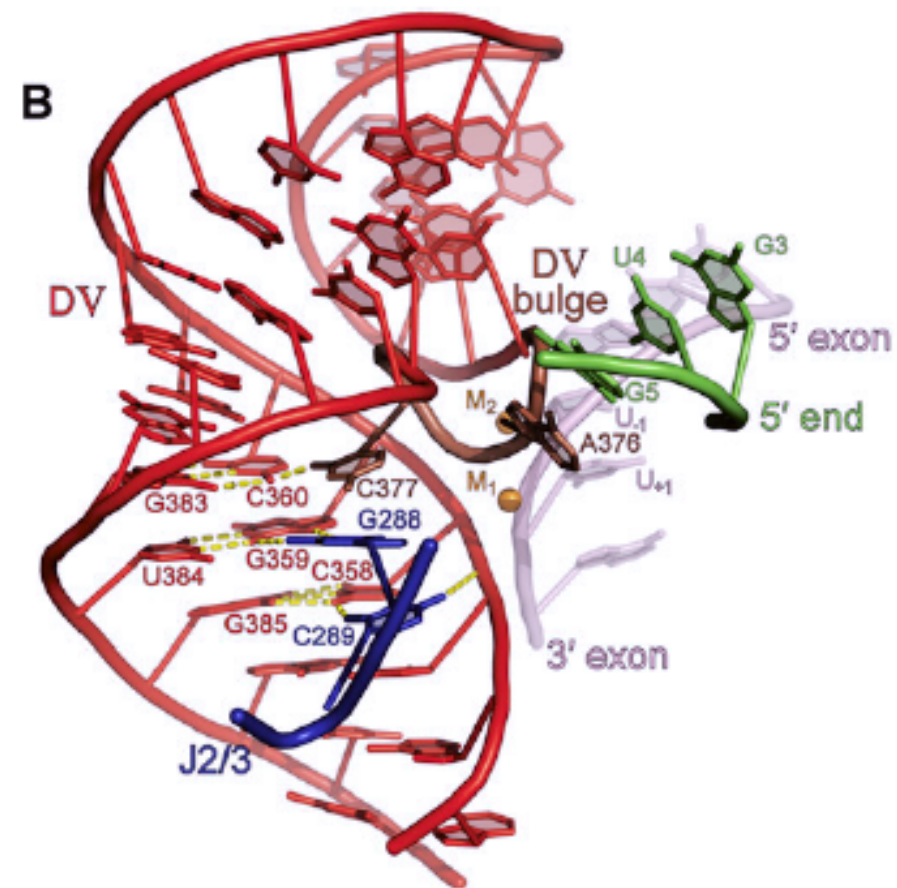

Figure 4.3: Domain DV structure showing interactions with other domains (adapted from Keating et al (2010).

(A) Secondary structure of domain DV. (B) Representation of the domain DV tertiary structure. The catalytic bulge of domain DV is shown in brown, while the rest of domain DV is shown in red. The upstream terminus of the intron is shown in green and $\mathrm{J} 2 / 3$ is blue. The group II intron structural analysis was conducted on the refined model with pdb code $3 \mathrm{EOH}$ (Toor et al, 2008b). All interactions described and shown here are also present in the re-refined model with pdb code 3IGI (Toor et al, 2010).

indirectly with part of helix I and the ACAGAGA box (Figure 3.11), it could help to promote the formation of the putative catalytic triple helix discussed above. Moreover, by interacting with the terminal loop and the 5' part of the stem of the U6-ISL, Cwc2 could potentially also promote an active conformation of the ISL. Thus, in the spliceosome, Cwc2 could, at least in part, substitute for the DI domain that in group II introns is responsible for inducing an active conformation of DV. However, whether the proposed catalytic triple helix (Keating et al, 2010; Toor et al, 2008a) indeed forms in the spliceosome remains to be seen. Cwc2 could potentially even play a more active role in the creation of an active site by forming direct hydrogen bonds with nucleotides of the catalytic AGC triad in helix Ib and in this way replace one or more of the proposed base triplet interactions. The observed interactions of Cwc2 with the catalytic RNA structural elements of the spliceosome place Cwc2 at the heart of the catalytic center. Another protein situated close to the active site of the spliceosome is Prp8 (Grainger \& Beggs, 2005). Prp8 contacts all of the chemically reactive sites of the 
A

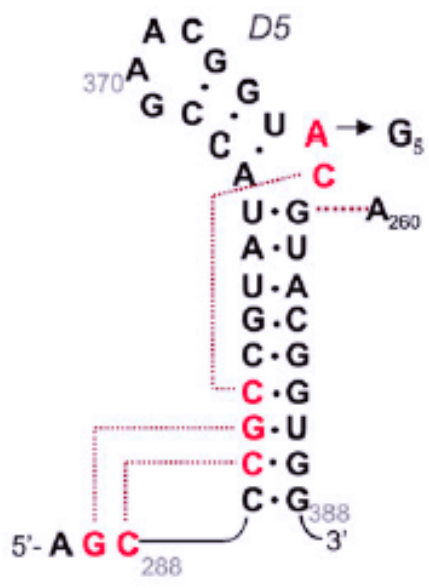

$\sqrt{2} / 3$
B

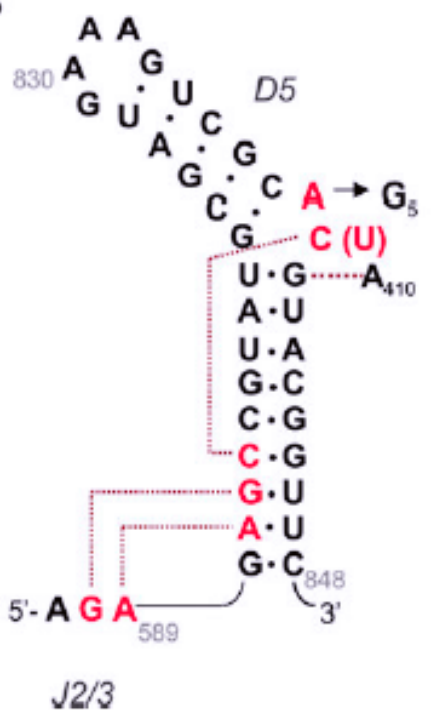

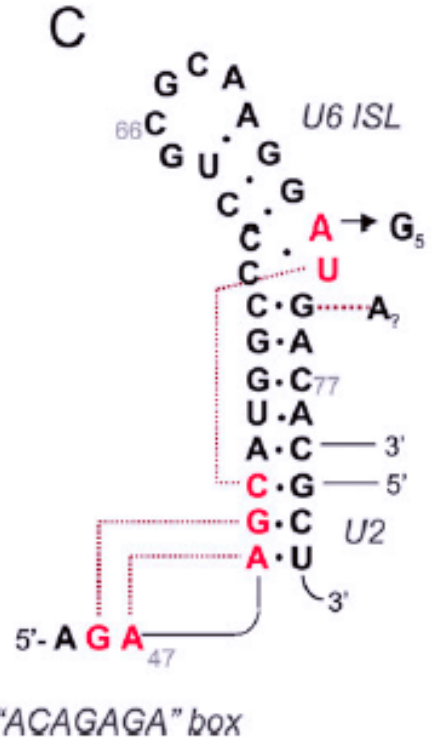

Figure 4.4: Tertiary interactions involving DV and, hypothetically, U6 snRNA (adapted from Keating et al (2010) ) .

(A) Interactions observed crystallographically for the Oceanobacillus iheyensis group IIC intron. (B) Cognate interactions inferred for the ai5 $\gamma$ group IIB intron. (C) Cognate interactions inferred for the eukaryotic spliceosome. The secondary structural representation derives from a U6 helix $1 \mathrm{~b}$ model for the human spliceosomal active site (Madhani \& Guthrie, 1992).

spliceosome, and it harbours an RNase H-like domain in its C-terminal region (Pena et al, 2008; Ritchie et al, 2008; Yang et al, 2008), which helps to assemble and stabilize the spliceosome's catalytic core. As Prp8 and Cwc2 contact distinct regions of the catalytically important RNA elements of the spliceosome, the two proteins appear to cooperate in promoting a catalytically active conformation of the spliceosomal RNA-RNA interaction network (see above and Butcher and Brow (2005)). The essential nature of the collaboration between spliceosomal RNA elements and both Cwc2 and Prp8 in catalyzing the splicing reaction, along with its evolutionary conservation, supports the idea that the spliceosome is an RNP enzyme containing active RNA rather than a ribozyme per se (Abelson, 2008).

\subsection{Perspectives}

The starting point of this thesis was the hypothesis that essential contacts between DV and DI in group II self-splicing introns also might exist within the spliceosomal context between the U6-ISL and some other yet unknown factors. Extensive RNA analysis revealed that the yeast 
protein Cwc2 is in close contact with regions of the U6-ISL. Remarkably, a comparison between these interactions and those observed between DV and DI of group II introns revealed several similarities. What still remains unclear is the attribution of the RNA crosslinks to a certain region of Cwc2 and how other factors interact with the spliceosomal RNA network. Although efforts were made to address these questions, definite answers are still missing. A promising approach towards a better understanding of these important points is the implementation of mass spectrometry to analyze protein-RNA crosslinks derived from purified and subsequently crosslinked spliceosomes. For a binary system, consisting of recombinant Cwc2 and in vitro transcribed U6 snRNA, this approach has already been proven useful (Schmitzova et al, 2012). Unfortunately, analyses of this kind are very material demanding and up to now it was not possible to purify sufficient amounts of spliceosomes from S. cerevisiae for such experiments. However, first attempts have been made to scale up the yeast spliceosome purification obtaining preliminary promising results. In this way, several additional questions could be addressed in the near future, allowing not only to characterize in more detail the interactions of Cwc2 with the spliceosome but also leading to discoveries of other important protein-RNA interactions. Structural analysis of spliceosomes in general would greatly profit from purification procedures resulting in higher yields of isolated spliceosomes. 


\section{References}

Abelson J (2008) Is the spliceosome a ribonucleoprotein enzyme? Nat Struct Mol Biol 15: $1235-1237$

Abu Dayyeh BK, Quan TK, Castro M, Ruby SW (2002) Probing interactions between the U2 small nuclear ribonucleoprotein and the DEAD-box protein, Prp5. The Journal of biological chemistry 277: 20221-20233

Arenas JE, Abelson JN (1997) Prp43: An RNA helicase-like factor involved in spliceosome disassembly. Proc Natl Acad Sci U S A 94: 11798-11802

Aronova A, Bacikova D, Crotti LB, Horowitz DS, Schwer B (2007) Functional interactions between Prp8, Prp18, Slu7, and U5 snRNA during the second step of pre-mRNA splicing. RNA (New York, NY 13: 1437-1444

Bessonov S, Anokhina M, Will CL, Urlaub H, Luhrmann R (2008) Isolation of an active step I spliceosome and composition of its RNP core. Nature 452: 846-850

Blum (1987) Improved silver staining of plant proteins, RNA and DNA in polyacrylamide gels. Electrophoresis

Boulanger SC, Belcher SM, Schmidt U, Dib-Hajj SD, Schmidt T, Perlman PS (1995) Studies of point mutants define three essential paired nucleotides in the domain 5 substructure of a group II intron. Molecular and cellular biology 15: 4479-4488

Brow DA (2002) Allosteric cascade of spliceosome activation. Annual review of genetics 36: 333-360

Brow DA, Guthrie C (1988) Spliceosomal RNA U6 is remarkably conserved from yeast to mammals. Nature 334: 213-218

Butcher SE, Brow DA (2005) Towards understanding the catalytic core structure of the spliceosome. Biochem Soc Trans 33: 447-449

Chan SP, Cheng SC (2005) The Prp19-associated complex is required for specifying interactions of U5 and U6 with pre-mRNA during spliceosome activation. The Journal of biological chemistry 280: 31190-31199 
Chan SP, Kao DI, Tsai WY, Cheng SC (2003) The Prp19p-associated complex in spliceosome activation. Science 302: 279-282

Company M, Arenas J, Abelson J (1991) Requirement of the RNA helicase-like protein PRP22 for release of messenger RNA from spliceosomes. Nature 349: 487-493

Cordin O, Hahn D, Beggs JD (2012) Structure, function and regulation of spliceosomal RNA helicases. Curr Opin Cell Biol

Costa M, Michel F, Westhof E (2000) A three-dimensional perspective on exon binding by a group II self-splicing intron. The EMBO journal 19: 5007-5018

Crick F (1970) Central dogma of molecular biology. Nature 227: 561-563

de Lencastre A, Hamill S, Pyle AM (2005) A single active-site region for a group II intron. Nat Struct Mol Biol 12: 626-627

Deckert J, Hartmuth K, Boehringer D, Behzadnia N, Will CL, Kastner B, Stark H, Urlaub H, Luhrmann R (2006) Protein composition and electron microscopy structure of affinitypurified human spliceosomal B complexes isolated under physiological conditions. Molecular and cellular biology 26: 5528-5543

Deutsch M, Long M (1999) Intron-exon structures of eukaryotic model organisms. Nucleic Acids Res 27: 3219-3228

Dix I, Russell CS, O'Keefe RT, Newman AJ, Beggs JD (1998) Protein-RNA interactions in the U5 snRNP of Saccharomyces cerevisiae. RNA (New York, NY 4: 1239-1250

Ehresmann C, Baudin F, Mougel M, Romby P, Ebel JP, Ehresmann B (1987) Probing the structure of RNAs in solution. Nucleic Acids Res 15: 9109-9128

Eldho NV, Dayie KT (2007) Internal bulge and tetraloop of the catalytic domain 5 of a group II intron ribozyme are flexible: implications for catalysis. Journal of molecular biology 365: 930-944

Fabrizio P, Dannenberg J, Dube P, Kastner B, Stark H, Urlaub H, Luhrmann R (2009) The evolutionarily conserved core design of the catalytic activation step of the yeast spliceosome. Molecular cell 36: 593-608

Fabrizio P, McPheeters DS, Abelson J (1989) In vitro assembly of yeast U6 snRNP: a functional assay. Genes Dev 3: 2137-2150 
Fairman ME, Maroney PA, Wang W, Bowers HA, Gollnick P, Nilsen TW, Jankowsky E (2004) Protein displacement by DExH/D "RNA helicases" without duplex unwinding. Science 304: 730-734

Fedorova O, Mitros T, Pyle AM (2003) Domains 2 and 3 interact to form critical elements of the group II intron active site. Journal of molecular biology 330: 197-209

Ferat JL, Michel F (1993) Group II self-splicing introns in bacteria. Nature 364: 358-361

Frank DN, Roiha H, Guthrie C (1994) Architecture of the U5 small nuclear RNA. Molecular and cellular biology 14: 2180-2190

Frazer LN, Nancollis V, O'Keefe RT (2008) The role of Snu114p during pre-mRNA splicing. Biochem Soc Trans 36: 551-553

Gordon PM, Piccirilli JA (2001) Metal ion coordination by the AGC triad in domain 5 contributes to group II intron catalysis. Nature structural biology 8: 893-898

Gottschalk A, Neubauer G, Banroques J, Mann M, Luhrmann R, Fabrizio P (1999) Identification by mass spectrometry and functional analysis of novel proteins of the yeast [U4/U6.U5] tri-snRNP. The EMBO journal 18: 4535-4548

Gozani O, Feld R, Reed R (1996) Evidence that sequence-independent binding of highly conserved U2 snRNP proteins upstream of the branch site is required for assembly of spliceosomal complex A. Genes Dev 10: 233-243

Gozani O, Potashkin J, Reed R (1998) A potential role for U2AF-SAP 155 interactions in recruiting U2 snRNP to the branch site. Molecular and cellular biology 18: 4752-4760

Grainger RJ, Beggs JD (2005) Prp8 protein: at the heart of the spliceosome. RNA (New York, NY 11: 533-557

Hogg R, McGrail JC, O'Keefe RT (2010) The function of the NineTeen Complex (NTC) in regulating spliceosome conformations and fidelity during pre-mRNA splicing. Biochem Soc Trans 38: 1110-1115

Hudson BP, Martinez-Yamout MA, Dyson HJ, Wright PE (2004) Recognition of the mRNA AU-rich element by the zinc finger domain of TIS11d. Nat Struct Mol Biol 11: 257-264 
Jacquier A, Michel F (1987) Multiple exon-binding sites in class II self-splicing introns. Cell 50: $17-29$

Keating KS, Toor N, Perlman PS, Pyle AM (2010) A structural analysis of the group II intron active site and implications for the spliceosome. RNA (New York, NY 16: 1-9

Kim SH, Lin RJ (1996) Spliceosome activation by PRP2 ATPase prior to the first transesterification reaction of pre-mRNA splicing. Molecular and cellular biology 16: 68106819

Konarska MM, Query CC (2005a) Insights into the mechanisms of splicing: more lessons from the ribosome. Genes Dev 19: 2255-2260

Konarska MM, Query CC (2005b) Insights into the mechanisms of splicing: more lessons from the ribosome. Genes Dev 19: 2255-2260

Konarska MM, Vilardell J, Query CC (2006) Repositioning of the reaction intermediate within the catalytic center of the spliceosome. Molecular cell 21: 543-553

Kretzner L, Krol A, Rosbash M (1990) Saccharomyces cerevisiae U1 small nuclear RNA secondary structure contains both universal and yeast-specific domains. Proc Natl Acad Sci U S A 87: 851-855

Laemmli UK (1970) Cleavage of structural proteins during the assembly of the head of bacteriophage T4. Nature 227: 680-685

Lopez PJ, Seraphin B (1999) Genomic-scale quantitative analysis of yeast pre-mRNA splicing: implications for splice-site recognition. RNA (New York, NY 5: 1135-1137

Lu P, Lu G, Yan C, Wang L, Li W, Yin P (2012) Structure of the mRNA splicing complex component Cwc2: insights into RNA recognition. Biochem J 441: 591-597

Madhani HD, Guthrie C (1992) A novel base-pairing interaction between U2 and U6 snRNAs suggests a mechanism for the catalytic activation of the spliceosome. Cell 71: 803817

Madhani HD, Guthrie C (1994a) Dynamic RNA-RNA interactions in the spliceosome. Annual review of genetics 28: 1-26

Madhani HD, Guthrie C (1994b) Randomization-selection analysis of snRNAs in vivo: evidence for a tertiary interaction in the spliceosome. Genes Dev 8: 1071-1086 
McGrail JC, Krause A, O'Keefe RT (2009) The RNA binding protein Cwc2 interacts directly with the U6 snRNA to link the nineteen complex to the spliceosome during pre-mRNA splicing. Nucleic Acids Res

Merril CR, Goldman D, Sedman SA, Ebert MH (1981) Ultrasensitive stain for proteins in polyacrylamide gels shows regional variation in cerebrospinal fluid proteins. Science 211: $1437-1438$

Moore MJ, Sharp PA (1993) Evidence for two active sites in the spliceosome provided by stereochemistry of pre-mRNA splicing. Nature 365: 364-368

Ohi MD, Gould KL (2002) Characterization of interactions among the Cef1p-Prp19passociated splicing complex. RNA (New York, NY 8: 798-815

Pena V, Rozov A, Fabrizio P, Luhrmann R, Wahl MC (2008) Structure and function of an RNase H domain at the heart of the spliceosome. The EMBO journal 27: 2929-2940

Puig O, Caspary F, Rigaut G, Rutz B, Bouveret E, Bragado-Nilsson E, Wilm M, Seraphin B (2001) The tandem affinity purification (TAP) method: a general procedure of protein complex purification. Methods (San Diego, Calif 24: 218-229

Pyle AM, Lambowitz AM (2006) Group II Introns: Ribozymes That Splice RNA and Invade DNA. The RNA World (Cold Spring Harbor Laboratory Press, Cold Spring Harbor, NY, ed 3)

Rasche N, Dybkov O, Schmitzova J, Akyildiz B, Fabrizio P, Luhrmann R (2012) Cwc2 and its human homologue RBM22 promote an active conformation of the spliceosome catalytic centre. The EMBO journal

Rhode BM, Hartmuth K, Westhof E, Luhrmann R (2006) Proximity of conserved U6 and U2 snRNA elements to the 5' splice site region in activated spliceosomes. The EMBO journal 25: 2475-2486

Ritchie DB, Schellenberg MJ, Gesner EM, Raithatha SA, Stuart DT, Macmillan AM (2008) Structural elucidation of a PRP8 core domain from the heart of the spliceosome. Nat Struct Mol Biol 15: 1199-1205

Robart AR, Seo W, Zimmerly S (2007) Insertion of group II intron retroelements after intrinsic transcriptional terminators. Proc Natl Acad Sci U S A 104: 6620-6625 
Sambrook J, Russell DW, Maniatis T (1989) Molecular Cloning: A Laboratory Manual. Cold Spring Harbor, NY: Cold Spring Harbor Laboratory Press

Schmitzova J, Rasche N, Dybkov O, Kramer K, Fabrizio P, Urlaub H, Luhrmann R, Pena V (2012) Crystal structure of Cwc2 reveals a novel architecture of a multipartite RNA-binding protein. The EMBO journal

Schneider S, Campodonico E, Schwer B (2004) Motifs IV and V in the DEAH box splicing factor Prp22 are important for RNA unwinding, and helicase-defective Prp22 mutants are suppressed by Prp8. The Journal of biological chemistry 279: 8617-8626

Schwer B, Gross CH (1998) Prp22, a DExH-box RNA helicase, plays two distinct roles in yeast pre-mRNA splicing. The EMBO journal 17: 2086-2094

Shevchenko A, Wilm M, Vorm O, Mann M (1996) Mass spectrometric sequencing of proteins silver-stained polyacrylamide gels. Analytical chemistry 68: 850-858

Shukla GC, Padgett RA (2002) A catalytically active group II intron domain 5 can function in the U12-dependent spliceosome. Mol Cell 9: 1145-1150

Shuster EO, Guthrie C (1988) Two conserved domains of yeast U2 snRNA are separated by 945 nonessential nucleotides. Cell 55: 41-48

Sigel RK, Vaidya A, Pyle AM (2000) Metal ion binding sites in a group II intron core. Nature structural biology 7: 1111-1116

Small EC, Leggett SR, Winans AA, Staley JP (2006) The EF-G-like GTPase Snu114p regulates spliceosome dynamics mediated by Brr2p, a DExD/H box ATPase. Molecular cell 23: 389-399

Spingola M, Grate L, Haussler D, Ares M, Jr. (1999) Genome-wide bioinformatic and molecular analysis of introns in Saccharomyces cerevisiae. RNA (New York, NY 5: 221-234

Staley JP, Guthrie C (1998) Mechanical devices of the spliceosome: motors, clocks, springs, and things. Cell 92: 315-326

Steitz TA, Steitz JA (1993) A general two-metal-ion mechanism for catalytic RNA. Proc Natl Acad Sci U S A 90: 6498-6502

Studier FW (2005) Protein production by auto-induction in high density shaking cultures. Protein expression and purification 41: 207-234 
Teplova M, Patel DJ (2008) Structural insights into RNA recognition by the alternativesplicing regulator muscleblind-like MBNL1. Nat Struct Mol Biol 15: 1343-1351

Toor N, Keating KS, Fedorova O, Rajashankar K, Wang J, Pyle AM (2010) Tertiary architecture of the Oceanobacillus iheyensis group II intron. RNA (New York, NY 16: 57-69

Toor N, Keating KS, Taylor SD, Pyle AM (2008a) Crystal structure of a self-spliced group II intron. Science 320: 77-82

Toor N, Rajashankar K, Keating KS, Pyle AM (2008b) Structural basis for exon recognition by a group II intron. Nat Struct Mol Biol 15: 1221-1222

Tseng CK, Liu HL, Cheng SC (2011) DEAH-box ATPase Prp16 has dual roles in remodeling of the spliceosome in catalytic steps. RNA (New York, NY 17: 145-154

Turner IA, Norman CM, Churcher MJ, Newman AJ (2006) Dissection of Prp8 protein defines multiple interactions with crucial RNA sequences in the catalytic core of the spliceosome. RNA (New York, NY 12: 375-386

Urlaub H, Hartmuth K, Lührmann R (2005) Protein-RNA Crosslinking in Native Ribonucleoprotein Particles. Handbook of RNA Biochemistry 1: Chapter 21

Valadkhan S, Jaladat Y (2010) The spliceosomal proteome: at the heart of the largest cellular ribonucleoprotein machine. Proteomics 10: 4128-4141

Valles Y, Halanych KM, Boore JL (2008) Group II introns break new boundaries: presence in a bilaterian's genome. PloS one 3: e1488

Vander Kooi CW, Ren L, Xu P, Ohi MD, Gould KL, Chazin WJ. (2010) The Prp19 WD40 domain contains a conserved protein interaction region essential for its function. Structure, Vol. 18, pp. 584-593.

Vidal VP, Verdone L, Mayes AE, Beggs JD (1999) Characterization of U6 snRNA-protein interactions. RNA (New York, NY 5: 1470-1481

Vijayraghavan U, Parker R, Tamm J, Iimura Y, Rossi J, Abelson J, Guthrie C (1986) Mutations in conserved intron sequences affect multiple steps in the yeast splicing pathway, particularly assembly of the spliceosome. The EMBO journal 5: 1683-1695 
Villa T, Guthrie C (2005) The Isy1p component of the NineTeen complex interacts with the ATPase Prp16p to regulate the fidelity of pre-mRNA splicing. Genes Dev 19: 1894-1904

Wachtel C, Manley JL (2009) Splicing of mRNA precursors: the role of RNAs and proteins in catalysis. Mol Biosyst 5: 311-316

Wahl MC, Will CL, Luhrmann R (2009) The Spliceosome: Design Principles of a Dynamic RNP Machine. Cell 136: 701-718

Wank H, SanFilippo J, Singh RN, Matsuura M, Lambowitz AM (1999) A reverse transcriptase/maturase promotes splicing by binding at its own coding segment in a group II intron RNA. Molecular cell 4: 239-250

Warkocki Z, Odenwalder P, Schmitzova J, Platzmann F, Stark H, Urlaub H, Ficner R, Fabrizio P, Luhrmann R (2009) Reconstitution of both steps of Saccharomyces cerevisiae splicing with purified spliceosomal components. Nat Struct Mol Biol 16: 1237-1243

Whittaker E, Beggs JD (1991) The yeast PRP8 protein interacts directly with pre-mRNA. Nucleic Acids Res 19: 5483-5489

Wiest DK, O'Day CL, Abelson J (1996) In vitro studies of the Prp9.Prp11.Prp21 complex indicate a pathway for U2 small nuclear ribonucleoprotein activation. The Journal of biological chemistry 271: 33268-33276

Will CL, Lührmann R (2006) Spliceosome Structure and Function. The RNA World

Xu D, Friesen JD (2001) Splicing factor slt11p and its involvement in formation of U2/U6 helix II in activation of the yeast spliceosome. Molecular and cellular biology 21: 1011-1023

Xu YZ, Query CC (2007) Competition between the ATPase Prp5 and branch region-U2 snRNA pairing modulates the fidelity of spliceosome assembly. Molecular cell 28: 838-849

Yang K, Zhang L, Xu T, Heroux A, Zhao R (2008) Crystal structure of the beta-finger domain of Prp8 reveals analogy to ribosomal proteins. Proc Natl Acad Sci U S A 105: 1381713822

Yean SL, Wuenschell G, Termini J, Lin RJ (2000) Metal-ion coordination by U6 small nuclear RNA contributes to catalysis in the spliceosome. Nature 408: 881-884

Zimmerly S, Guo H, Perlman PS, Lambowitz AM (1995) Group II intron mobility occurs by target DNA-primed reverse transcription. Cell 82: 545-554 
References 


\section{Appendix}

\subsection{List of abbreviations}

\begin{tabular}{|c|c|}
\hline 3’sS & 3` splice site \\
\hline 5’SS & 5‘ splice site \\
\hline${ }^{\circ} \mathrm{C}$ & degree celsius \\
\hline A & adenosine \\
\hline $\mathrm{ADP}$ & adenosine-5`-diphosphate \\
\hline APS & ammonium peroxy sulfate \\
\hline ATP & adenosine-5`-triphosphate \\
\hline bp & basepair \\
\hline $\mathrm{C}$ & cytosine \\
\hline $\mathrm{Ci}$ & Curie \\
\hline $\mathrm{CV}$ & column volumes \\
\hline $\mathrm{Da}$ & Dalton \\
\hline DNA & deoxyribonucleic acid \\
\hline dNTPs & deoxynucleotide-5‘-triphosphates \\
\hline DTT & 1,4- dithiothreitol \\
\hline EDTA & ethylendiamine-N, N, N`, N`-tetraacetic acid \\
\hline fmol & femtomole \\
\hline G & guanosine \\
\hline GDP & guanosine-5'-diphosphate \\
\hline GTP & gunosine-5'-triphosphate \\
\hline $\mathrm{h}$ & hour(s) \\
\hline $\mathrm{kDa}$ & kilo-Dalton \\
\hline l & liter \\
\hline Lsm & Like-Sm \\
\hline$\mu$ & micro \\
\hline$\mu l$ & microliter \\
\hline$\mu \mathrm{m}$ & micrometer \\
\hline$\mu \mathrm{M}$ & micromolar \\
\hline
\end{tabular}




\begin{tabular}{|c|c|}
\hline M & molar \\
\hline $\min$ & minute \\
\hline $\mathrm{ml}$ & milliliter \\
\hline $\mathrm{mM}$ & milimolar \\
\hline mRNA & messenger RNA \\
\hline MS & mass spectrometry \\
\hline $\mathrm{n}$ & nano \\
\hline $\mathrm{nM}$ & nanomolar \\
\hline nmol & nmol \\
\hline NP-40 & Nonidet P-40 \\
\hline $\mathrm{nt}$ & nucleotide \\
\hline NTPs & nucleotide-5'-triphosphates \\
\hline OD & optical density \\
\hline PAA & poly-acrylamide \\
\hline PAGE & poly-acrylamide gel electrophoresis \\
\hline PCI & phenol-chloroform-isoamylalcohol \\
\hline PCR & polymerase chain reaction \\
\hline PEG & polyethylene glycol \\
\hline pmol & picomole \\
\hline pre-mRNA & pre-messenger RNA \\
\hline Prp & pre-mRNA processing \\
\hline RNA & ribonucleic acid \\
\hline RNP & ribonucleoprotein \\
\hline RT & room temperature \\
\hline S & Svedberg \\
\hline S. cerevisiae & Saccharomyces cerevisiae \\
\hline SDS & sodium dodecylsulfate \\
\hline Sm & "Smith”, patient in which Sm proteins were first discovered \\
\hline snRNA & small nuclear ribonucleic acid \\
\hline snRNP & small nuclear ribonucleoprotein \\
\hline $\mathrm{T}$ & thymidine \\
\hline TBE & tris-borate-EDTA buffer \\
\hline $\mathrm{TE}$ & Tris-EDTA buffer \\
\hline TEMED & N, N, N', N'-tetramethylethylendiamine \\
\hline
\end{tabular}


$\mathrm{U}$

U snRNA

U snRNP

UV

YPD uridine

uridine rich small nuclear ribonucleic acid

uridine rich small nuclear ribonucleoprotein

ultraviolet

yeast extract, peptone, dextrose 


\subsection{Publications}

Parts of this work have been published in:

Ohrt T, Prior M, Dannenberg J, Odenwalder P, Dybkov O, Rasche N, Schmitzova J, Gregor I, Fabrizio P, Enderlein J, Luhrmann R (2012) Prp2-mediated protein rearrangements at the catalytic core of the spliceosome as revealed by dcFCCS. RNA (New York, NY 18: 1244-1256

Rasche N, Dybkov O, Schmitzova J, Akyildiz B, Fabrizio P, Luhrmann R Cwc2 and its human homologue RBM22 promote an active conformation of the spliceosome catalytic centre. The EMBO journal

Schmitzova J, Rasche N, Dybkov O, Kramer K, Fabrizio P, Urlaub H, Luhrmann R, Pena V (2012) Crystal structure of Cwc2 reveals a novel architecture of a multipartite RNA-binding protein. The EMBO journal 


\subsection{Acknowledgements}

An dieser Stelle möchte ich mich ganz herzlich bei all denen bedanken, die mich während dieser Arbeit unterstützt und motiviert haben.

Reinhard Lührmann danke ich für die Zeit, die ich in einer ausgezeichneten wissenschaftlichen Umgebung an einem spannenden und erfolgreichen Projekt arbeiten durfte. Ich bedanke mich für all die Energie, die er in mein Projekt investiert hat, um mir stets neue Impulse zu geben und mir dabei zu helfen, den roten Fanden nicht aus den Augen zu verlieren.

Mein ganz besonderer Dank gilt Patrizia Fabrizio für die beste Betreuung, die man sich wünschen kann. Ich bedanke mich für die unzähligen Antworten auf all meine Fragen, die zahlreichen Diskussionen und all die Hilfestellungen, die sie mir gegeben hat. Vielen Dank für die tolle Zeit!

Bei Olexandr Dybkov bedanke ich mich für die ausgezeichnete Zusammenarbeit und dafür, dass ich so viel von ihm lernen durfte. Vielen Dank auch für die nette Zeit in Seattle und dafür, dass er ein toller Kollege war.

Ein herzliches Dankeschön geht an die weiteren Mitglieder meines Prüfungsausschusses: Prof. Ralf Ficner, Prof. Heike Krebber, Prof. Stefanie Pöggeler, Prof. Holger Stark, Prof. Gregor Bucher

Meinen Kollegen Carsten, Cornelius, Irina, Julia D., Michael, Norbert, Peter O., Ramazan und Thomas O. (in alphabetischer Reihenfolge $(;)$ ) gilt ebenfalls besonderer Dank, für all den Spaß den wir hatten und die tolle Zeit zusammen!

Thomas Conrad danke ich für pralle, gesunde Hefe-Zellen in Kilogramm -Mengen und seine Expertise in Sachen E-Bass.

Katharina Kramer, Monika Raabe, Johanna Lehne, Uwe Pleßmann und Henning Urlaub danke ich für die Durchführung der MS-Analysen. 
Jana Schmitzova, Markus Matthes und Vlad Pena für die Hilfe mit rekombinanten Proteinen und eine tolle Zusammenarbeit.

Gabi, Uschi, Gertrud, Juliane, Irene, Kami und all den anderen helfenden Händen der Abteilung danke ich für ihre Unterstützung.

Ein großes Dankeschön auch an all die anderen Mitglieder der Abteilung für eine tolle Atmosphäre und eine gute Zeit.

Julia danke ich sehr für ihre Geduld und Unterstützung, auch in anstrengenden Phasen! 


\subsection{Curriculum vitae}

Nicolas Rasche

Geburtsdatum: 06. Februar 1982

Geburtsort: Bad Driburg

Staatsangehörigkeit: deutsch

Schulbildung

1988 bis 1992 katholische Grundschule, Brakel

1992 bis 1998 städt. Petrus-Legge-Gymnasium, Brakel

1998 bis $2001 \quad$ Gymnasium St. Xaver, Bad Driburg

Abitur Juni 2001

\section{Wehrersatzdienst}

2001 bis 2002

Zivildienst, Naturkundlicher Verein Egge-Weser, Borgentreich

\section{Studium}

Studium an der Georg-August-Universität Göttingen im

\section{Diplomstudiengang Biologie}

Hauptfach: Biochemie

1. Nebenfach: Chemie

2. Nebenfach: Mikrobiologie

Mündliche Prüfungen im November 2006 
Diplomarbeit November 2006 bis Oktober 2007 zum Thema:

„, Sphingolipid-abhängige Funktion von Phosphatidylinositol-4-

Phosphat-5-Kinasen aus Arabidopsis thaliana “

in der Abt. Biochemie der Pflanze, Universität Göttingen,

Betreuer: $\quad$ Prof. Dr. Ivo Feussner

Korreferent: $\quad$ Prof. Dr. Oliver Einsle

\section{Promotion}

2008 bis 2012 Promotion bei Prof. Dr. Reinhard Lührmann, Abteilung Zelluläre

Biochemie, Max-Planck-Institut für biophysikalische Chemie,

Göttingen

Titel der Arbeit: „Untersuchungen zum Mechanismus der katalytischen

Aktivierung von Spleißosomen aus Saccharomyces Cerevisiae“

\section{Veröffentlichungen}

Ohrt T, Prior M, Dannenberg J, Odenwalder P, Dybkov O, Rasche N, Schmitzova J, Gregor I, Fabrizio P, Enderlein J, Luhrmann R (2012) Prp2-mediated protein rearrangements at the catalytic core of the spliceosome as revealed by dcFCCS. RNA (New York, NY 18: 1244-1256

Rasche N, Dybkov O, Schmitzova J, Akyildiz B, Fabrizio P, Luhrmann R Cwc2 and its human homologue RBM22 promote an active conformation of the spliceosome catalytic centre. The EMBO journal

Reumann S, Babujee L, Ma C, Wienkoop S, Siemsen T, Antonicelli GE, Rasche N, Luder F, Weckwerth W, Jahn O (2007) Proteome analysis of Arabidopsis leaf peroxisomes reveals novel targeting peptides, metabolic pathways, and defense mechanisms. The Plant cell 19: 3170-3193 
Schmitzova J, Rasche N, Dybkov O, Kramer K, Fabrizio P, Urlaub H, Luhrmann R, Pena V (2012) Crystal structure of Cwc2 reveals a novel architecture of a multipartite RNA-binding protein. The EMBO journal

\section{Kongressbeiträge}

"Meeting of the European Associated Laboratory (LEA) on pre-mRNA splicing”, 2009, Göttingen

Präsentation eines Vortrags mit dem Titel: "Investigation of RNA-protein crosslinks in purified spliceosomal complexes from Saccharomyces cerevisiae”.

“ $15^{\text {th }}$ Annual Meeting Of The RNA Society”, 2010, Seattle (USA)

Präsentation eines Posters mit dem Titel: "The evolutionarily conserved protein Cwc2/RBM22 assists in stabilization of the spliceosomal RNA network before and during catalysis".

“ $7^{\text {th }}$ International PhD student symposium Horizons in Molecular Biology”, 2010, Göttingen Präsentation eines Vortrags mit dem Titel: “The evolutionarily conserved protein Cwc2/RBM22 assists in stabilization of the spliceosomal RNA network before and during catalysis". 


\subsection{Erklärung}

hiermit versichere ich, dass die Dissertation mit dem Titel „Untersuchungen zum Mechanismus der katalytischen Aktivierung von Spleißosomen aus Saccharomyces Cerevisiae“ von mir selbstständig und ohne unerlaubte Hilfe angefertigt worden ist.

Göttingen, den 29.05.2012

Nicolas Rasche 